University of Nebraska - Lincoln

DigitalCommons@University of Nebraska - Lincoln

U.S. National Park Service Publications and

Papers

National Park Service

3-4-2020

\title{
Asynchronous carbon sink saturation in African and Amazonian tropical forests
}

\author{
Wannes Hubau \\ University of Leeds \& Royal Museum for Central Africa \& Ghent University, whubau@gmai.com \\ Simon L. Lewis \\ University of Leeds \& University College London \\ et. al. Authors
}

Follow this and additional works at: https://digitalcommons.unl.edu/natlpark

Part of the Environmental Education Commons, Environmental Policy Commons, Environmental Studies Commons, Fire Science and Firefighting Commons, Leisure Studies Commons, Natural Resource Economics Commons, Natural Resources Management and Policy Commons, Nature and Society Relations Commons, Other Environmental Sciences Commons, Physical and Environmental Geography Commons, Public Administration Commons, and the Recreation, Parks and Tourism Administration Commons

Hubau, Wannes; Lewis, Simon L.; and Authors, et. al., "Asynchronous carbon sink saturation in African and Amazonian tropical forests" (2020). U.S. National Park Service Publications and Papers. 204. https://digitalcommons.unl.edu/natlpark/204

This Article is brought to you for free and open access by the National Park Service at DigitalCommons@University of Nebraska - Lincoln. It has been accepted for inclusion in U.S. National Park Service Publications and Papers by an authorized administrator of DigitalCommons@University of Nebraska - Lincoln. 


\section{Asynchronous carbon sink saturation in African and Amazonian tropical forests}

https://doi.org/10.1038/s41586-020-2035-0

Received: 9 June 2019

Accepted: 19 December 2019

Published online: 4 March 2020

Check for updates

U.S. government works are not subject to copyright.

\section{A list of authors and affiliations appears at the end of the paper.}

Structurally intact tropical forests sequestered about half of the global terrestrial carbon uptake over the 1990s and early 2000s, removing about 15 per cent of anthropogenic carbon dioxide emissions ${ }^{1-3}$. Climate-driven vegetation models typically predict that this tropical forest 'carbon sink' will continue for decades ${ }^{4,5}$. Here we assess trends in the carbon sink using 244 structurally intact African tropical forests spanning 11 countries, compare them with 321 published plots from Amazonia and investigate the underlying drivers of the trends. The carbon sink in live aboveground biomass in intact African tropical forests has been stable for the three decades to 2015, at 0.66 tonnes of carbon per hectare per year ( 95 per cent confidence interval 0.53-0.79), in contrast to the long-term decline in Amazonian forests ${ }^{6}$.

Therefore the carbon sink responses of Earth's two largest expanses of tropical forest have diverged. The difference is largely driven by carbon losses from tree mortality, with no detectable multi-decadal trend in Africa and a long-term increase in Amazonia. Both continents show increasing tree growth, consistent with the expected net effect of rising atmospheric carbon dioxide and air temperature ${ }^{7-9}$. Despite the past stability of the African carbon sink, our most intensively monitored plots suggest a post-2010 increase in carbon losses, delayed compared to Amazonia, indicating asynchronous carbon sink saturation on the two continents. A statistical model including carbon dioxide, temperature, drought and forest dynamics accounts for the observed trends and indicates a long-term future decline in the African sink, whereas the Amazonian sink continues to weaken rapidly. Overall, the uptake of carbon into Earth's intact tropical forests peaked in the 1990s. Given that the global terrestrial carbon sink is increasing in size, independent observations indicating greater recent carbon uptake into the Northern Hemisphere landmass ${ }^{10}$ reinforce our conclusion that the intact tropical forest carbon sink has already peaked. This saturation and ongoing decline of the tropical forest carbon sink has consequences for policies intended to stabilize Earth's climate.
Tropical forests account for approximately one-third of Earth's terrestrial gross primary productivity and one-half of Earth's carbon stored in terrestrial vegetation ${ }^{11}$. Thus, small biome-wide changes in tree growth and mortality can have global impacts, either buffering or exacerbating the increase in atmospheric $\mathrm{CO}_{2}$. Models ${ }^{2,4,5,7,12}$, groundbased observations ${ }^{13-15}$, airborne atmospheric $\mathrm{CO}_{2}$ measurements $\mathrm{s}^{3,16}$, inferences from remotely sensed data ${ }^{17}$ and synthetic approaches ${ }^{3,8,18}$ each suggest that, after accounting for land-use change, the remaining structurally intact tropical forests (that is, those not affected by direct anthropogenic impacts such as logging) are increasing in carbon stocks. This structurally intact tropical forest carbon sink is estimated at approximately $1.2 \mathrm{Pg} \mathrm{C} \mathrm{yr}^{-1}$ over 1990-2007 using scaled inventory plot measurements ${ }^{1}$. Yet, despite its relevance to policy, changes in this key carbon sink remain highly uncertain ${ }^{19,20}$.

Globally, the terrestrial carbon sink is increasing ${ }^{2,7,8,21}$. Between 1990 and 2017 the land surface sequestered about $30 \%$ of all anthropogenic carbon dioxide emissions ${ }^{1,21}$. Rising $\mathrm{CO}_{2}$ concentrations are thought to have boosted photosynthesis more than rising air temperatures have enhanced respiration, resulting in an increasing global terrestrial carbon sink ${ }^{2,4,7,8,21}$. Yet, for Amazonia, recent results from repeated censuses of intact forest inventory plots show a progressive two-decade decline in sink strength primarily due to an increase in carbon losses from tree mortality ${ }^{6}$. It is unclear if this simply reflects region-specific drought impacts ${ }^{22,23}$, or potentially chronic pan-tropical impacts of either heat-related tree mortality ${ }^{24,25}$, or results from internal forest dynamics as past increases in carbon gains leave the system ${ }^{26}$. A more recent deceleration of the rate of increase in carbon gains from tree growth is also contributing to the declining Amazon sink ${ }^{6}$. Again, it is not known whether this is a result of either pan-tropical saturation of $\mathrm{CO}_{2}$ fertilization, or rising air temperatures, or is simply a regional drought impact. To address these uncertainties, we (1) analyse an unprecedented long-term inventory dataset from Africa, (2) pool the new African and existing Amazonian records ${ }^{6}$ to investigate the putative environmental drivers of changes in the tropical forest carbon sink, and (3) project its likely future evolution.

We collected, compiled and analysed data from structurally intact old-growth forests from the African Tropical Rainforest Observation Network ${ }^{27}$ (217 plots) and other sources (27 plots) spanning the period 1January 1968 to 31 December 2014 (Extended Data Fig. 1; Supplementary Table 1 ). In each plot (mean size, $1.1 \mathrm{ha}$ ), all trees $\geq 100 \mathrm{~mm}$ in stem 

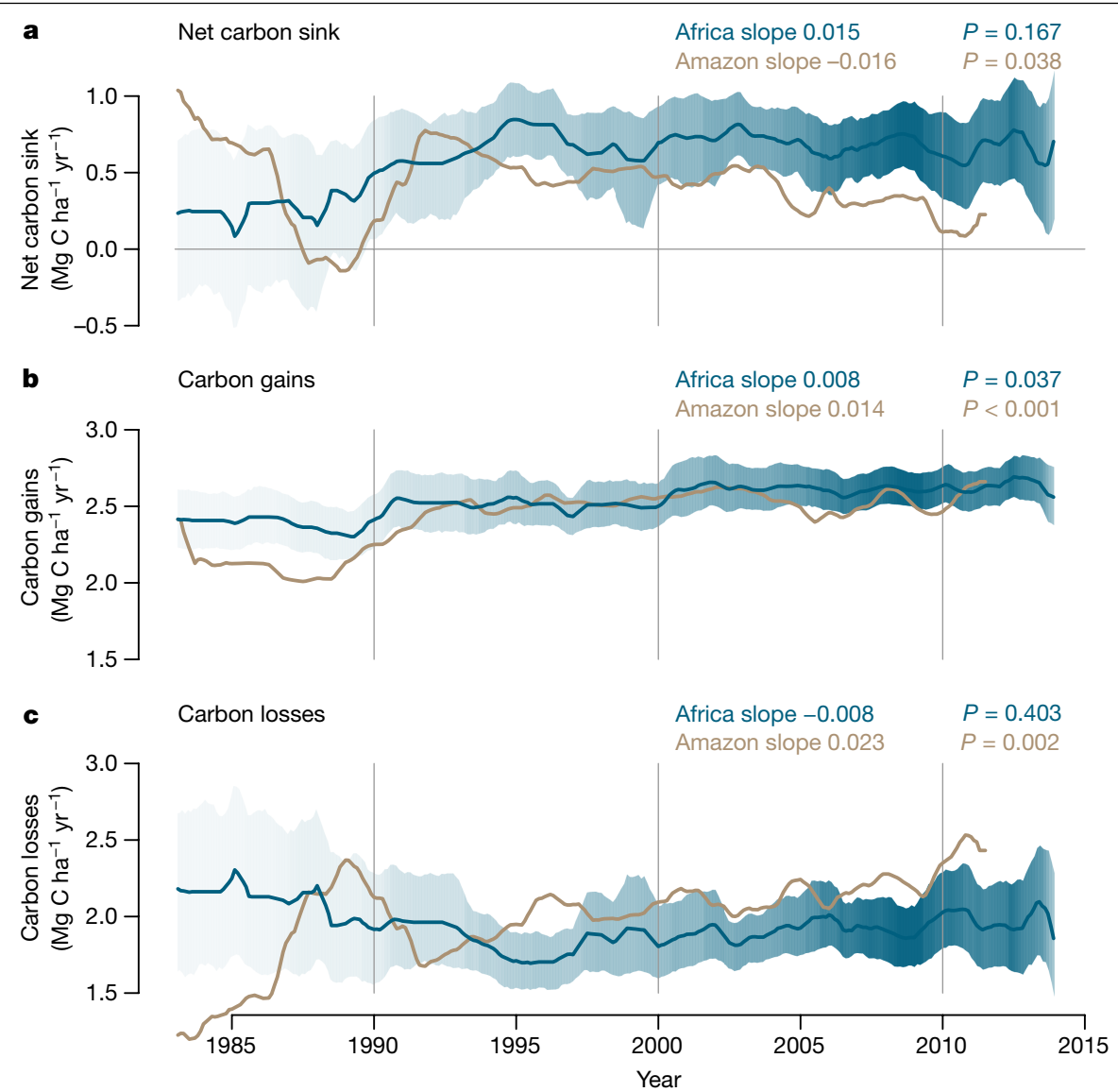

Fig. 1 | Long-term carbon dynamics of structurally intact oldgrowth tropical forests in Africa and Amazonia. a-c, Trends in net aboveground live biomass carbon (a), carbon gains to the system from wood production (b), and carbon losses from the system from tree mortality (c), measured in 244 African inventory plots (blue lines) and contrasting published ${ }^{6}$ Amazonian inventory data (brown lines; 321 plots). For Africa we show complete years with at least 25 plots monitored; for Amazonia we show the published record ${ }^{6}$. Shading corresponds to the $95 \% \mathrm{CI}$, with darker shading indicating a greater number of plots monitored in that year (the lightest shading indicates the minimum 25 plots monitored). The $\mathrm{CI}$ for the Amazonian dataset is omitted for clarity, but can be seen in Fig. 3. Slopes and $P$ values are from linear mixed effects models (see Methods). diameter were identified, mapped and measured at least twice using standardized methods $(135,625$ trees monitored). Live biomass carbon stocks were estimated for each census date, with carbon gains and losses calculated for each interval (Extended Data Fig. 2).

\section{Continental carbon sink trends}

We detect no long-term trend in the per unit area African tropical forest carbon sink over three decades to 2015 ( $P=0.167$; Fig. 1$)$. The aboveground live biomass sink averaged 0.66 tonnes of carbon per hectare per year $\left(0.66 \mathrm{Mg} \mathrm{C}^{-1} \mathrm{yr}^{-1}\right.$ with $95 \%$ confidence interval $(\mathrm{Cl})$ of $0.53-0.79$ and $n=244$ ) and was significantly greater than zero for every year since 1990 (Fig. $1 ; P<0.001$ for each time period in Table 1 ). Although very similar to past reports $\left(0.63 \mathrm{MgC} \mathrm{ha}^{-1} \mathrm{yr}^{-1}\right)^{13}$, this first estimate of the temporal trend in Africa contrasts with the significantly declining $(P=0.038)$ Amazonian trend ${ }^{6}$ (Fig. 1). A linear mixed effects model shows a significant difference in the slopes of the sink trends for the two continents over the common time window (pooled data from both continents, common time window, 1 January 1983 to mid-2011; $P=0.017)$. Therefore, the per unit area sink strength of the two largest expanses of tropical forest on Earth diverged in the 1990s and 2000s.

The proximal cause of the divergent sink patterns is a significant increase $(P=0.002)$ in carbon losses (from tree mortality, that is, the loss of carbon from the live biomass pool) in Amazonian forests, with no detectable trend over three decades in African forests $(P=0.403$; Fig. 1 ; Table 1). A linear mixed effects model using pooled data shows a significant difference in slopes of carbon losses between the two continents over the common time window $(P=0.027$; 1 January 1983 to mid-2011). Long-term trends in carbon gains (from tree growth and newly recruited trees) show significant increases on both continents ( $P=0.037$ for Africa; $P<0.001$ for Amazon; Fig. 1$)$, and we could detect no difference in slopes between the continents $(P=0.348$; carbon gains from tree growth alone also show no continental difference in long-term trends, $P=0.322$ ). However, an assessment of how underlying environmental drivers affect carbon gains and losses is needed to understand the ultimate causes of the divergent sink patterns.

\section{Understanding the carbon sink trends}

We first investigate those environmental drivers exhibiting long-term change that affect photosynthesis and respiration in theory-driven models: atmospheric $\mathrm{CO}_{2}$ concentration, surface air temperature and water availability. Bivariate models (Fig. 2) and a linear mixed effects model of carbon gains (Extended Data Table 1), with censuses nested within plots, and pooling the new African and published Amazonian data, show a significant positive relationship with $\mathrm{CO}_{2}(P=0.021$ in Fig. 2; $P=0.001$ in Extended Data Table 1), and significant negative relationships with mean annual temperature (MAT; $P<0.001$ in Fig. 2 and Extended Data Table 1$)$ and drought $(P=0.003$ in Fig. 2; $P<0.001$ in Extended Data Table 1), with drought measured as the maximum climatological water deficit (MCWD) ${ }^{14}$. These results are consistent with a positive $\mathrm{CO}_{2}$ fertilization effect, and negative effects 
Table 1 | Carbon sink in structurally intact old-growth tropical forests in Africa, Amazonia and the pan-tropics, 1980-2040

\begin{tabular}{|c|c|c|c|c|c|c|c|c|}
\hline \multirow[t]{2}{*}{ Period } & \multicolumn{2}{|c|}{ Number of plots } & \multicolumn{3}{|c|}{ Per unit area aboveground live biomass $\mathrm{C}$ sink $\left(\mathrm{Mg} \mathrm{C} \mathrm{ha}^{-1} \mathrm{yr}^{-1}\right)$} & \multicolumn{3}{|c|}{ Total $\mathrm{C}$ sink $\left(\mathrm{Pg} \mathrm{C} \mathrm{yr}{ }^{-1}\right)^{a}$} \\
\hline & Africa & Amazon & Africa & Amazon & Pan-tropics ${ }^{b}$ & Africa & Amazon & Pan-tropics ${ }^{b}$ \\
\hline 1980-1990 & 45 & 73 & $\mathbf{0 . 3 3}(0.06-0.63)$ & $\mathbf{0 . 3 5}(0.06-0.59)$ & $0.35(0.07-0.62)$ & $\mathbf{0 . 2 8}(0.05-0.53)$ & $\mathbf{0 . 4 9}(0.08-0.82)$ & $\mathbf{0 . 8 7}(0.16-1.52)$ \\
\hline 1990-2000 & 96 & 172 & $0.67(0.43-0.89)$ & $\mathbf{0 . 5 3}(0.42-0.65)$ & $\mathbf{0 . 5 7}(0.39-0.74)$ & $\mathbf{0 . 5 0}(0.32-0.66)$ & $0.68(0.54-0.83)$ & $1.26(0.88-1.63)$ \\
\hline $2000-2010$ & 194 & 291 & $\mathbf{0 . 7 0}(0.55-0.84)$ & $\mathbf{0 . 3 8}(0.26-0.48)$ & $\mathbf{0 . 5 0}(0.35-0.64)$ & $\mathbf{0 . 4 6}(0.37-0.56)$ & $\mathbf{0 . 4 5}(0.31-0.57)$ & $0.99(0.70-1.25)$ \\
\hline $2010-2015^{c}$ & 184 & 172 & $0.66(0.40-0.91)$ & $0.24(0.00-0.47)$ & $\mathbf{0 . 4 0}(0.15-0.65)$ & $\mathbf{0 . 4 0}(0.24-0.56)$ & $0.27(0.00-0.52)$ & $0.73(0.25-1.18)$ \\
\hline $2010-2020^{d}$ & - & - & $0.63(0.36-0.89)$ & $\mathbf{0 . 2 3}(-0.05-0.50)$ & $\mathbf{0 . 3 8}(0.11-0.65)$ & $\mathbf{0 . 3 7}(0.21-0.53)$ & $0.25(-0.05-0.54)$ & $\mathbf{0 . 6 8}(0.17-1.16)$ \\
\hline $2020-2030^{d}$ & - & - & $0.59(0.24-0.93)$ & $0.12(-0.29-0.51)$ & $\mathbf{0 . 3 0}(-0.08-0.67)$ & $\mathbf{0 . 3 1}(0.13-0.49)$ & $0.12(-0.29-0.52)$ & $\mathbf{0 . 4 7}(-0.15-1.07)$ \\
\hline $2030-2040^{d}$ & - & - & $0.55(0.08-0.99)$ & $\mathbf{0 . 0 0}(-0.54-0.49)$ & $0.21(-0.29-0.67)$ & $0.26(0.04-0.47)$ & $0.00(-0.50-0.46)$ & $0.29(-0.46-0.97)$ \\
\hline
\end{tabular}

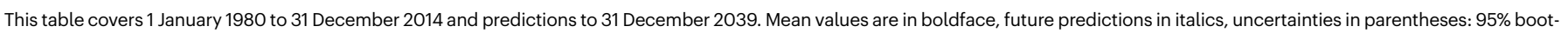
strapped confidence intervals for 1980-2015, and $2 \sigma$ for the predictions (2010-2040).

${ }^{a}$ The total continental $\mathrm{C}$ sink is the per unit area aboveground C sink multiplied by intact forest area (from ref. '; see Extended Data Table 2) and includes continent-specific estimates of three carbon-stock components that were not measured in the inventory plots: trees with a diameter at breast height of $<100 \mathrm{~mm}$, lianas and roots (see Methods).

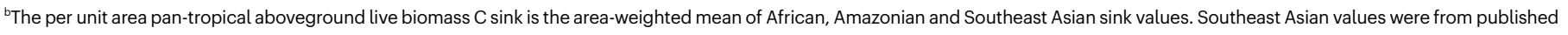

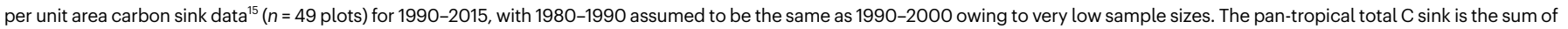

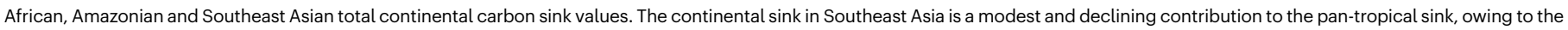

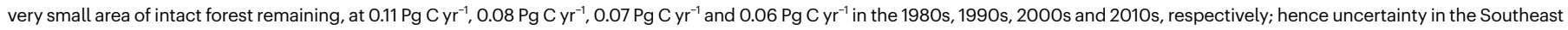
Asian sink cannot reverse the pan-tropical declining sink trend.

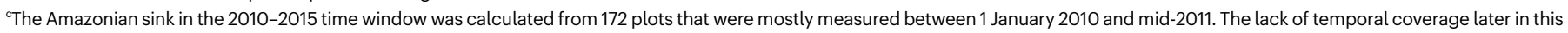

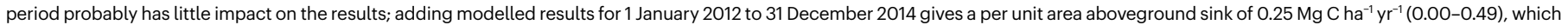
would increase the pan-tropical total $\mathrm{C}$ sink by $0.01 \mathrm{Pg} \mathrm{C} \mathrm{yr}^{-1}$.

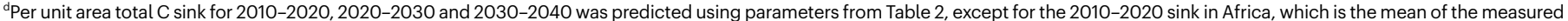

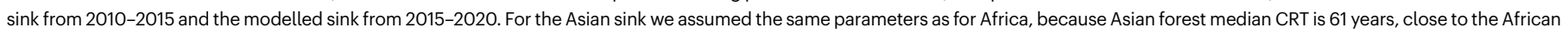
median of 63 years.

of higher temperatures and drought on tree growth, consistent with temperature-dependent increases in autotrophic respiration, and temperature- and drought-dependent reductions in carbon assimilation. By contrast, the equivalent models for carbon losses show no significant relationships with $\mathrm{CO}_{2}(P=0.363$ in Fig. $2 ; P=0.344$ in Extended Data Table 1), MAT ( $P=0.789$ in Fig. $2 ; P=0.804$ in Extended Data Table 1$)$ or MCWD $(P=0.338$ in Fig. $2 ; P=0.325$ in Extended Data Table 1$)$.

We further investigate the responses of carbon gains and losses (for which the above analysis has no explanatory power) by expanding our potential explanatory variables to include five more. These are the changes in environmental conditions $\left(\mathrm{CO}_{2}\right.$-change, MAT-change, MCWD-change, see Extended Data Fig. 3 for calculation details) and two attributes of forests that may influence their response to the same environmental changes: the plot mean wood density (which in old-growth forests correlates with belowground resource availability ${ }^{28,29}$ ) and the plot carbon residence time (CRT, which measures how long fixed carbon remains in the system and hence reflects when past increases in carbon gains leave the system as elevated carbon losses ${ }^{30}$ ).

The minimum adequate carbon gain model using our expanded explanatory variables (best-ranked model using multimodel inference) has a significant positive relationship with $\mathrm{CO}_{2}$-change $(P=0.013)$, and significant negative relationships with $\operatorname{MAT}(P=0.001)$, MAT-change $(P<0.001)$, MCWD $(P<0.001)$ and wood density $(P=0.015$; Table 2; model-average results are similar, see Methods and Supplementary Tables 2-4). The retention of both MAT and MAT-change suggests that higher temperatures correspond to lower tree growth, and that trees only partially acclimate to recently rising temperatures, which further reduces growth, consistent with warming experiments ${ }^{31}$ and observations ${ }^{9}$. The inclusion of higher wood density and its relationship to lower carbon gains (Extended Data Fig. 4), alongside no significant temporal trends in wood density (Extended Data Fig. 5), suggests that old-growth forests with denser-wooded tree communities typically have fewer available below ground resources, or such patterns may also emerge from disturbance regimes lacking large-scale exogenous events, consistent with previous studies ${ }^{26,28,32}$.

The minimum adequate carbon gain model using our expanded explanatory variables also highlights continental differences. Between 1January 2000 and 31 December 2014 modelled African forest carbon gains increased by $3.1 \%$ compared with a $0.1 \%$ decline in Amazonia over the same interval (Table 2). In Africa, from 2000 to 2015, the increase in carbon gains was composed of a $3.7 \%$ increase from $\mathrm{CO}_{2}$-change, partially offset by increasing droughts depleting gains by $0.5 \%$, and only a slight decline in gains of $0.1 \%$ resulting from temperature increases (Table 2), because the rate of temperature change (MAT-change) decelerated over this time window (Extended Data Fig. 5). For Amazonia, the same $3.7 \%$ increase in carbon gains due to $\mathrm{CO}_{2}$-change was seen. Opposing this trend was increasing droughts-and the greater sensitivity to drought of Amazonian forests-which reduced carbon gains by 2.7\% (five times the impact in Africa), and temperature increases at the same rate as in the past (that is, MAT-change is zero) further reduced gains by $1.1 \%$ (ten times the impact in Africa), leaving a net change in gains slightly below zero (Table 2). Therefore, the stalling of carbon gain increases in Amazonia in the decade to mid-2011 ${ }^{6}$ is a response to drought and temperature and not due to an unexpected saturation of $\mathrm{CO}_{2}$ fertilization.

Overall, the larger modelled increase in carbon gains in Africa relative to Amazonia appear to be driven by slower warming, fewer or less extreme droughts, lower forest sensitivity to droughts, and overall lower temperatures (African forests are on average $\sim 1.1^{\circ} \mathrm{C}$ cooler than Amazonian forests, because they typically grow at higher elevations of $\sim 200$ metres above sea level). Other continental differences may also be influencing the results, including higher nitrogen deposition in African tropical forests due to the seasonal burning of nearby savannahs ${ }^{33}$ and biogeographical history resulting in differing contemporary species pools and resulting functional attributes ${ }^{34,35}$.

The minimum adequate carbon loss model using our expanded explanatory variables shows significantly higher losses with $\mathrm{CO}_{2}$-change $(P=0.026)$ and MAT-change $(P<0.001)$ and significantly lower losses with MCWD $(P=0.030)$ and CRT $(P<0.001$; Table 2$)$. Thus, changes in carbon losses appear to be largely a function of past carbon gains. First, the greater losses in forests with shorter CRT conform to a 'high-gain, high-loss' forest dynamics pattern ${ }^{26,28}$. Second, wetter plots have a longer growing season and thus they have higher gains and correspondingly higher losses, explaining the negative relationship with MCWD. Third, as increasing $\mathrm{CO}_{2}$ levels result in additional carbon gains, after some time these additional past gains leave the system, resulting in 


\section{a}
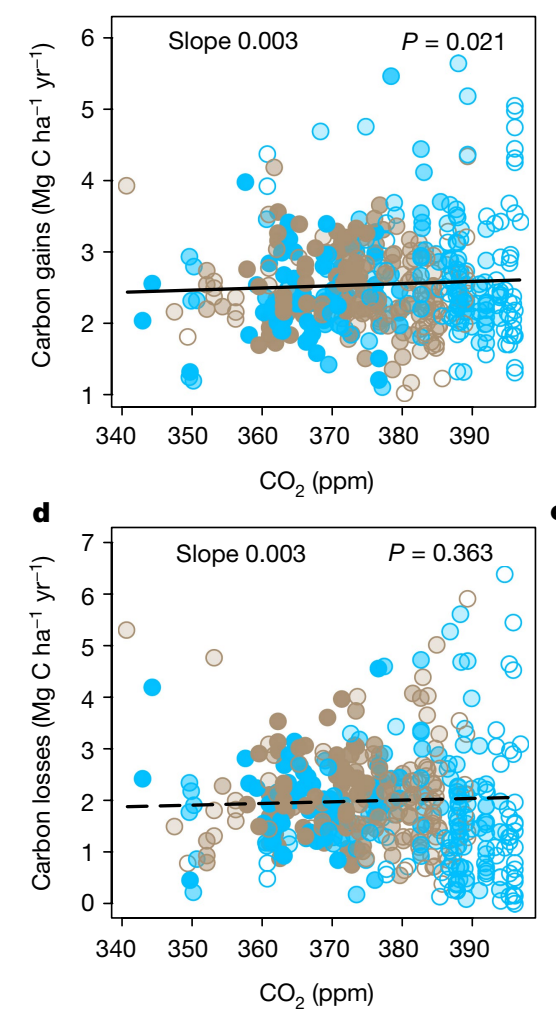

d

Fig. 2 | Potential environmental drivers of carbon gains and losses in structurally intact old-growth tropical forests in Africa and Amazonia. Aboveground carbon gains, from woody production $(\mathbf{a}-\mathbf{c})$, and aboveground carbon losses, from tree mortality $(\mathbf{d}-\mathbf{f})$, are presented as time-weighted mean values for each plot, that is, each census within a plot is weighted by its length, against the corresponding values of atmospheric carbon dioxide concentration $\left(\mathrm{CO}_{2}\right)$, temperature (MAT) and drought (MCWD), for African (blue) and Amazonian (brown) inventory plots. For visual clarity each data point therefore represents an inventory plot, and the shading represents the total monitoring length, with empty circles corresponding to plots monitored for $\leq 5$ years and solid circles for plots monitored for $>20$ years. Solid lines show

greater carbon losses, which explains the positive relationship with $\mathrm{CO}_{2}$-change. Finally, in addition to these relationships with carbon gains, the inclusion of MAT-change $(P<0.001)$ indicates tree mortality induced by heat or by increased vapour pressure deficit ${ }^{24}$. Overall, our results imply that chronic long-term environmental change factors, temperature and $\mathrm{CO}_{2}$, rather than simply the direct effects of drought, underlie longer-term trends in tropical forest tree mortality, although other changes such as rising liana infestation rates seen in Amazonia ${ }^{36,37}$ cannot be excluded.

The minimum adequate carbon loss model using our expanded explanatory variables replicates the continental trends (Fig. 3). The overall modelled lower loss rates in Africa reflect their longer CRT (69 years, 95\% CI, 66-72), compared with Amazonian forests (56 years, 95\% $\mathrm{Cl}, 54-59)$ while over the 2000-2015 window the much smaller modelled increase in loss rates in Africa compared to Amazonia results from a slower increase in warming and a stable CRT in Africa compared to continued warming at previous rates and a shortening CRT in Amazonian forests (Table 2; Extended Data Fig. 5). Furthermore, given that losses appear to lag behind gains, they should relate to the long-term CRT of plots. This is what we find: the longer the CRT the smaller the increase in carbon losses, with no increase in losses for plots with CRT $\geq 77$ years (Extended Data Fig. 6). Consequently, owing to the typically longer CRT of African forests, increasing losses in Africa ought to appear 10-15 years after the increase in Amazon losses began (around 1995). c

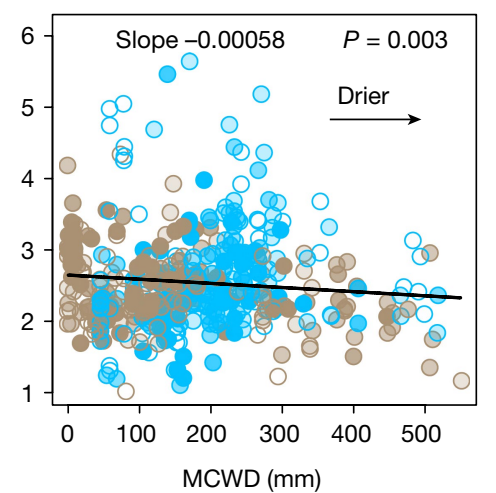

f

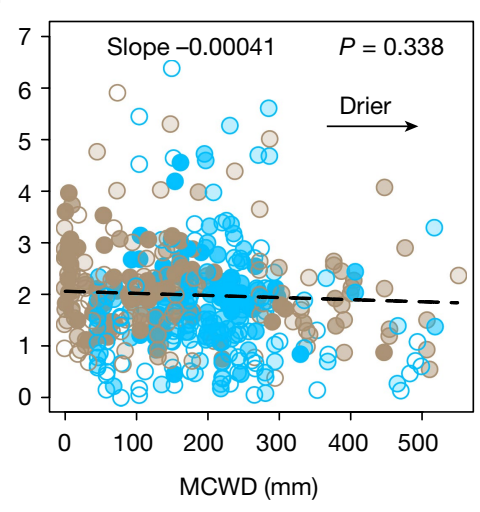

significant trends and dashed lines show non-significant trends calculated using linear mixed effects models with census intervals $(n=1,566)$ nested within plots $(n=565)$, using an empirically derived weighting based on interval length and plot area, on the untransformed pooled Africa and Amazon dataset (see Methods). Slopes and $P$ values are from the same linear mixed effects models. Carbon loss data and models are presented untransformed for comparison with carbon gains, but transformation is needed to fit normality assumptions; performing linear mixed effects models on transformed carbon loss data does not change the presented significance trends, nor does including all three parameters and transformed data in a model (see Extended Data Table1).

Strikingly, in Africa the most intensely monitored plots suggest that losses began increasing from about 2010 (Extended Data Fig. 7), and plots with shorter CRT are driving the increase (Extended Data Fig. 8). Thus, a mortality-dominated decline of the African carbon sink appears to have begun very recently.

\section{Future of the tropical forest carbon sink}

Our carbon gain and loss models (Table 2) can be used to make a tentative estimate of the future size of the per unit area intact forest carbon sink (Fig. 3). Extrapolations of the changes in the predictor variables from 1983-2015 forward to 31 December 2039 (Extended Data Fig. 5) show declines in the sink on both continents (Fig.3). By 2030 the carbon sink in aboveground live biomass in intact African tropical forest is predicted to decline by $14 \%$ from the measured $2010-15$ mean to $0.57 \mathrm{MgC} \mathrm{ha}^{-1} \mathrm{yr}^{-1}(2 \sigma$ range, 0.16-0.96; Fig. 3). The Amazon sink continues to rapidly decline, reaching zero in 2035 (2 $\sigma$ range, 2011-2089; Fig. 3). Our estimated sink strength on both continents in the 2020s and 2030s is sensitive to future $\mathrm{CO}_{2}$ emissions pathways $\left(\mathrm{CO}_{2} \text {-change }\right)^{38}$, resulting temperature increase (MAT, MAT-change) and hydrological changes (MCWD), plus changes in forest dynamics (CRT), but the sink is always lower than levels seen in the 2000s (see Methods and Supplementary Table 5). Therefore, the carbon sink strength of the world's two most extensive tropical forests have now saturated, albeit asynchronously. 
Table 2 | Minimum adequate models to predict carbon gains and losses in African and Amazonian forests

\begin{tabular}{|c|c|c|c|c|c|}
\hline \multicolumn{6}{|c|}{ Carbon gains ( $\left.\mathrm{Mg} \mathrm{C} \mathrm{ha}^{-1} \mathrm{yr}^{-1}\right)$} \\
\hline Predictor variable & Parameter value & Standard error & $t$ value & $P$ value & $2000-2015$ change in gains (\%) \\
\hline Intercept & $5.255 \mid 5.395$ & $0.603 \mid 0.614$ & $8.7 \mid 8.8$ & $<0.001$ & - \\
\hline $\mathrm{CO}_{2}$-change $\left(\mathrm{ppm} \mathrm{yr} \mathrm{r}^{-1}\right)^{\mathrm{b}}$ & 0.238 & 0.096 & 2.5 & 0.013 & $3.69 \% \mid 3.71 \%$ \\
\hline MAT $\left({ }^{\circ} \mathrm{C}\right)$ & -0.083 & 0.025 & -3.3 & 0.001 & $-0.67 \% \mid-1.07 \%$ \\
\hline MAT-change $\left({ }^{\circ} \mathrm{C} y r^{-1}\right)^{c}$ & -1.243 & 0.233 & -5.3 & $<0.001$ & $0.58 \% \mid 0.00 \%{ }^{d}$ \\
\hline MCWD $(\mathrm{mm} \times 1,000)$ & $-0.405 \mid-1.391$ & $0.381 \mid 0.24$ & $-1.1 \mid-5.8$ & $0.289 \mid<0.001$ & $-0.52 \% \mid-2.73 \%$ \\
\hline Wood density $\left(\mathrm{g} \mathrm{cm}^{-3}\right)$ & -1.295 & 0.530 & -2.4 & 0.015 & $0.05 \% \mid 0.00 \%$ \\
\hline \multicolumn{6}{|c|}{ Carbon losses $\left(\mathrm{Mg} \mathrm{C} \mathrm{ha}^{-1} \mathrm{yr}^{-1}\right)^{\mathrm{e}}$} \\
\hline Predictor variable & Parameter value & Standard error & $t$ value & $P$ value & $2000-2015$ change in losses (\%) \\
\hline Intercept & 1.216 & 0.086 & 14.1 & $<0.001$ & - \\
\hline $\mathrm{CO}_{2}$-change $\left(\mathrm{ppm} \mathrm{yr}{ }^{-1}\right)^{\mathrm{b}}$ & 0.130 & 0.059 & 2.2 & 0.026 & $11.38 \% \mid 14.81 \%$ \\
\hline MAT-change $\left({ }^{\circ} \mathrm{C} \mathrm{yr}^{-1}\right)^{\mathrm{c}}$ & 0.766 & 0.162 & 4.7 & $<0.001$ & $-1.56 \% \mid 0.00 \%$ \\
\hline MCWD $(\mathrm{mm} \times 1,000)$ & -0.232 & 0.107 & -2.2 & 0.030 & $-1.21 \% \mid-2.42 \%$ \\
\hline CRT (years) & -0.003 & 0.001 & -6.1 & $<0.001$ & $-0.57 \% \mid 1.39 \%$ \\
\hline
\end{tabular}

This table shows the best-ranked gains and loss models. Where continental values differ, those for Africa are reported first, followed by 'l', then the Amazonian values.

${ }^{a}$ The 1 January 2000 to 31 December 2014 change in gains/losses for each predictor variable was estimated allowing only the focal predictor to vary; this change was then expressed as a

percentage of the annual gains/losses in the year 2000, allowing all predictors to vary.

${ }^{\mathrm{b}}$ Change over the past 56 years (see Extended Data Fig. 3).

${ }^{\circ}$ Change over the past 5 years (see Extended Data Fig. 3).

${ }^{\mathrm{d}} \mathrm{A}$ positive value for Africa indicates that MAT increased more slowly over 2000-2015 compared to the mean increase over 1983-2015, therefore contributing to an increase in gains; a zero

value for Amazonia indicates that the rate of MAT increase was the same over 2000-2015 as the mean increase over 1983-2015.

${ }^{e}$ Carbon loss values were normalized via power-law transformation, with power parameter $\lambda=0.361$.

\section{Scaling results to the pan-tropics}

Scaling our estimated mean sink strength by forest area for each continent signifies that Earth has passed the point of peak carbon sequestration into intact tropical forests (Table 1). The continental sink in Amazonia peaked in the 1990s, followed by a decline, driven by sink strength peaking in the 1990s and a continued decline in forest area (Table 1). In Africa the per unit area sink strength peaked later, in the 2000-2010 period, but the continental African sink peaked in the 1990s, owing to the decline in forest area in the 2000s outpacing the small per unit area increase in sink strength. Including the modest uptake in the much smaller area of intact Asian tropical forest ${ }^{15}$ indicates that total pan-tropical carbon uptake peaked in the 1990s (Table 1).

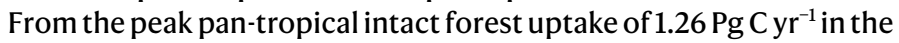
1990 s, we project a continued decline reaching just $0.29{\mathrm{Pg} \mathrm{C} \mathrm{yr}^{-1}}^{-1}$ in the 2030 s (multi-decade decline of $\sim 0.24 \mathrm{Pg} \mathrm{C} \mathrm{yr}^{-1}$ per decade), driven by (1) reduced mean pan-tropical sink strength decline of $0.1 \mathrm{MgC} \mathrm{ha}^{-1} \mathrm{yr}^{-1}$ per decade and (2) ongoing forest area losses of $\sim 13.5$ million ha $\mathrm{rr}^{-1}$ (see Extended Data Table 2 for forest area details). Critically, climate-driven vegetation model simulations have not predicted that the peak net carbon uptake into intact tropical forests has already been passed ${ }^{2,4,5}$.

\section{Discussion}

Our method of scaling to arrive at a pan-tropical sink estimate-in common with other studies using similar datasets ${ }^{1,6,13}$-is limited. Yet, pervasive net carbon uptake is expected given that we find a strong and ongoing $\mathrm{CO}_{2}$ fertilization effect. Using our $\mathrm{CO}_{2}$ response in Table 2, we find an increase in aboveground carbon stocks of $10.8 \pm 3.7 \mathrm{MgC} \mathrm{ha}^{-1}$ per $100 \mathrm{ppm} \mathrm{CO}_{2}$, equivalent to $6.5 \pm 2.2 \%$ ( \pm standard error; using an area-weighted pan-tropical mean aboveground carbon stock of $\left.165 \mathrm{Mg} \mathrm{Cha}^{-1}\right)$. This is comparable to the $5.0 \pm 1.2 \%$ increase in tropical forest $\mathrm{C}$ stocks per $100 \mathrm{ppm} \mathrm{CO}$ derived from a recent synthesis of $\mathrm{CO}_{2}$ fertilization experiments, despite a lack of data from old-growth tropical forests ${ }^{39}$. Our result is within the range of climate-driven vegetation models ${ }^{2,7}$, although it is greater than results from a number of recently published models that include potential nutrient constraints, reported as $5.9 \pm 4.7 \mathrm{MgC} \mathrm{ha}^{-1}$ per $100 \mathrm{ppm} \mathrm{CO}_{2}$ (ref. ${ }^{40}$ ). We find that the $\mathrm{CO}_{2}$ fertilization-driven uptake is currently only partially offset by the negative impacts of similarly widespread rising air temperatures $\left(-2.0 \pm 0.4 \mathrm{MgC} \mathrm{ha}^{-10} \mathrm{C}^{-1}\right.$, from Table 2$)$, consistent with models ${ }^{7}$, limited experiments ${ }^{31}$ and independent observations ${ }^{9}$, plus well-documented negative responses to drought ${ }^{41,42}$. Long-term and extensive increases in satellite-derived greenness in tropical regions that have not experienced major changes in land-use management ${ }^{17,43}$, particularly in central Africa in the past decade ${ }^{44}$, indicate increases in tropical forest net primary productivity, providing further evidence that the sink is a widespread phenomenon.

Nonetheless, our analyses suggest that this pervasive intact tropical forest sink in live biomass is in long-term decline, having peaked first in Amazonia, and more recently followed by African forests, explaining the prior Africa-Amazon carbon sink divergence as part of a longerterm pattern of asynchronous saturation and decline. Over time, the continued $\mathrm{CO}_{2}$ fertilization effect is being increasingly counteracted by the impacts of higher temperatures and droughts on tree growth and mortality, which are modulated by internal forest dynamics, with forests with the shortest CRT saturating first.

From an atmospheric perspective, the full impacts of the contribution to the saturation of the sink from slowing carbon gains are experienced immediately, but the contribution from rising carbon losses is delayed because dead trees do not decompose instantaneously. Decomposition of this dead tree mass is about half complete in 4 years, and about $85 \%$ complete in 10 years, so rising carbon losses result in delayed carbon additions to the atmosphere ${ }^{45}$. Hence, from an atmospheric perspective, the intact tropical forest biomass carbon sink probably peaked a few years later than our inventory data indicate and the full impacts are not yet realized. The pan-tropical carbon sink in live biomass declined by $0.27 \mathrm{Pg} \mathrm{C} \mathrm{yr}^{-1}$ between the $1990 \mathrm{~s}$ and 2000s (Table 1), but accounting for dead wood decomposition ${ }^{45}$ shows

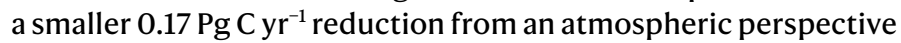
(see Methods).

Given that the overall global terrestrial carbon sink is increasing, a weakening intact tropical forest sink implies that the extra-tropical carbon sink has increased over the past two decades. Independent observations of interhemispheric atmospheric $\mathrm{CO}_{2}$ concentration 

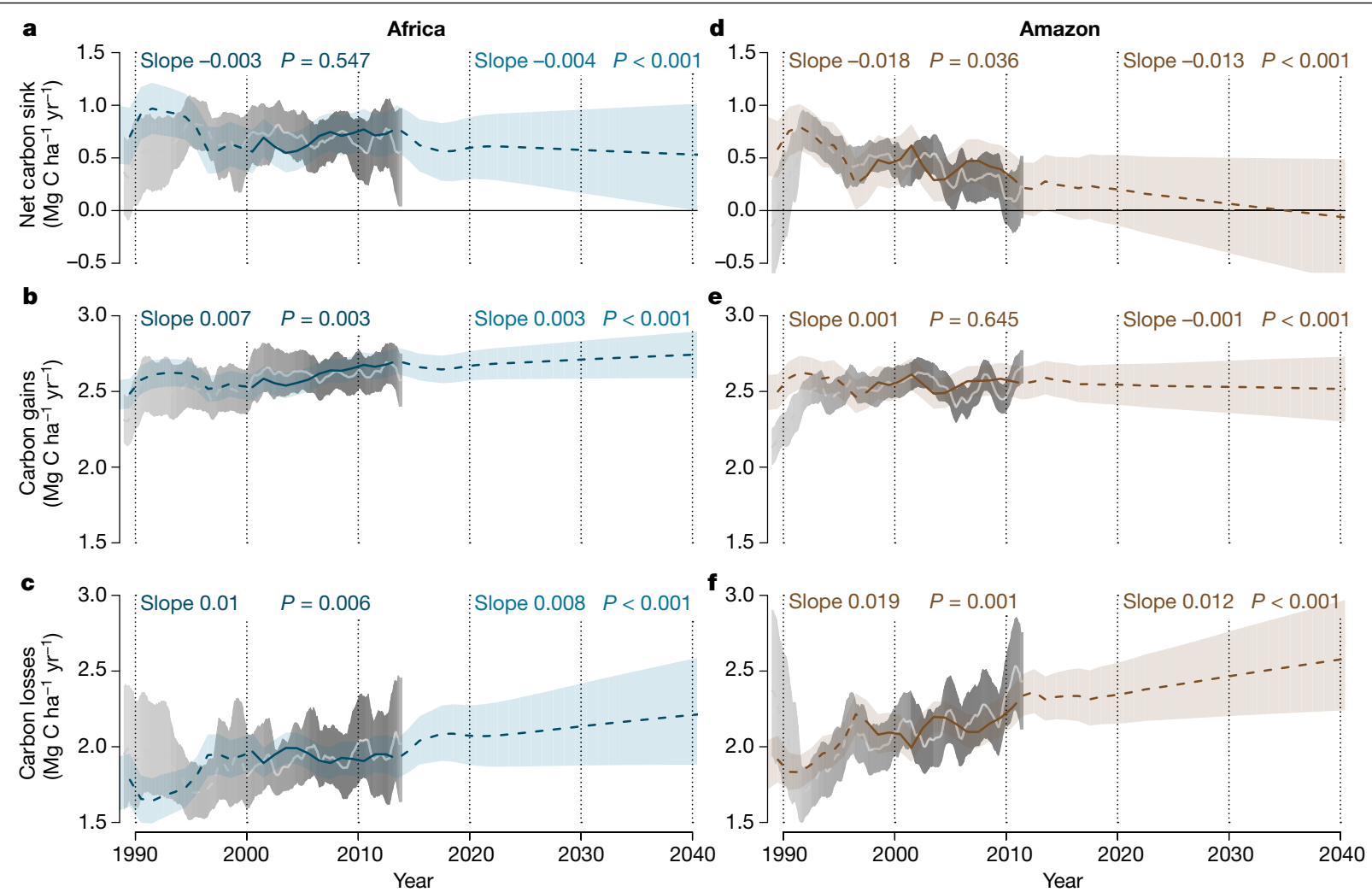

Fig. 3 | Modelled past and future carbon dynamics of structurally intact oldgrowth tropical forests in Africa and Amazonia. a-f, Predictions of net aboveground live biomass carbon (a,d), carbon gains $(\mathbf{b}, \mathbf{e})$, and carbon losses (c,f), for African (left panels) and Amazonian (right panels) plot inventory networks, based on $\mathrm{CO}_{2}$-change, MAT, MAT-change, drought (MCWD), plot wood density, and plot CRT, using observations in Africa until 31 December 2014 and Amazonia until mid-2011, and extrapolations of prior trends to

indicates that carbon uptake into the Northern Hemisphere landmass has increased at a greater rate than the global terrestrial carbon sink since the 1990s, with a further disproportionate increase in the $2000 \mathrm{~s}^{10}$. The interhemispheric analysis suggests a weakening of the tropical forest sink by $\sim 0.2 \mathrm{Pg} \mathrm{C} \mathrm{yr}^{-1}$ between the $1990 \mathrm{~s}$ and $2000 \mathrm{~s}^{10}$, which is similar to the $0.17 \mathrm{Pg} \mathrm{C} \mathrm{yr}^{-1}$ weakening over the same time period that we find. This reinforces our conclusion that the intact tropical forest carbon sink has already saturated.

In summary, our results indicate that although intact tropical forests remain major stores of carbon and are key centres of biodiversity ${ }^{11}$, their ability to sequester additional carbon in trees is waning. In the 1990s intact tropical forests removed $17 \%$ of anthropogenic $\mathrm{CO}_{2}$ emissions. This declined to an estimated $6 \%$ in the 2010s, because the pan-tropical weighted average per unit area sink strength declined by $33 \%$, forest area decreased by $19 \%$ and anthropogenic $\mathrm{CO}_{2}$ emissions increased by $46 \%$. Although tropical forests are more immediately threatened by deforestation ${ }^{46}$ and degradation ${ }^{47}$, and the future carbon balance will also depend on secondary forest dynamics ${ }^{48}$ and forest restoration plans ${ }^{49}$, our analyses show that they are also affected by atmospheric chemistry and climatic changes. Given that the intact tropical forest carbon sink is set to end sooner than even the most pessimistic climatedriven vegetation models predict ${ }^{4,5}$, our analyses suggest that climate change impacts in the tropics may become more severe than predicted. Furthermore, the carbon balance of intact tropical forests will only stabilize once $\mathrm{CO}_{2}$ concentrations and the climate stabilizes.

Continued on-the-ground monitoring of the world's remaining intact tropical forests will be required to test our prediction that the carbon sink in live trees will continue to decline, particularly as future changes in the tree species composition may alter the resilience of the sink and
31 December 2039. Model predictions are in blue (Africa) and brown (Amazon), with solid lines spanning the window when $\geq 75 \%$ of plots were monitored to show model consistency with the observed trends, and shading showing upper and lower confidence intervals accounting for uncertainties in the model (both fixed and random effects) and uncertainties in the predictor variables. Lightgrey lines and grey shading are the mean and $95 \% \mathrm{CI}$ of the observations from the African and Amazonian plot networks.

because we cannot exclude the possibility of decadal-scale climate impacts on these forests. Such direct ground-based measurements also provide a constraint on estimating the size, location and climate sensitivity of the terrestrial carbon sink. In addition, our conclusion that tree mortality and internal forest dynamics are important controls on the future of the tropical forest carbon sink may assist in improving the vegetation components of Earth System Models ${ }^{50}$ and contribute to reducing terrestrial carbon cycle feedback uncertainty ${ }^{19,20}$. Our findings also have policy implications. At the individual country level, given that intact tropical forests are a carbon sink but the rate of reduction will differ continentally and probably regionally (for example, aseasonal Amazon forests are less affected by droughts), national greenhouse gas reporting will require careful forest monitoring. At the international level, given that tropical forests are likely to sequester less carbon in the future than Earth System Models predict, an earlier date by which to reach net zero anthropogenic greenhouse gas emissions will be required to meet any given commitment to limit the global heating of Earth.

\section{Online content}

Any methods, additional references, Nature Research reporting summaries, source data, extended data, supplementary information, acknowledgements, peer review information; details of author contributions and competing interests; and statements of data and code availability are available at https://doi.org/10.1038/s41586-020-2035-0.

1. Pan, Y. et al. A large and persistent carbon sink in the world's forests. Science 333, 988-993 (2011).

2. Sitch, S. et al. Recent trends and drivers of regional sources and sinks of carbon dioxide. Biogeosciences 12, 653-679 (2015). 
3. Gaubert, B. et al. Global atmospheric $\mathrm{CO}_{2}$ inverse models converging on neutral tropical land exchange, but disagreeing on fossil fuel and atmospheric growth rate. Biogeosciences 16, 117-134 (2019).

4. Huntingford, $\mathrm{C}$. et al. Simulated resilience of tropical rainforests to $\mathrm{CO}_{2}$-induced climate change. Nat. Geosci. 6, 268-273 (2013).

5. Mercado, L. M. et al. Large sensitivity in land carbon storage due to geographical and temporal variation in the thermal response of photosynthetic capacity. New Phytol. 218, 1462-1477 (2018).

6. Brienen, R. J. W. et al. Long-term decline of the Amazon carbon sink. Nature 519, 344-348 (2015).

7. Piao, S. et al. Evaluation of terrestrial carbon cycle models for their response to climate variability and to $\mathrm{CO}_{2}$ trends. Glob. Change Biol. 19, 2117-2132 (2013).

8. Schimel, D., Stephens, B. B. \& Fisher, J. B. Effect of increasing $\mathrm{CO}_{2}$ on the terrestrial carbon cycle. Proc. Natl Acad. Sci. USA 112, 436-441 (2015).

9. Anderegg, W. R. L. et al. Tropical nighttime warming as a dominant driver of variability in the terrestrial carbon sink. Proc. Natl Acad. Sci. USA 112, 15591-15596 (2015).

10. Ciais, P. et al. Five decades of northern land carbon uptake revealed by the interhemispheric $\mathrm{CO}_{2}$ gradient. Nature 568, 221-225 (2019).

11. Lewis, S. L., Edwards, D. P. \& Galbraith, D. Increasing human dominance of tropical forests. Science 349, 827-832 (2015)

12. Pugh, T. A. M. et al. Role of forest regrowth in global carbon sink dynamics. Proc. Natl Acad. Sci. USA 116, 4382-4387 (2019).

13. Lewis, S. L. et al. Increasing carbon storage in intact African tropical forests. Nature 457, 1003-1006 (2009).

14. Phillips, O. L. et al. Drought sensitivity of the Amazon rainforest. Science 323, 1344-1347 (2009).

15. Qie, L. et al. Long-term carbon sink in Borneo's forests halted by drought and vulnerable to edge effects. Nat. Commun. 8, 1966 (2017).

16. Gatti, L. V. et al. Drought sensitivity of Amazonian carbon balance revealed by atmospheric measurements. Nature 506, 76-80 (2014).

17. Nemani, R. R. et al. Climate-driven increases in global terrestrial net primary production from 1982 to 1999. Science 300, 1560-1563 (2003).

18. Keenan, T. F. et al. Recent pause in the growth rate of atmospheric $\mathrm{CO}_{2}$ due to enhanced terrestrial carbon uptake. Nat. Commun. 7, 13428 (2016)

19. Booth, B. B. B. et al. High sensitivity of future global warming to land carbon cycle processes. Environ. Res. Lett. 7, 024002 (2012)

20. Lombardozzi, D. L., Bonan, G. B., Smith, N. G., Dukes, J. S. \& Fisher, R. A. Temperature acclimation of photosynthesis and respiration: a key uncertainty in the carbon cycleclimate feedback. Geophys. Res. Lett. 42, 8624-8631 (2015).

21. Le Quéré, C. et al. Global carbon budget 2018. Earth Syst. Sci. Data 10, 2141-2194 (2018).

22. Lewis, S. L., Brando, P. M., Phillips, O. L., van der Heijden, G. M. F. \& Nepstad, D. The 2010 Amazon drought. Science 331, 554 (2011).

23. Feldpausch, T. R. et al. Amazon forest response to repeated droughts. Glob. Biogeochem Cycles 30, 964-982 (2016).

24. McDowell, N. et al. Drivers and mechanisms of tree mortality in moist tropical forests. New Phytol. 219, 851-869 (2018).

25. Aleixo, I. et al. Amazonian rainforest tree mortality driven by climate and functional traits Nat. Clim. Chang. 9, 384-388 (2019).

26. Lewis, S. L. et al. Concerted changes in tropical forest structure and dynamics: evidence from 50 South American long-term plots. Phil. Trans. R. Soc. Lond. B 359, 421-436 (2004).

27. Lewis, S. L. et al. Above-ground biomass and structure of 260 African tropical forests. Phil. Trans. R. Soc. Lond. B 368, 20120295 (2013).

28. Quesada, C. A. et al. Basin-wide variations in Amazon forest structure and function are mediated by both soils and climate. Biogeosciences 9, 2203-2246 (2012).

29. Malhi, Y. et al. The above-ground coarse wood productivity of 104 neotropical forest plots. Glob. Change Biol. 10, 563-591 (2004)

30. Galbraith, D. et al. Residence times of woody biomass in tropical forests. Plant Ecol. Divers. 6, 139-157 (2013).

31. Reich, P. B. et al. Boreal and temperate trees show strong acclimation of respiration to warming. Nature 531, 633-636 (2016).

32. ter Steege, H. et al. Continental-scale patterns of canopy tree composition and function across Amazonia. Nature 443, 444-447 (2006)

33. Bauters, M. et al. High fire-derived nitrogen deposition on central African forests. Proc. Natl Acad. Sci. USA 115, 549-554 (2018).

34. Parmentier, I. et al. The odd man out? Might climate explain the lower tree alphadiversity of African rain forests relative to Amazonian rain forests? J. Ecol. 95 1058-1071 (2007).

35. Slik, J. W. F. et al. Phylogenetic classification of the world's tropical forests. Proc. Natl Acad. Sci. USA 115, 1837-1842 (2018).

36. Phillips, O. L. et al. Increasing dominance of large lianas in Amazonian forests. Nature 418 , 770-774 (2002).

37. Schnitzer, S. A. \& Bongers, F. Increasing liana abundance and biomass in tropical forests: emerging patterns and putative mechanisms. Ecol. Lett. 14, 397-406 (2011).

38. Meinshausen, $M$. et al. The RCP greenhouse gas concentrations and their extensions from 1765 to 2300. Clim. Change 109, 213-241 (2011)

39. Terrer, C. et al. Nitrogen and phosphorus constrain the $\mathrm{CO}_{2}$ fertilization of global plant biomass. Nat. Clim. Chang. 9, 684-689 (2019).

40. Fleischer, $\mathrm{K}$. et al. Amazon forest response to $\mathrm{CO}_{2}$ fertilization dependent on plant phosphorus acquisition. Nat. Geosci. 12, 736-741 (2019)

41. Jiang, Y. et al. Widespread increase of boreal summer dry season length over the Congo rainforest. Nat. Clim. Chang. 9, 617-622 (2019).

42. Gloor, M. et al. Recent Amazon climate as background for possible ongoing and future changes of Amazon humid forests. Glob. Biogeochem. Cycles 29, 1384-1399 (2015).

43. Kolby Smith, W. et al. Large divergence of satellite and Earth system model estimates of global terrestrial $\mathrm{CO}_{2}$ fertilization. Nat. Clim. Chang. 6, 306-310 (2016).
44. Chen, C. et al. China and India lead in greening of the world through land-use management. Nature Sustain. 2, 122-129 (2019).

45. Chambers, J. Q., Higuchi, N., Schimel, J. P., Ferreira, L. V. \& Melack, J. M. Decomposition and carbon cycling of dead trees in tropical forests of the central Amazon. Oecologia 122 380-388 (2000)

46. Hansen, M. C. et al. High-resolution global maps of 21st-century forest cover change. Science 342, 850-853 (2013).

47. Pearson, T. R. H., Brown, S., Murray, L. \& Sidman, G. Greenhouse gas emissions from tropical forest degradation: an underestimated source. Carbon Balance Manag. 12, 3 (2017).

48. Schwartz, N. B., Uriarte, M., DeFries, R., Gutierrez-Velez, V. H. \& Pinedo-Vasquez, M. A. Land-use dynamics influence estimates of carbon sequestration potential in tropical second-growth forest. Environ. Res. Lett. 12, 074023 (2017).

49. Lewis, S. L., Wheeler, C. E., Mitchard, E. T. A. \& Koch, A. Regenerate natural forests to store carbon. Nature 568, 25-28 (2019).

50. $\mathrm{Yu}, \mathrm{K}$. et al. Pervasive decreases in living vegetation carbon turnover time across forest climate zones. Proc. Natl Acad. Sci. USA 116, 24662-24667 (2019).

Publisher's note Springer Nature remains neutral with regard to jurisdictional claims in published maps and institutional affiliations.

(C) The Author(s), under exclusive licence to Springer Nature Limited 2020

U.S. government works are not subject to copyright.

Wannes Hubau ${ }^{1,2,3,95} \bowtie$, Simon L. Lewis ${ }^{1,4,95}$, Oliver L. Phillips', Kofi Affum-Baffoe ${ }^{5}$, Hans Beeckman ${ }^{2}$, Aida Cuni-Sanchez ${ }^{4,6}$, Armandu K. Daniels ${ }^{7}$, Corneille E. N. Ewango ${ }^{8,9,10}$ Sophie Fauset ${ }^{11}$, Jacques M. Mukinzi ${ }^{8,12,13}$, Douglas Sheil ${ }^{14}$, Bonaventure Sonké ${ }^{15}$,

Martin J. P. Sullivan ${ }^{1,16}$, Terry C. H. Sunderland ${ }^{17,18}$, Hermann Taedoumg ${ }^{15,19}$, Sean C. Thomas ${ }^{20}$, Lee J. T. White ${ }^{21,22,23}$, Katharine A. Abernethy ${ }^{22,23}$, Stephen Adu-Bredu ${ }^{24}$

Christian A. Amani ${ }^{17,25}$, Timothy R. Baker', Lindsay F. Banin ${ }^{26}$, Fidèle Baya ${ }^{27,28}$

Serge K. Begne ${ }^{1,15}$, Amy C. Bennett', Fabrice Benedet ${ }^{29,30}$, Robert Bitariho ${ }^{31}$,

Yannick E. Bocko ${ }^{32}$, Pascal Boeckx ${ }^{33}$, Patrick Boundja ${ }^{17,34}$, Roel J. W. Brienen', Terry Brncic ${ }^{34}$ Eric Chezeaux ${ }^{35}$, George B. Chuyong ${ }^{36}$, Connie J. Clark ${ }^{37}$, Murray Collins ${ }^{38,39}$,

James A. Comiskey ${ }^{40,41}$, David A. Coomes ${ }^{42}$, Greta C. Dargie', Thales de Haulleville ${ }^{2}$,

Marie Noel Djuikouo Kamdem ${ }^{36}$, Jean-Louis Doucet ${ }^{43}$, Adriane Esquivel-Muelbert ${ }^{1,44}$ Ted R. Feldpausch ${ }^{45}$, Alusine Fofanah ${ }^{46}$, Ernest G. Foli ${ }^{24}$, Martin Gilpin', Emanuel Gloor', Christelle Gonmadje ${ }^{47}$, Sylvie Gourlet-Fleury ${ }^{29,30}$, Jefferson S. Hall ${ }^{48}$, Alan C. Hamilton ${ }^{49}$ David J. Harris ${ }^{50}$, Terese B. Hart ${ }^{51,52}$, Mireille B. N. Hockemba ${ }^{34}$, Annette Hladik ${ }^{53}$ Suspense A. Ifo ${ }^{54}$, Kathryn J. Jeffery ${ }^{23}$, Tommaso Jucker ${ }^{55}$, Emmanuel Kasongo Yakusu ${ }^{2,3,10}$, Elizabeth Kearsley ${ }^{2,56}$, David Kenfack ${ }^{48,57}$, Alexander Koch ${ }^{4,58}$, Miguel E. Leal ${ }^{59}$, Aurora Levesley ${ }^{1}$, Jeremy A. Lindsell ${ }^{60,61}$, Janvier Lisingo ${ }^{62}$, Gabriela Lopez-Gonzalez', Jon C. Lovett ${ }^{1,63}$, Jean-Remy Makana ${ }^{62}$, Yadvinder Malhi ${ }^{64}$, Andrew R. Marshall ${ }^{6,65,66}$, $\mathrm{Jim}_{\text {Martin }}{ }^{67}$, Emanuel H. Martin ${ }^{57,68}$, Faustin M. Mbayu ${ }^{10}$, Vincent P. Medjibe ${ }^{37,69,70}$, Vianet Mihindou ${ }^{21,70}$, Edward T. A. Mitchard ${ }^{38}$, Sam Moore ${ }^{64}$, Pantaleo K. T. Munishi ${ }^{11}$, Natacha Nssi Bengone ${ }^{21}$, Lucas Ojo ${ }^{72}$, Fidèle Evouna Ondo ${ }^{70}$, Kelvin S.-H. Peh ${ }^{73,74}$ Georgia C. Pickavance', Axel Dalberg Poulsen ${ }^{50}$, John R. Poulsen ${ }^{37}$, Lan Qie ${ }^{1,75}$, Jan Reitsma ${ }^{76}$, Francesco Rovero ${ }^{77,78}$, Michael D. Swaine ${ }^{79}$, Joey Talbot $^{1,80}$, James Taplin ${ }^{81}$, David M. Taylor ${ }^{82}$, Duncan W. Thomas ${ }^{83}$, Benjamin Toirambe ${ }^{2,84}$, John Tshibamba Mukendi i, 10,85, Darlington Tuagben ${ }^{7,86}$, Peter M. Umunay ${ }^{87,88}$, Geertje M. F. van der Heijden ${ }^{89}$, Hans Verbeeck ${ }^{56}$, Jason Vleminckx ${ }^{90,91}$, Simon Willcock ${ }^{92}$, Hannsjörg Wöll ${ }^{93}$, John T. Woods ${ }^{94}$ \& Lise Zemagho ${ }^{15}$

School of Geography, University of Leeds, Leeds, UK. ${ }^{2}$ Service of Wood Biology, Roya Museum for Central Africa, Tervuren, Belgium. ${ }^{3}$ Department of Environment, Laboratory of Wood Technology (Woodlab), Ghent University, Ghent, Belgium. ${ }^{4}$ Department of Geography University College London, London, UK. ${ }^{5}$ Mensuration Unit, Forestry Commission of Ghana, Kumasi, Ghana. ${ }^{6}$ Department of Environment and Geography, University of York, York, UK. ${ }^{7}$ Forestry Development Authority of the Government of Liberia (FDA), Monrovia, Liberia. ${ }^{8} \mathrm{DR}$ Congo Programme, Wildlife Conservation Society, Kinshasa, Democratic Republic of Congo. ${ }^{9}$ Centre de Formation et de Recherche en Conservation Forestière (CEFRECOF), Epulu, Democratic Republic of Congo. ${ }^{10}$ Faculté de Gestion de Ressources Naturelles Renouvelables, Université de Kisangani, Kisangani, Democratic Republic of Congo. ${ }^{11} \mathrm{School}$ of Geography, Earth and Environmental Sciences, University of Plymouth, Plymouth, UK. ${ }^{12}$ Salonga National Park, Kinshasa, Democratic Republic of Congo. ${ }^{13}$ World Wide Fund for Nature, Gland, Switzerland. ${ }^{14}$ Faculty of Environmental Sciences and Natural Resource Management, Norwegian University of Life Sciences, Ås, Norway. ${ }^{15}$ Plant Systematic and Ecology Laboratory, Higher Teachers' Training College, University of Yaounde I, Yaounde, Cameroon. ${ }^{16}$ Department of Natural Sciences, Manchester Metropolitan University, Manchester, UK. ${ }^{17}$ Center for International Forestry Research (CIFOR), Bogor, Indonesia. ${ }^{8}$ Faculty of Forestry, University of British Columbia, Vancouver, British Columbia, Canada. ${ }^{19}$ Bioversity International, Yaounde, Cameroon. ${ }^{20}$ Faculty of Forestry, University of Toronto, Toronto, Ontario, Canada. ${ }^{21}$ Ministry of Forests, Seas, Environment and Climate, Libreville, Gabon. ${ }^{22}$ Institut de Recherche en Écologie Tropicale, Libreville, Gabon. ${ }^{23}$ Department of Biological and Environmental Sciences, University of Stirling, Stirling, UK. ${ }^{24}$ Forestry Research nstitute of Ghana (FORIG), Kumasi, Ghana. ${ }^{25}$ Université Officielle de Bukavu, Bukavu, Democratic Republic of Congo. ${ }^{26}$ UK Centre for Ecology \& Hydrology, Penicuik, UK. ${ }^{27}$ Ministère des Eaux, Forêts, Chasse et Pêche (MEFCP), Bangui, Central African Republic. ${ }^{28}$ Institut Centrafricain de Recherche Agronomique (ICRA), Bangui, Central African Republic. ${ }^{29}$ Forêts et Sociétés (F\&S), Centre de Coopération Internationale en Recherche Agronomique pour le Développement (CIRAD), Montpellier, France. ${ }^{30}$ Forêts et Sociétés (F\&S), Université de Montpellier, Montpellier, France. ${ }^{31}$ The Institute of Tropical Forest Conservation (ITFC), Mbarara University of Science and Technology (MUST), Mbarara, Uganda. ${ }^{32}$ Faculté des 
Sciences et Techniques, Laboratoire de Botanique et Écologie, Université Marien Ngouabi, Brazzaville, Republic of Congo. ${ }^{33}$ Isotope Bioscience Laboratory-ISOFYS, Ghent University, Ghent, Belgium. ${ }^{34}$ Congo Programme, Wildlife Conservation Society, Brazzaville, Republic of Congo. ${ }^{35}$ Rougier-Gabon, Libreville, Gabon. ${ }^{36}$ Faculty of Science, Department of Botany and Plant Physiology, University of Buea, Buea, Cameroon. ${ }^{37}$ Nicholas School of the Environment, Duke University, Durham, NC, USA. ${ }^{38}$ School of GeoSciences, University of Edinburgh, Edinburgh, UK. ${ }^{39}$ Grantham Research Institute on Climate Change and the Environment, London, UK. ${ }^{40}$ Inventory and Monitoring Program, National Park Service, Fredericksburg, VA, USA. ${ }^{41}$ Smithsonian Institution, Washington, DC, USA. ${ }^{42}$ Department of Plant Sciences, University of Cambridge, Cambridge, UK. ${ }^{43}$ TERRA, Forest is Life, Gembloux Agro-Bio Tech, University of Liège, Liège, Belgium. ${ }^{44}$ School of Geography, Earth and Environmental Sciences, University of Birmingham, Birmingham, UK. ${ }^{45}$ Department of Geography, College of Life and Environmental Sciences, University of Exeter, Exeter, UK. ${ }^{46}$ The Gola Rainforest National Park, Kenema, Sierra Leone. ${ }^{47}$ National Herbarium, Yaounde, Cameroon. ${ }^{48}$ Forest Global Earth Observatory (ForestGEO), Smithsonian Tropical Research Institute, Washington, DC, USA. ${ }^{49}$ Kunming Institute of Botany, Chinese Academy of Sciences, Kunming, China. ${ }^{50}$ Royal Botanic Garden Edinburgh, Edinburgh, UK. ${ }^{51}$ Lukuru Wildlife Research Foundation, Kinshasa, Democratic Republic of Congo. ${ }^{52}$ Division of Vertebrate Zoology, Yale Peabody Museum of Natural History, New Haven, CT, USA. ${ }^{53}$ Département Hommes et Environnement, Muséum National d'Histoire Naturel, Paris, France. ${ }^{54}$ École Normale Supérieure (ENS), Département des Sciences et Vie de la Terre, Laboratoire de Géomatique et d'Écologie Tropicale Appliquée, Université Marien Ngouabi, Brazzaville, Republic of Congo. ${ }^{55}$ School of Biological Sciences, University of Bristol, Bristol, UK. ${ }^{56}$ Department of Environment, Laboratory of Computational \& Applied Vegetation Ecology (Cavelab), Ghent University, Ghent, Belgium. ${ }^{57}$ Tropical Ecology, Assessment and Monitoring (TEAM) Network, Arlington, VA, USA. ${ }^{58}$ Department of Earth Sciences, University of Hong Kong, Hong Kong, China. ${ }^{59}$ Uganda Programme, Wildlife Conservation Society, Kampala, Uganda. ${ }^{60} \mathrm{~A}$ Rocha International, Cambridge, UK. ${ }^{61}$ Centre for Conservation Science, The Royal Society for the Protection of Birds, Sandy, UK. ${ }^{62}$ Faculté des Sciences, Laboratoire d'Écologie et Aménagement Forestier, Université de Kisangani, Kisangani, Democratic Republic of Congo.
${ }^{63}$ Royal Botanic Gardens, Kew, London, UK. ${ }^{64}$ Environmental Change Institute, School of Geography and the Environment, University of Oxford, Oxford, UK. ${ }^{65}$ Tropical Forests and People Research Centre, University of the Sunshine Coast, Sippy Downs, Queensland, Australia. ${ }^{66}$ Flamingo Land Ltd, Kirby Misperton, UK. ${ }^{67}$ Fleming College, Peterborough, Ontario, Canada. ${ }^{68}$ Udzungwa Ecological Monitoring Centre, Mang'ula, Tanzania. ${ }^{69} \mathrm{Commission}$ of Central African Forests (COMIFAC), Yaounde, Cameroon. ${ }^{70}$ Agence Nationale des Parcs Nationaux, Libreville, Gabon. ${ }^{71}$ Sokoine University of Agriculture, Morogoro, Tanzania. ${ }^{72}$ University of Abeokuta, Abeokuta, Nigeria. ${ }^{73}$ School of Biological Sciences, University of Southampton, Southampton, UK. ${ }^{74}$ Department of Zoology, Conservation Science Group, University of Cambridge, Cambridge, UK. ${ }^{75}$ School of Life Sciences, University of Lincoln, Lincoln, UK. ${ }^{76}$ Bureau Waardenburg, Culemborg, The Netherlands. ${ }^{77}$ Department of Biology, University of Florence, Florence, Italy. ${ }^{78}$ Tropical Biodiversity Section, MUSE-Museo delle Scienze, Trento, Italy. ${ }^{79}$ Department of Plant \& Soil Science, School of Biological Sciences, University of Aberdeen, Aberdeen, UK. ${ }^{80}$ Institute for Transport Studies, University of Leeds, Leeds, UK. ${ }^{81}$ UK Research \& Innovation, Innovate UK, London, UK. ${ }^{82}$ Department of Geography, National University of Singapore, Singapore, Singapore. ${ }^{83}$ Biology Department, Washington State University, Vancouver, WA, USA. ${ }^{84}$ Ministère de l'Environnement et Développement Durable, Kinshasa, Democratic Republic of Congo. ${ }^{85}$ Faculté des Sciences Appliquées, Université de Mbujimayi, Mbujimayi, Democratic Republic of Congo. ${ }^{86}$ Friends of Ecosystem and the Environment, Monrovia, Liberia. ${ }^{87}$ Yale School of Forestry and Environmental Studies, Yale University, New Haven, CT, USA. ${ }^{8}$ Wildlife Conservation Society, New York, NY, USA. ${ }^{89}$ School of Geography, University of Nottingham, Nottingham, UK. ${ }^{90}$ International Center for Tropical Botany, Department of Biological Sciences, Florida International University, Miami, FL, USA. ${ }^{91}$ Faculté des Sciences, Service d'Évolution Biologique et Écologie, Université Libre de Bruxelles, Brussels, Belgium. ${ }^{92}$ School of Natural Sciences, University of Bangor, Bangor, UK. ${ }^{93}$ Independent Researcher, Bad Aussee, Austria. ${ }^{94}$ W.R.T. College of Agriculture and Forestry, University of Liberia, Monrovia, Liberia. ${ }^{95}$ These authors contributed equally: Wannes Hubau, Simon L. Lewis. ${ }^{凶}$-mail: whubau@gmail.com 


\section{Article}

\section{Methods}

\section{Plot selection}

Closed canopy (that is, not woody savannah) old-growth mixed-age forest inventory plots were selected using commonly used crite$\mathrm{ria}^{6,13,27}$ : structurally intact (that is, free of fire and industrial logging); all trees with diameter at reference height $\geq 100 \mathrm{~mm}$ measured at least twice; area $\geq 0.2 \mathrm{ha}$; altitude $<1,500 \mathrm{~m}$ above sea level; MAT $\geq 20.0^{\circ} \mathrm{C}^{51}$; annual precipitation $\geq 1,000 \mathrm{~mm}^{51}$; located $\geq 50 \mathrm{~m}$ from anthropogenic forest edges. Of the 244 plots included in the study, 217 contribute to the African Tropical Rainforest Observatory Network (AfriTRON; www.afritron.org), with data curated at www.ForestPlots.net ${ }^{52,53}$. These include plots from Sierra Leone, Liberia, Ghana, Nigeria, Cameroon, Gabon, Republic of Congo, Democratic Republic of Congo, Uganda and Tanzania $^{52,53}$ (Extended Data Fig. 1). Fifteen plots are part of the TEAM network, from Cameroon, Republic of Congo, Tanzania and Uganda ${ }^{54-57}$. Nine plots contribute to the ForestGEO network, from Cameroon and Democratic Republic of Congo ${ }^{58}$ (9 plots from Democratic Republic of Congo, with codes SNG, contribute to both AfriTRON and ForestGEO networks, included above in the AfriTRON total). Finally, three plots from Central African Republic are part of the CIRAD network ${ }^{59,60}$. The large majority of plots are sited in terra firme (not inundated by river water) forests and have mixed species composition, although four are in seasonally flooded forest and 14 plots are in Gilbertiodendron dewevrei monodominant forest, a locally common forest type in Africa (Supplementary Table 1 ). The 244 plots have a mean size of 1.1 ha (median, 1 ha), with a total plot area of 277.9 ha. The dataset comprises 391,968 diameter measurements on 135,625 stems, of which $89.9 \%$ were identified to species, $97.5 \%$ to genus and $97.8 \%$ to family. Mean total monitoring period is 11.8 years, mean census length 5.7 years, with a total of 3,214 hectare years of monitoring. The 321 Amazon plots are published and were selected using the same criteria ${ }^{6}$, except in the African selection criteria we specified a minimum anthropogenic edge distance and added a minimum temperature threshold.

\section{Plot inventory and tree biomass carbon estimation}

Tree-level aboveground biomass carbon is estimated using an allometric equation with parameters for tree diameter (in $\mathrm{mm}$ ), tree height (in $\mathrm{m}$ ) and wood mass density (in $\left.\mathrm{g} \mathrm{cm}^{-3}\right)^{61}$. The calculation of each is discussed in turn. All calculations were performed using the R statistical platform, version 3.2.1 (ref. ${ }^{62}$ ) using the BiomasaFP R package, version 0.2.1 (ref. $^{63}$ ).

Tree diameter. In all plots, all woody stems with $\geq 100 \mathrm{~mm}$ diameter at $1.3 \mathrm{~m}$ from the base of the stem ('diameter at breast height', $\mathrm{DBH}$, in $\mathrm{mm}$ ), or $0.5 \mathrm{~m}$ above deformities or buttresses, were measured, mapped and identified using standard forest inventory methods ${ }^{64,65}$. The height of the point of measurement (POM) was marked on the trees and recorded, so that the same POM is used at the subsequent forest census. For stems developing deformities or buttresses over time that could potentially disturb the initial POM, the POM was raised approximately $500 \mathrm{~mm}$ above the deformity. Estimates of the diameter growth of trees with changed POM used the ratio of new to old POMs, to create a single trajectory of growth from the series of diameters at two POM heights ${ }^{6,13,65}$. We used standardized protocols to assess typographical errors and potentially erroneous diameter values (for example, trees shrinking by $>5 \mathrm{~mm}$ ), missing values, failures to find the original POM, and other issues. Where necessary we estimated the likely value via interpolation or extrapolation from other measurements of that tree, or when this was not possible we used the median or mean growth rate of trees in the same plot, census and size-class. We used the median growth rate for size classes of DBH $=100-199 \mathrm{~mm}$ and $200-399 \mathrm{~mm}$. We used the mean growth rate for a size class with $\mathrm{DBH}>400 \mathrm{~mm}$, as there were fewer trees in the largest size class ${ }^{65}$. We interpolated measurements for $1.3 \%$ of diameters, extrapolated $0.9 \%$, and used median growth rates for $1.5 \%$.
Tree height. Height of individuals from ground to the top leaf, hereafter $H_{\mathrm{t}}$, was measured in 204 plots, using a laser hypsometer (Nikon forestry Pro) from directly below the crown (most plots), a laser or ultrasonic distance device with an electronic tilt sensor, a manual clinometer, or by direct measurement, that is, climbing the tree. Only trees where the top was visible were selected ${ }^{66}$. In most plots, tree selection was similar: the 10 largest trees were measured, together with 10 randomly selected trees per diameter from five classes: $100-199 \mathrm{~mm}, 200-299$ $\mathrm{mm}, 300-399 \mathrm{~mm}, 400-499 \mathrm{~mm}$, and $500+\mathrm{mm}$ trees, following standard protocols ${ }^{66}$. We measured the actual height of 24,270 individual trees from 204 plots. We used these data and the local.heights function in $\mathrm{R}$ package BiomasaFP ${ }^{63}$ to fit 3-parameter Weibull relationships:

$$
H_{\mathrm{t}}=a\left(1-\mathrm{e}^{-b \mathrm{DBH}^{c}}\right)
$$

We chose the Weibull model (with Weibull parameters $a, b$ and $c$ ) because it is known to be robust ${ }^{66,67}$. We parameterized separate $H_{\mathrm{t}}$ DBH relationships for four different combinations of edaphic forest type and biogeographical region: (1) terra firme forest in West Africa, (2) terra firme forest in Lower Guinea and the Western Congo Basin, (3) terra firme forest in Eastern Congo Basin and East Africa, (4) seasonally flooded forest from Lower Guinea and the Western Congo Basin (there were no seasonally flooded forest plots in the other biogeographical regions). The parameters are: (1) terra firme forest in West Africa, $a=56.0 ; b=0.0401 ; c=0.744 ;(2)$ terra firme forest in Lower Guinea and the Western Congo Basin, $a=47.6 ; b=0.0536 ; c=0.755$; (3) terra firme forest in the Eastern Congo Basin and East Africa, $a=50.8 ; b=0.0499$; $c=0.706$; and finally (4) seasonally flooded forest from Lower Guinea and the Western Congo Basin, $a=38.2 ; b=0.0605 ; c=0.760$. For each of these combinations of forest type and bioregion, the local.heights function combines all height measurements from all plots belonging to that forest type/bioregion and fits the Weibull model parameters using nonlinear least squares (nls function in $\mathrm{R}$ with default settings), with starting values of $a=25, b=0.05$ and $c=0.7$ chosen because they led to regular model convergence. We fitted these models either treating each observation equally or with weights proportional to each tree's basal area. These weights give more importance to large trees during model fitting. We selected the best fitting of these models, determining this to be the model that minimized prediction error of stand biomass when calculated with estimated heights or observed heights. In this way, we selected the non-weighted model for terra firme forests in Lower Guinea/Western Congo Basin and for flooded forests in the Lower Guinea/Western Congo Basin; we selected the weighted model for the other two biogegraphical regions (West Africa and Eastern Congo Basin/ East Africa). The parameters were used to estimate $H_{\mathrm{t}}$ from DBH for all tree DBH measurements for input into the allometric equation. Median measured individual total tree height is $20.5 \mathrm{~m}$; the height range is 3.1 to $72.5 \mathrm{~m}$. The root mean squared error (RMSE) between the full dataset of measured heights and the predicted heights is $5.7 \mathrm{~m}$, which is $8.0 \%$ of the total range. Furthermore, RMSE is $5.3 \mathrm{~m}$ in terra firme forest in West Africa (7.5\% of the range; $n=9,771$ trees); RMSE is $6.4 \mathrm{~m}$ in terra firme forest in Lower Guinea and the Western Congo Basin $(8.7 \%$ of the range; $n=10,838$ trees); RMSE is $4.8 \mathrm{~m}$ in terra firme forest in the Eastern Congo Basin and East Africa (8.8\% of the range; $n=3,269$ trees); and RMSE is $4.1 \mathrm{~m}$ in seasonally flooded forest from Lower Guinea and the Western Congo Basin (12.5\% of the range; $n=392$ trees).

Wood density. Dry wood density $(\rho)$ measurements were compiled for 730 African species from published sources and stored in www. ForestPlots.net; most were sourced from the Global Wood Density Database on the Dryad digital repository (www.datadryad.org) (68,69. $^{6}$. Each individual in the tree inventory database was matched to a taxonspecific mean wood density value. Species in both the tree inventory and wood density databases were standardized for orthography and 
synonymy using the African Plants Database (www.ville-ge.ch/cjb/bd/ africa/) to maximize matches ${ }^{13}$. For incompletely identified individuals or for individuals belonging to species not in the $\rho$ database, we used the mean $\rho$ value for the next-highest known taxonomic category (genus or family, as appropriate). For unidentified individuals, we used the mean wood density value of all individual trees in the $\operatorname{plot}^{13,52}$.

Allometric equation. For each tree we used a published allometric equation ${ }^{61}$ to estimate aboveground biomass. We then converted this to carbon, assuming that aboveground carbon ( $\mathrm{AGC}$, in $\mathrm{Mg} \mathrm{Cha}^{-1}$ ) is $45.6 \%$ of aboveground biomass ${ }^{70}$. Thus:

$$
\mathrm{AGC}=0.456 \times\left(0.0673 \times\left(\rho \times \mathrm{DBH}^{2} \times H_{\mathrm{t}}\right)^{0.976}\right) / 1,000
$$

with DBH in mm, dry wood density $\rho$ in $\mathrm{g} \mathrm{cm}^{-3}$, and total tree height $H_{\mathrm{t}}$ in $\mathrm{m}$ ( ref. $^{61}$ ). Aboveground carbon in living biomass for each plot at each census date was estimated as the sum of the AGC of each living stem, divided by plot area (in hectares).

\section{Carbon gain and carbon loss estimation}

Net carbon sink (in $\mathrm{Mg} \mathrm{C} \mathrm{ha}^{-1} \mathrm{yr}^{-1}$ ) is estimated as carbon gains minus carbon losses. Carbon gains (in $\mathrm{Mg} \mathrm{Cha}^{-1} \mathrm{yr}^{-1}$ ) are the sum of the aboveground live biomass carbon additions from the growth of surviving stems and the addition of newly recruited stems (recruits are stems reaching a $\mathrm{DBH} \geq 100 \mathrm{~mm}$ during a given census interval), divided by the census length (in years) and plot area (in hectares). For each stem that survived a census interval, carbon additions from its growth $\left(\mathrm{MgC} \mathrm{ha}^{-1} \mathrm{yr}^{-1}\right)$ were calculated as the difference between its AGC at the end census of the interval and its AGC at the beginning census of the interval. For each stem that recruited during the census interval (that is, reaching $\mathrm{DBH} \geq 100 \mathrm{~mm}$ ), carbon additions were calculated in the same way, assuming $\mathrm{DBH}=0 \mathrm{~mm}$ at the start of the interval, following standard procedures ${ }^{6,65}$. Carbon losses (in $\mathrm{Mg} \mathrm{C} \mathrm{ha}^{-1} \mathrm{yr}^{-1}$ ) are estimated as the sum of aboveground biomass carbon from all stems that died during a census interval, divided by the census length (in years) and plot area (in hectares). Both carbon gains and carbon losses are calculated using standard methods ${ }^{6}$, including a census interval bias correction, using the SummaryAGWP function of the R package BiomasaFP $^{63,64,68}$.

As carbon gains (and losses, see below) are affected by a census interval bias, with the underestimate increasing with census length, we corrected this bias by accounting for (1) the carbon additions from trees that grew before they died within an interval (unobserved growth) and (2) the carbon additions from trees that reached $100 \mathrm{~mm} \mathrm{DBH}$ (that is, were recruited) and then died within the same interval (unobserved recruitment $)^{65,71}$.

The first component, the unobserved growth of a stem that died during a census interval, is estimated as the difference between AGC at death and AGC at the start of the census. These are calculated using equation (2), from $\mathrm{DBH}_{\text {death }}$ and $\mathrm{DBH}_{\text {start }}$, respectively. The latter is part of the data, the first can be estimated as: $\mathrm{DBH}_{\text {death }}=\mathrm{DBH}_{\text {start }} \times G \times Y_{\text {mean }}$, where $G$ is the plot-level median diameter growth rate (in $\mathrm{mm} \mathrm{yr}^{-1}$ ) of the size class the tree was in at the start of the census interval (size classes are defined as $\mathrm{DBH}<200 \mathrm{~mm}, 400 \mathrm{~mm}>\mathrm{DBH} \geq 200 \mathrm{~mm}$ and $\mathrm{DBH} \geq 400$ $\mathrm{mm}$ ) and $Y_{\text {mean }}$ is the mean number of years that trees survived in the census interval before dying. $Y_{\text {mean }}$ is calculated from the number of trees that are expected to have died in each year of the census interval, which is derived from the plot-level per capita mortality rate $\left(m_{\mathrm{a}}\right.$; as percentage of dead trees per year) calculated following equation (5) in ref. ${ }^{71}$.

The second component, the growth of recruits that were not observed because they died during the census interval, is estimated by calculating the number of unobserved recruits and diameter at death for each unobserved recruit. The number of unobserved recruits in a given year (stems ha ${ }^{-1} \mathrm{yr}^{-1}$ ) is estimated as: $N_{\mathrm{u} . \mathrm{r}}=R_{\mathrm{a}}-P_{\text {surv }} \times R_{\mathrm{a}}$, where $R_{\mathrm{a}}$ (number of recruited stems ha- $\mathrm{yr}^{-1}$ ) is the per-area annual recruitment calculated following equation (11) in ref. ${ }^{71}$ and $P_{\text {surv }}$ is the probability of each recruit surviving until the next census: $P_{\text {surv }}=\left(1-m_{\mathrm{a}}\right)^{T}$, where $T$ is the number of years remaining in the census interval.Summing $N_{\text {u.r }}$ for each year in a census interval gives the total number of unobserved recruits in that census interval. We then estimate diameter at death for each unobserved recruit, which is given in millimetres by $\mathrm{DBH}_{\text {death,u.r }}=100+$ $\left(G_{\mathrm{s}} \times Y_{\text {mean-rec }}\right)$, where $G_{\mathrm{s}}$ is the plot-level median diameter growth rate (in $\mathrm{mm} \mathrm{yr}^{-1}$ ) of the smallest size class (that is, DBH $<200 \mathrm{~mm}$ ) and $Y_{\text {mean-rec }}$ is the mean number of years that unobserved recruits survived in the census interval before dying. $Y_{\text {mean-rec }}$ is calculated as follows: from $m_{\text {a }}$ we can calculate the number of recruits in a given year that died in each subsequent year, and from this calculate the mean lifespan of recruits in a given year that died before the next census; $Y_{\text {mean-rec }}$ is then the mean of each year's recruit-lifespan, weighted by the number of unobserved recruits in each year.

The census interval bias correction (components one and two combined) typically add $<3 \%$ to plot-level carbon gains calculated for each plot census interval. Carbon losses are affected by the same census interval bias, so we corrected this bias by accounting for the additional carbon losses from the trees that were recruited and then died within the same interval, and the additional carbon losses resulting from the growth of the trees that died in the interval ${ }^{6,15,63}$. These two components are calculated in the same way as for carbon gains and typically add $<3 \%$ to plot-level carbon losses.

Carbon gains include both gains from the growth of surviving stems and new recruits. Separating carbon gains from the tree growth of surviving stems and newly recruited stems shows that carbon gains from recruitment are small overall, and are significantly lower in Africa than in the Amazon (in Africa, $0.17 \mathrm{Mg} \mathrm{Cha}^{-1} \mathrm{yr}^{-1} ; \mathrm{Cl}: 0.16-0.18$ versus in the Amazon, $0.27 \mathrm{Mg} \mathrm{Cha}^{-1} \mathrm{yr}^{-1}$; $\mathrm{Cl}: 0.25-0.28, P<0.001$; two-way Wilcoxon test), but this is compensated by carbon gains from survivors being significantly larger in Africa (2.33 $\left.\mathrm{Mg} \mathrm{Cha}^{-1} \mathrm{yr}^{-1} ; \mathrm{Cl}: 2.27-2.39\right)$ than in the Amazon (2.13 Mg C ha $\left.{ }^{-1} \mathrm{yr}^{-1} ; \mathrm{Cl}: 2.09-2.17, P=0.014\right)$. Therefore, gains overall (sum of gains from surviving stems and newly recruited stems) are indistinguishable between the continents (in Africa, 2.57 Mg Cha $\mathrm{yr}^{-1}$; $\mathrm{Cl}$ : 2.51-2.67 versus in the Amazon, 2.46 $\mathrm{MgC} \mathrm{ha}^{-1} \mathrm{yr}^{-1}$; Cl: 2.41-2.50, $P=0.460$; two-way Wilcoxon test). The lower carbon gains from recruitment in Africa are probably due to the lower stem turnover rates and longer CRT.

\section{Long-term gain, loss and net carbon sink trend estimation}

The estimated mean and uncertainty in carbon gains, carbon losses and the net carbon sink of the African plots from 1 January 1983 to 31 December 2014 (Fig. 1, Extended Data Fig. 7 and Extended Data Fig. 8) were calculated following ref. ${ }^{6}$ to allow direct comparison with published Amazonian results. First, each census interval value was interpolated for each 0.1-year period within the census interval. Then, for each 0.1-year period between 1 January 1983 and 31 December 2014, we calculated a weighted mean of all plots monitored at that time, using the square root of plot area as a weighting factor ${ }^{6}$. Confidence intervals for each 0.1-year period were bootstrapped.

Trends in carbon gains, losses and the net carbon sink over time were assessed using linear mixed effects models (Imer function in R, Ime4 package $\mathrm{e}^{72}$ ), providing the linear slopes reported in Fig. 1 . These models regress the midpoint of each census interval against the value of the response variable for that census interval. Plot identity was included as a random effect, that is, by assuming that the intercept can vary randomly among plots. We did not include slope as a random effect, consistent with previously published Amazon analyses ${ }^{6}$, because models did not converge owing to some plots having too few census intervals. Observations were weighted by plot size and census interval length. Weighting for the Africa data was derived empirically, by assuming a priori that there is no significant relation between the net carbon sink and census interval length or plot size, following ref. ${ }^{13}$. The following weighting removes all pattern in the residuals: 


$$
\text { Weight }=\sqrt[3]{\text { length }_{\text {int }}}+\sqrt[4]{\text { plotsize }}-1
$$

where length $_{\text {int }}$ is the length of the census interval, in years. Significance was assessed by regressing the residuals of the net carbon sink model against the weights $(P=0.702)$. Similar published weighting was used for the Amazon plots ${ }^{6}$.

Differences in long-term slopes between the two continents for carbon gains, carbon losses and net carbon sink, reported in the main text, were also assessed using linear mixed effects models and weighting, as described above, but performed on the combined African and Amazonian datasets and limited to their common time window, 1January 1983 to mid-2011. For these three tests on the pooled data (gains, losses and net sink) we included an additional interaction term between census interval date and continent, where a significant interaction would indicate that the slopes differ between continents. The statistical significance of continental differences in slope were assessed using the $F$-statistic (ANOVA function in R, car package $\mathrm{e}^{73}$ ). Shortening the common time window to the 20 years when the continents are bestsampled, mid-1991 to mid-2011, gave very similar results, including a divergent continental $\operatorname{sink}(P=0.04)$.

\section{Continental and pan-tropical carbon sink estimates}

The per unit area total net carbon sink (in $\mathrm{MgC} \mathrm{ha}^{-1} \mathrm{yr}^{-1}$ ) for each time period in Table 1 (each decade between 1 January 1980 and 31 December 2009; and between 1 January 2010 and 31 December 2014) is the sum of three components. The first component is the per unit area aboveground carbon sink from living trees and lianas with $\mathrm{DBH} \geq 100 \mathrm{~mm}$. For Africa we use the per unit area net carbon sink values presented in this paper. For Amazonia, we use data in ref. ${ }^{6}$. For Southeast Asia, we use inventory data collected using similar standardized methods from 49 plots in ref. ${ }^{15}$. For each time window, we use all plots for which census dates overlap the period, weighted by the square root of plot area, as for the solid lines in Fig. 1. The second component is the per unit area aboveground carbon sink from living trees and lianas with $\mathrm{DBH}<100 \mathrm{~mm}$. This is calculated as $5.19 \%, 9.40 \%$ and $5.46 \%$ of the first component (that is, aboveground carbon of large living trees) in Africa, Amazonia and Southeast Asia respectively ${ }^{74}$. The third component is the per unit area belowground carbon sink in live biomass, that is, roots. This is calculated as $25 \%, 37 \%$ and $17 \%$ of the aboveground carbon of living trees with $\mathrm{DBH} \geq 100 \mathrm{~mm}$ in Africa $^{13}$, Amazonia ${ }^{6}$ and Southeast Asia $^{75}$ respectively.

For each time period in Table 1 we calculated the continental-scale total carbon sink $\left(\mathrm{Pg} \mathrm{C} \mathrm{yr}^{-1}\right)$ by multiplying the per unit area total net carbon sink described above by the area of intact forest on each continent at that time interval (in ha) reported in Extended Data Table 2. Decades are calculated from 1 January 1990 to 31 December 1999. For comparability with previous continental-sink results, we used continental values of intact forest area for 1990, 2000, 2005 and 2010 as published in ref. ${ }^{1}$, that is, total forest area minus forest regrowth. We used the 1990-2010 data to fit an exponential model for each continent and used this model to estimate intact forest area for 1980 and 2015.

Finally, in the main text we calculated the proportion of anthropogenic $\mathrm{CO}_{2}$ emissions removed by Earth's intact tropical forests, as the total pan-tropical carbon sink from Table 1 divided by the total anthropogenic $\mathrm{CO}_{2}$ emissions. Total anthropogenic $\mathrm{CO}_{2}$ emissions are calculated as the sum of emissions from fossil fuel and land-use change and are estimated at 7.6 $\mathrm{Pg} \mathrm{C} \mathrm{yr}^{-1}$ in the 1990s, 9.0 $\mathrm{Pg} \mathrm{C} \mathrm{yr}^{-1}$ in the 2000s, and 11.1 $\mathrm{Pg} \mathrm{C} \mathrm{yr}^{-1}$ in the 2010s (ref. ${ }^{21}$, assuming $1.7 \%$ growth in fossil fuel emissions in 2018 and 2019, and mean 2010-2017 land-use change emissions for 2018 and 2019).

\section{Carbon sink from an atmospheric perspective}

To estimate the evolution of the carbon sink from an atmospheric perspective, we assumed that the contribution to the atmosphere from carbon gains are experienced immediately, while the contribution to the atmosphere from carbon losses must take into account the delay in decomposition of dead trees. We did this by calculating total forest carbon loss $\left(\mathrm{Mg} \mathrm{C} \mathrm{ha}^{-1} \mathrm{yr}^{-1}\right)$ for each year in the period 1 January 1950 to 31 December 2014, using the mean 1 January 1983 to 31 December 2014 records from Fig. 1 and assuming constant losses before 1983 (1.9 Mg C ha ${ }^{-1} \mathrm{yr}^{-1}$ and $1.5 \mathrm{Mg} \mathrm{C} \mathrm{ha}^{-1} \mathrm{yr}^{-1}$ for Africa and Amazonia respectively). Then, for each focal year in the period 1950-2014, we calculated how much carbon was released to the atmosphere in the subsequent years as follows: $y_{i}=x_{0} \times \mathrm{e}^{-0.17(i-1)}-x_{0} \times \mathrm{e}^{-0.17 i}$, where $x_{0}$ is the total forest carbon loss of the focal year; $y_{i}$ is the carbon released to the atmosphere at $i$ years from the focal year; and $-0.17 \mathrm{yr}^{-1}$ is a constant decomposition rate calculated for tropical forests in the Amazon ${ }^{45}$. For example, carbon loss was $1.95 \mathrm{Mg} \mathrm{C} \mathrm{ha}^{-1}$ in 1990 in African forests (Fig. 1), from which $0.31 \mathrm{Mg} \mathrm{C}^{-1}$ was released to the atmosphere in 1991; 0.26 Mg Cha ${ }^{-1}$ in 1992; 0.22 $\mathrm{MgC} \mathrm{ha}^{-1}$ in 1993; 0.07 Mg C ha $\mathrm{Mn}^{-1}$ in 2000 and $0.01 \mathrm{Mg} \mathrm{Cha}^{-1}$ in 2010. Hence, of the full $1.95 \mathrm{Mg} \mathrm{Cha}^{-1}$ dead tree biomass from 1990, $50 \%$ was released to the atmosphere after 4 years, $\sim 85 \%$ after 10 years, and $\sim 97 \%$ after 20 years. Finally, for each year between 1983 and 2014, the total contribution to the atmosphere from carbon losses was calculated as the sum of all carbon contributions released at that year, including all carbon loss pools from previous years that are released during the focal year (an approach similar to ref. ${ }^{6}$ ). We then calculated decadal-scale mean contributions to the atmosphere from carbon losses to estimate the carbon sink from an atmospheric perspective, reported in the main text.

\section{Predictor variable estimates (1983-2015)}

For each census interval of each plot, we examined potential predictor variables that may explain the long-term trends in carbon gains and carbon losses, reported in Table 2 and Extended Data Table 1. First, the environmental conditions during the census interval; second, the rate of change of these parameters; and third, forest attributes that may affect how different forests respond to the same environmental change. The predictor variable estimates for each census need to avoid bias due to seasonal variation, for example the intra-annual variability in atmospheric $\mathrm{CO}_{2}$ concentration. We therefore applied the following procedure to avoid seasonal variability impacts on long-term trends: (1) the length of each focal census interval was rounded to the nearest complete year (for example, a 1.1-year interval became a 1 year interval); (2) we computed dates that minimized the difference between actual fieldwork dates and complete-year census dates, while ensuring that subsequent census intervals of a plot do not overlap. The resulting sequence of non-overlapping census intervals was used to calculate interval-specific means for each environmental predictor variable to remove seasonal effects. The mean difference between the actual fieldwork dates and the complete-year census dates is 0.13 decimal years.

The first group of potential predictor variables, estimated for each census interval of each plot, are theory-driven choices: atmospheric $\mathrm{CO}_{2}$ concentration, MAT and drought intensity, which we quantified as MCWD ${ }^{14,20,76,77}$.

Atmospheric $\mathrm{CO}_{2}$ concentration. $\mathrm{CO}_{2}$ (in ppm) is estimated as the mean of the monthly mean values from the Mauna Loa record ${ }^{78}$ over the complete year census interval. While atmospheric $\mathrm{CO}_{2}$ concentration is highly correlated with time $\left(R^{2}=0.98\right)$, carbon gains are slightly better correlated with $\mathrm{CO}_{2}\left(R_{\mathrm{adj}}{ }^{2}=0.0027\right)$ than with time $\left(R_{\mathrm{adj}}{ }^{2}=0.0025\right)$, as expected from theory.

Mean annual temperature. MAT (in ${ }^{\circ} \mathrm{C}$ ) was derived from the temporally resolved (1901-2015) dataset of monthly mean temperature from the Climatic Research Unit (CRU TS version $4.03 ; \sim 3,025-\mathrm{km}^{2}$ resolution; released 15 May 2019; https://crudata.uea.ac.uk/cru/data/hrg//79. We downscaled the data to $1-\mathrm{km}^{2}$ resolution using the WorldClim v2 data$\operatorname{set}^{51,80}$, by subtracting the difference in mean monthly temperature, 
and applying this monthly correction to all months ${ }^{81}$. We then calculated MAT for each complete year census interval of each plot using the downscaled monthly CRU record.

Maximum climatological water deficit. MCWD (in mm) was derived from the $3,025-\mathrm{km}^{2}$ resolution Global Precipitation Climatology Centre dataset (GPCC version 6.0) that includes many more rain gauges than CRU in tropical Africa ${ }^{82,83}$. Because GPCC ends in 2013 we combined it with satellite-based Tropical Rainfall Measurement Mission data (TRMM $3 \mathrm{~B} 43 \mathrm{~V} 7$ product, $\sim 757-\mathrm{km}^{2}$ resolution $)^{84}$. The fit for the overlapping time period (1998-2013) was used to correct any systematic difference between GPCC and TRMM: GPCC $=a+b \times$ GPCC, with $\mathrm{GPCC}^{\prime}$ the adjusted GPCC record and $a$ and $b$ being different parameters for each month of the year and for each continent. Precipitation was then downscaled to $1-\mathrm{km}^{2}$ resolution using the WorldClim datase $\mathrm{t}^{51,80}$, by dividing by the ratio in mean monthly rainfall, and applying this monthly correction to all months ${ }^{81}$. For each census interval we extracted monthly precipitation values and estimated evapotranspiration to calculate monthly climatological water deficit (CWD), a commonly used metric of dry season intensity for tropical forests ${ }^{14,76,77}$. Monthly CWD values were calculated for each subsequent series of 12 months (complete years) $)^{77}$. Monthly CWD estimation begins with the wettest month of the first year in the interval, and is calculated as $100 \mathrm{~mm}$ per month evapotranspiration (ET) minus monthly precipitation $(P)$. Then, $\mathrm{CWD}_{i}$ values for the subsequent 11 months $(i)$ were calculated recursively as: $\mathrm{CWD}_{i}=\mathrm{ET}-P_{i}+\mathrm{CWD}_{i-1}$, where negative $\mathrm{CWD}_{i}$ values were set to zero $^{77}$ (no drought conditions). This procedure was repeated for each subsequent complete 12 months. We then calculated the annual MCWD as the largest monthly CWD value for every complete year within the census interval, with the MCWD of a census interval being the mean of the annual MCWD values within the census interval. Larger MCWD indicates more severe water deficits.

We assume evapotranspiration is $100 \mathrm{~mm}$ per month on both continents, based on measurements from Amazonia ${ }^{76,77}$, more limited measurements from West Africa summarized in ref. ${ }^{85}$, , redictive skill ${ }^{86}$, and use in past studies on both continents ${ }^{14,87}$. MCWD therefore represents a precipitation-driven dry season deficit, given that evapotranspiration remains constant. An alternative assessment, using a data-driven evapotranspiration product ${ }^{88,89}$, gave a mean evapotranspiration of $95 \mathrm{~mm}$ and $98 \mathrm{~mm}$ per month for the African and Amazonian plot networks respectively (mean for the 1982-2008 period). Using these values did not affect the results.

To calculate the environmental change of potential predictor vari-

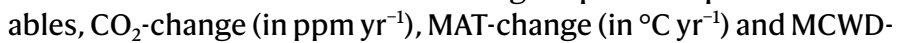
change (in $\mathrm{mm} \mathrm{yr}^{-1}$ ), we selected an optimum period over which to calculate the change, derived empirically by assessing the correlation of carbon gains (all plots, all censuses) with the change in each environmental variable, using linear mixed effects models (Imer function in $\mathrm{R}$, lme 4 package $\left.{ }^{72}\right)$. The annualized change in the environmental variable was calculated as the change between the focal interval and a prior interval (termed the baseline period) with a lengthening time window ranging from 1 year through to 80 years before the focal interval (that is, 80 linear mixed effects models per variable). We calculated Akaike's Information Criterion (AIC) for each model and selected the interval length with the lowest AIC. Thus, MAT-change $=\left(\mathrm{MAT}_{i}-\mathrm{MAT}_{\mathrm{b}}\right)$ / $\left(\right.$ date $_{i}-$ date $_{\mathrm{b}}$ ), where MAT ${ }_{i}$ is the MAT over the focal census interval calculated using the procedure described above, MAT $_{\mathrm{b}}$ is the MAT over a baseline period before the focal interval, date $e_{i}$ is the mid-date of the focal census interval and date $e_{b}$ is the mid-date of the baseline period. The Imer results show that the baseline period for MAT-change is 5 years and for $\mathrm{CO}_{2}$-change it is 56 years, while MCWD showed no clear trend, so MCWD-change was not included in the models (see Extended Data Fig. 3). All three results conform to a priori theoretical expectations. For $\mathrm{CO}_{2}$ a maximum response to an integrated 56 years of change is expected because forest stands will respond most strongly to $\mathrm{CO}_{2}$ when most individuals have grown under the new rapidly changing condition, which should be at its maximum at a time approximately equivalent to the CRT of a forest stand ${ }^{30,90}$ (mean of 62 years in the pooled dataset). For MAT, 5 years is consistent with experiments showing temperature acclimation of leaf- and plant-level photosynthetic and respiration processes over half-decadal timescales ${ }^{31,91}$. MCWD has no overall trend suggesting that once a drought ends, its impact on tree growth fades rapidly, as seen in other studies ${ }^{14,92}$. Furthermore, in the moist tropics wet-season rainfall is expected to recharge soil water, so lagged impacts of droughts are not expected.

We calculated estimates of two forest attributes that may alter responses to environmental change as potential predictor variables: wood density and CRT. In intact old-growth forests, mean wood density (in $\mathrm{g} \mathrm{cm}^{-3}$ ) is inversely related to resource availability ${ }^{28,93,94}$, as is seen in our dataset (carbon gains and plot-level mean wood density are negatively correlated; Extended Data Fig. 4). Wood density is calculated for each census interval in the dataset, as the mean wood density of all trees alive at the end of the census interval, to be consistent with the previous Amazon analysis ${ }^{6}$. Carbon residence time (CRT, in years) is a measure of the time that fixed carbon stays in the system. CRT is a potential correlate of the impact of past carbon gains on later carbon losses ${ }^{30}$. To avoid circularity in the models, the equation used to calculate CRT differed depending on the response variable. If the response variable is carbon loss, the CRT equation is based on gains: $C R T=A G C / g a i n s$, with AGC for each interval based on AGC at the end of the interval, and the gains for each interval calculated as the time-weighted mean of the gains in the interval and the previous intervals (that is, long-term gains). If the response variable is carbon gains, the CRT equation is based on losses: $\mathrm{CRT}=\mathrm{AGC} /$ losses. The equation employed for use in the carbon loss model (based on gains) is the standard formula used to calculate CRT and is retained in the minimum adequate model (see below and Table 2). The non-standard CRT equation (based on losses) used in the carbon gain model is not retained in the minimum adequate model (see below).

\section{Statistical modelling of the carbon gain, loss and sink trends}

We first constructed two models including those environmental drivers exhibiting long-term change that impact theory-driven models of photosynthesis and respiration as predictor variables: $\mathrm{CO}_{2}$, MAT and MCWD. One model had carbon gains as the response variable, the other had carbon losses as the response variable (both in $\mathrm{MgC} \mathrm{ha}^{-1} \mathrm{yr}^{-1}$ ). Models were fitted using the Ime function in $\mathrm{R}$, with maximum likelihood (NLME package ${ }^{95}$ ). All census intervals within all plots were used, weighted by plot size and census length (using equation (3)). Plot identity was included as a random effect, that is, assuming that the intercept can vary randomly among plots. All predictor variables in the models were scaled without centring (scale function in R, RASTER package ${ }^{62}$ ). Carbon gain values were normally distributed but carbon loss values required a power-law transformation $(\lambda=0.361)$ to meet normality criteria. Multi-parameter models are: carbon gains $=$ intcp $+a \times \mathrm{CO}_{2}+$ $b \times \mathrm{MAT}+c \times \mathrm{MCWD}($ model 1$)$; carbon losses $=$ intcp $+a \times \mathrm{CO}_{2}+b \times \mathrm{MAT}+$ $c \times$ MCWD (model 2); where intcp is the estimated model intercept, and $a, b$ and $c$ are model parameters giving the slope of relationships with environmental predictor variables. For multi-parameter model outputs see Extended Data Table 1, for single-parameter relationships, Fig. 2.

The second pair of models include the same environmental predictors $\left(\mathrm{CO}_{2}\right.$, MAT, MCWD), plus their rate of change $\left(\mathrm{CO}_{2}\right.$-change, MAT-change, but not MCWD-change, as explained above), and forest attributes that may alter how forests respond to the same environmental change (wood density, CRT), as described above. We also evaluated the possible inclusion of a differential continent effect of each variable in the full model. We first constructed models with only a single predictor variable, and allowed different slopes in each continent. Next, if removal of the continent-specific slope (using stepAIC function in $\mathrm{R}$, MASS package ${ }^{96}$ ) increased model AIC then the continent-specific 
slope was included in the full model for that variable. Only MCWD showed a significant differential continent-specific slope $(P<0.001)$. This implies that forests on both continents have common responses to $\mathrm{CO}_{2}, \mathrm{CO}_{2}$-change, MAT, MAT-change, wood density and CRT, but respond differently to differences in MCWD. This may be because wetadapted species are much rarer in Africa than in Amazonia as a result of large differences in past climate variation ${ }^{34}$. Last, we allowed different intercepts for the two continents to potentially account for differing biogeographical or other continent-specific factors. For the carbon loss model, we applied the same continent-specific effects for slope as for the carbon gain model. Carbon loss values were transformed using a power-law transformation $(\lambda=0.361)$ to meet normality criteria.

For both carbon gains and losses we parameterized a global model including the significant continent-specific effect of MCWD, selecting the most parsimonious simplified model using all-subsets regres$\operatorname{sion}^{97,98}$. To do so, we first generated a set of models with all possible combinations (subsets) of fixed effect terms in the global model using the dredge function of the MuMIn package in $\mathrm{R}^{99}$. We then chose the best-ranked simplified model based on the second-order Akaike Information Criterion (known as AICc), hereafter called the 'minimum adequate carbon gain/loss model', reported in Table 2 . The minimum adequate models are: carbon gains $=$ intcp $\times$ continent $+a \times \mathrm{CO}_{2}$-change $+b \times \mathrm{MAT}+c \times \mathrm{MAT}$-change $+d \times \mathrm{MCWD} \times$ continent $+e \times$ wood density (model 3); carbon losses $=$ intcp $+a \times \mathrm{CO}_{2}$-change $+b \times$ MAT-change + $c \times \mathrm{MCWD}+d \times \mathrm{CRT}$ (model 4$)$. Wood density was retained in the carbon gain model, probably because growth is primarily affected by resource availability, whereas CRT was retained in the carbon loss model, probably because losses are primarily affected by how long fixed carbon is retained in the system.

Table 2 presents model coefficients of the best-ranked gain model and best-ranked loss model selected using all-subsets regression. These best-ranked gain and loss models have weights of 0.310 and 0.132 respectively, which is almost double the weight of the secondrank models ( 0.152 and 0.075 respectively). In Supplementary Table 2 we also used the model.avg function of the MuMIn package to calculate a weighted mean of the coefficients of the models that together represent a cumulative weight-sum of 0.95 (that is, a 95\% confidence subset). Supplementary Table 2 (model-averaged) and Table 2 (bestranked) model parameters are very similar. Supplementary Tables 3 and 4 report the complete sets of carbon gains and loss models that contribute to the model average results.

The model-average results show the same continental differences in sensitivity to environmental variables as the best-ranked models. From 1January 2000 to 31 December 2014, carbon gains increased owing to $\mathrm{CO}_{2}$-change ( $+3.7 \%$ in both the averaged and the best-ranked models, both continents), whereas temperature rises led to a decline in gains, which especially had an effect in the Amazon ( $-1.14 \%$ and $-1.07 \%$ due to MAT and MAT-change together in the averaged and best-ranked model respectively). Finally, both model-average and best-ranked models result in similar predictions of the net carbon sink over the 1 January 1983 to 31 December 2039 period: the future net sink trend in Africa is -0.004 and -0.003 in the best-ranked and averaged models, respectively; in Amazonia the future net sink trend is -0.013 and -0.011 in the best-ranked and averaged models, respectively. The Amazon sink reaches zero in 2041 using model-averaged parameters compared to 2035 using the best-ranked models.

\section{Estimating future predictor variables to 2040}

To calculate future modelled trends in carbon gains and losses (Fig. 3), we first estimated annual records of the predictor variables $\left(\mathrm{CO}_{2}\right.$-change, MAT, MAT-change, MCWD, wood density and CRT) to 31 December 2039 (Extended Data Fig. 5).

To do so, we first calculated annual records for the period of the observed trends for each plot location (that is, from 1January 1983 to 31 December 2014 in Africa and 1January 1983 to mid-2011 in Amazonia).
For $\mathrm{CO}_{2}$-change, MAT, MAT-change and MCWD we extracted monthly records as described in the Methods section 'Predictor variable estimates (1983-2014)'. For wood density and CRT we interpolated to a 0.1 -year period within each census interval (as in Fig. 1). Then, we calculated the mean annual value of each predictor variable from the 244 plot locations in Africa, and separately the mean annual value of each predictor variable from the 321 plot locations in Amazonia (solid lines in Extended Data Fig. 5). For each predictor variable, we calculated annual records of upper and lower confidence intervals by respectively adding and subtracting $2 \sigma$ to the mean of each annual value (shaded area in Extended Data Fig. 5). Second, for each predictor variable we parameterized a linear model for each continent using the annual records for the period of the observed trends. Then for each predictor variable, the continent-specific linear regression models were used to estimate predictor variables for each plot location from 1 January 2015 to 31 December 2039 in Africa and from mid-2011 to 31 December 2039 in the Amazon (dotted lines in Extended Data Fig. 5).

\section{Estimating future carbon gain, loss and sink trends}

We used the minimum adequate models (Table 2) to predict annual records of carbon gain, carbon loss and the carbon sink for the plot networks in Africa and Amazonia over the period 1983 through to 2040 (Fig. 3). We extracted predicted carbon gain and loss values using the mean annual records for each predictor variable (predictSE.Ime function, AICcmodavg package ${ }^{100}$ ). Upper and lower confidence intervals were calculated accounting for uncertainties in the model (both fixed and random effects) and predictor variables using the $2 \sigma$ upper and lower confidence interval for each predictor variable (using predictSE. Ime). Finally, the net carbon sink was calculated by subtracting the losses from the gains. To obtain sink values in the future, reported in Table 1, annual per unit area sink predictions (from Fig. 3) were averaged over each decade and multiplied by the future forest area, as described above.

To test the sensitivity of the future predictions in Fig. 3, we reran the analysis by modifying future trajectories of predictor variables one at a time, while keeping all others the same, to assess the mean C sink over 2010-15 and 2030 (averaging at $\mathbf{2 0 3 0}$ is not necessary as trends in MAT-change and MCWD, which largely drive modelled inter-annual variability, are estimated as smooth trends in the future). For each predictor variable, we explored the potential impacts of the likely bounds of possibility: (1) by taking the steepest slope of either continent from the extrapolated trends, doubling this slope and applying it on both continents; and (2) by taking the steepest slope of either continent from the extrapolated trends, taking the additive inverse of this slope and applying it on both continents. These bounds represent deviations of $>2 \sigma$ from observed trends. Change in MAT also alters MAT-change, so we present the sensitivity of both parameters together.

Additionally, for $\mathrm{CO}_{2}$-change and MAT, we also calculated future slopes under three future Representative Concentration Pathway (RCP) scenario ${ }^{38}$ with different radiative forcing in 2100: RCP2.6, RCP4.5 and $\mathrm{RCP}$ 8.5. Future $\mathrm{RCPCO}_{2}$-change slopes $\left(\mathrm{ppm} \mathrm{yr}^{-1}\right)$ were calculated using $\mathrm{RCPCO} \mathrm{CO}_{2}$ concentration data for the years between 2015 and 2030 inclusive. Future RCP MAT and MAT-change slopes were obtained from plotspecific MAT values extracted from downscaled $\sim 1-\mathrm{km}^{2}$ resolution data for current ${ }^{80}$ and future ${ }^{51}$ climate from WorldClim, and averaged over 19 CMIP5 models. We subtracted the mean 2040-2060 climate MAT (that is, 2050) from the mean 1970-2000 climate MAT (that is, 1985), divided by 65 years to give the annual rate of change. We then calculated a mean slope over all plots per continent. Finally, to avoid mismatches between RCP-derived values of $\mathrm{CO}_{2}$ and MAT and the observed records, we removed any difference in intercept between the RCP trends and observed trends, so that the RCP trends were a continuation of the end-point of the observed trajectory (31 December 2014). We did not estimate the sensitivity of MCWD under the RCP scenarios, because the mean of the CMIP5 models do not show drought trends for our forest 
plot networks, unlike rain gauge data for the recent past ${ }^{41,42}$, and thus would show little or no sensitivity to MCWD. For each modified slope, Supplementary Table 5 reports the absolute decline in the sink in each continent in 2030 compared to the $2010-15$ mean sink. This shows that the future sink strength is sensitive to future environmental conditions, but within both RCP scenarios and our bounds of possibility we show a decline in the sink strength in both continents over the 2020s.

\section{Reporting summary}

Further information on research design is available in the Nature Research Reporting Summary linked to this paper.

\section{Data availability}

Source data to generate figures and tables are available from https:// doi.org/10.5521/Forestplots.net/2019_1.

\section{Code availability}

$\mathrm{R}$ code to generate figures and tables is available from: https://doi. org/10.5521/Forestplots.net/2019_1.

51. Hijmans, R. J., Cameron, S. E., Parra, J. L., Jones, P. G. \& Jarvis, A. Very high resolution interpolated climate surfaces for global land areas. Int. J. Climatol. 25, 1965-1978 (2005)

52. Lopez-Gonzalez, G., Lewis, S. L., Burkitt, M. \& Phillips, O. L. ForestPlots.net: a web application and research tool to manage and analyse tropical forest plot data. J. Veg. Sci. 22, 610-613 (2011)

53. Lopez-Gonzalez, G., Lewis, S. L., Burkitt, M., Baker, T. R. \& Phillips, O. L. ForestPlots.net Database http://www.forestplots.net (2009).

54. Sheil, D. \& Bitariho, R. Bwindi Impenetrable Forest TEAM Site https://www.wildlifeinsights org/team-network, TEAM-DataPackage-20151201235855 1254 (2009).

55. Kenfack, D. Korup National Park TEAM Site https://www.wildlifeinsights.org/team-network, TEAM-DataPackage-20151201235855_1254 (2011).

56. Rovero, F., Marshall, A. \& Martin, E. Udzungwa TEAM Site https://www.wildlifeinsights.org/ team-network, TEAM-DataPackage-20151130235007 5069 (2009).

57. Hockemba, M. B. N. Nouabalé Ndoki TEAM Site https://www.wildlifeinsights.org/teamnetwork, TEAM-DataPackage-20151201235855_1254 (2010).

58. Anderson-Teixeira, K. J. et al. CTFS-ForestGEO: a worldwide network monitoring forests in an era of global change. Glob. Change Biol. 21, 528-549 (2015).

59. Gourlet-Fleury, S. et al. Tropical forest recovery from logging: a 24 year silvicultural experiment from Central Africa. Phil. Trans. R. Soc. Lond. B 368, 20120302 (2013).

60. Claeys, F. et al. Climate change would lead to a sharp acceleration of Central African forests dynamics by the end of the century. Environ. Res. Lett. 14, 044002 (2019).

61. Chave, J. et al. Improved allometric models to estimate the aboveground biomass of tropical trees. Glob. Change Biol. 20, 3177-3190 (2014).

62. R Development Core Team R: A Language and Environment for Statistical Computing http://www.R-project.org/ (2015).

63. Lopez-Gonzalez, G., Sullivan, M. \& Baker, T. BiomasaFP. R package version 0.2.1 http://www.forestplots.net/en/resources/analysis (2017)

64. Phillips, O., Baker, T., Brienen, R. \& Feldpausch, T. RAINFOR field manual for plot establishment and remeasurement. http://www.rainfor.org/upload/ManualsEnglish/ RAINFOR_field_manual_version_2016.pdf (Univ. Leeds, 2016).

65. Talbot, J. et al. Methods to estimate aboveground wood productivity from long-term forest inventory plots. For. Ecol. Manage. 320, 30-38 (2014).

66. Sullivan, M. J. P. et al. Field methods for sampling tree height for tropical forest biomass estimation. Methods Ecol. Evol. 9, 1179-1189 (2018)

67. Feldpausch, T. R. et al. Tree height integrated into pantropical forest biomass estimates. Biogeosciences 9, 3381-3403 (2012)

68. Chave, J. et al. Towards a worldwide wood economics spectrum. Ecol. Lett. 12, 351-366 (2009).

69. Zanne, A. E. et al. Towards a Worldwide Wood Economics Spectrum https://doi. org/10.5061/dryad.234 (Dryad Digital Repository, 2009).

70. Martin, A. R., Doraisami, M. \& Thomas, S. C. Global patterns in wood carbon concentration across the world's trees and forests. Nat. Geosci. 11, 915-920 (2018).

71. Kohyama, T. S., Kohyama, T. I., Sheil, D. \& Rees, M. Definition and estimation of vital rates from repeated censuses: choices, comparisons and bias corrections focusing on trees. Methods Ecol. Evol. 9, 809-821 (2018).

72. Bates, D., Maechler, M., Bolker, B. \& Walker, S. Ime4: linear mixed-effects models using Eigen and S4. R package version 1.0-4 http://www.inside-r.org/packages/lme4/ versions/1-0-4 (2013).

73. Fox, J. Applied Regression Analysis and Generalized Linear Models 2nd edn (Sage Publishing, 2008).

74. Chave, J. et al. Assessing evidence for a pervasive alteration in tropical tree communities. PLoS Biol. 6, 0455-0462 (2008).

75. Yuen, J. Q., Ziegler, A. D., Webb, E. L. \& Ryan, C. M. Uncertainty in below-ground carbon biomass for major land covers in Southeast Asia. For. Ecol. Manage. 310, 915-926 (2013).

76. Aragão, L. E. O. C. et al. Spatial patterns and fire response of recent Amazonian droughts. Geophys. Res. Lett. 34, L07701 (2007).
77. Aragão, L. E. O. C. et al. Environmental change and the carbon balance of Amazonian forests. Biol. Rev. Camb. Phil. Soc. 89, 913-931 (2014).

78. Tans, P. \& Keeling, R. Trends in Atmospheric Carbon Dioxide for Mauna Loa, Hawail http://www.esrl.noaa.gov/gmd/ccgg/trends/ (ESRL, 2016).

79. Harris, I., Jones, P. D., Osborn, T. J. \& Lister, D. H. Updated high-resolution grids of monthly climatic observations - the CRU TS3.10 Dataset. Int. J. Climatol. 34, 623-642 (2014).

80. Fick, S. E. \& Hijmans, R. J. WorldClim 2: new 1-km spatial resolution climate surfaces for global land areas. Int. J. Climatol. 37, 4302-4315 (2017).

81. Ramirez-Villegas, J. \& Jarvis, A. Downscaling Global Circulation Model Outputs: The Delta Method. Decision and Policy Analysis Working Paper No. 1 https://cgspace.cgiar.org/ handle/10568/90731 (International Center for Tropical Agriculture (CIAT), 2010).

82. Schneider, U. et al. GPCC Full Data Reanalysis Version 6.0 at $0.5^{\circ}$ : Monthly Land-Surface Precipitation from Rain-Gauges built on GTS-based and Historic Data https://opendata. dwd.de/climate_environment/GPCC/html/fulldata_v6_doi_download.html (Global Precipitation Climatology Centre (GPCC) at Deutscher Wetterdienst, 2011).

83. Sun, Q. et al. Review of global precipitation data sets: data sources, estimation, and intercomparisons. Rev. Geophys. 56, 79-107 (2017).

84. Huffman, G. J. et al. The TRMM Multisatellite Precipitation Analysis (TMPA): quasi-global, multiyear, combined-sensor precipitation estimates at fine scales. J. Hydrometeorol. 8 , 38-55 (2007)

85. Kume, T. et al. Ten-year evapotranspiration estimates in a Bornean tropical rainforest. Agric. For. Meteorol. 151, 1183-1192 (2011).

86. Zelazowski, P., Malhi, Y., Huntingford, C., Sitch, S. \& Fisher, J. B. Changes in the potential distribution of humid tropical forests on a warmer planet. Phil. Trans. R. Soc. A 369, 137-160 (2011).

87. James, R., Washington, R. \& Rowell, D. P. Implications of global warming for the climate of African rainforests. Phil. Trans. R. Soc. Lond. B 368, 20120298 (2013).

88. Jung, M. et al. Recent decline in the global land evapotranspiration trend due to limited moisture supply. Nature 467, 951-954 (2010).

89. Jung, M. et al. Global patterns of land-atmosphere fluxes of carbon dioxide, latent heat, and sensible heat derived from eddy covariance, satellite, and meteorological observations. J. Geophys. Res. 116, https://doi.org/10.1029/2010JG001566 (2011).

90. Lloyd, J. \& Farquhar, G. D. The $\mathrm{CO}_{2}$ dependence of photosynthesis, plant growth responses to elevated atmospheric $\mathrm{CO}_{2}$ concentrations and their interaction with soil nutrient status. I. General principles and forest ecosystems. Funct. Ecol. 10, 4-32 (1996).

91. Aspinwall, M. J. et al. Convergent acclimation of leaf photosynthesis and respiration to prevailing ambient temperatures under current and warmer climates in Eucalyptus tereticornis. New Phytol. 212, 354-367 (2016).

92. Bonal, D., Burban, B., Stahl, C., Wagner, F. \& Hérault, B. The response of tropical rainforests to drought-lessons from recent research and future prospects. Ann. For. Sci. 73, 27-44 (2016).

93. Quesada, C. A . et al. Variations in chemical and physical properties of Amazon forest soils in relation to their genesis. Biogeosciences 7, 1515-1541 (2010).

94. Baker, T. R., Swaine, M. D. \& Burslem, D. F. R. P. Variation in tropical forest growth rates: combined effects of functional group composition and resource availability. Perspect. Plant Ecol. Evol. Syst. 6, 21-36 (2003).

95. Pinheiro, J. C. \& Bates, D. M. Mixed-Effects Models in S and S-PLUS 1st edn 528 (Springer, 2000).

96. Venables, W. N. \& Ripley, B. D. Modern Applied Statistics with S 4th edn 498 (Springer 2002).

97. Olejnik, S., Mills, J. \& Keselman, H. Using Wherry's adjusted $R^{2}$ and Mallow's Cp for model selection from all possible regressions. J. Exp. Educ. 68, 365-380 (2000)

98. Whittingham, M. J., Stephens, P. A., Bradbury, R. B. \& Freckleton, R. P. Why do we still use stepwise modelling in ecology and behaviour? J. Anim. Ecol. 75, 1182-1189 (2006).

99. Bartoń, K. MuMIn: Multi-Model Inference. Tools for performing model selection and model averaging. R package version 1.43 .6 (2019).

100. Gelman, A. \& Hill, J. Data Analysis Using Regression and Multilevel/Hierarchical Models (Cambridge Univ. Press, 2007)

101. Mayaux, P., De Grandi, G. \& Malingreau, J.-P. Central African forest cover revisited: a multisatellite analysis. Remote Sens. Environ. 71, 183-196 (2000).

102. Mayaux, P. et al. The Land Cover Map for Africa in the Year 2000 GLC2000 database, https://forobs.jrc.ec.europa.eu/products/glc2000/products.php (European Commission Joint Research Centre, 2003).

Acknowledgements This paper is a product of the African Tropical Rainforest Observatory Network (AfriTRON), curated at ForestPlots.net. AfriTRON has been supported by numerous people and grants since its inception. We sincerely thank the people of the many villages and local communities who welcomed our field teams and without whose support this work would not have been possible: Sierra Leone (villages: Barrie, Gaura, Koya, Makpele, Malema, Nomo, Tunkia; teams in protected areas: the Gola Rainforest National Park), Liberia (villages: Garley town, River Gbeh, Glaro Freetown), Ghana (villages: Nkwanta, Asenanyo, Bonsa, Agona, Boekrom, Dadieso, Enchi, Dabiasem, Mangowase, Draw, Fure, Esuboni, Okumaninin, Kade, Asamankese, Tinte Bepo, Tonton), Nigeria (Oban village), Gabon (villages: Ekobakoba, Mikongo, Babilone, Makokou, Tchimbele, Mondah, Ivindo, Ebe, Ekouk, Oveng, Sette Cama; teams in protected areas: Ivindo National Park, Lope National Park, Waka National Park; teams in concessions: Ipassa station, Kingele station, Leke/Moyabi Rougier Forestry Concession), Cameroon (villages: Campo, Nazareth, Lomié, Djomédjo, Alat-Makay, Somalomo, Deng Deng, Eyumojok, Mbakaou, Myere, Nguti, Bejange, Kekpane, Basho, Mendhi, Matene, Mboh, Takamanda, Obonyi, Ngoïla; teams in protected areas: Ejagham forest reserve), Democratic Republic of Congo (villages: Yoko, Yangambi, Epulu, Monkoto), Republic of Congo (villages: Bomassa, Ekolongouma, Bolembe, Makao, Mbeli, Kabo, Niangui, Ngubu, Goualaki, Essimbi). We thank the field assistants whose expertise and enthusiasm is indispensable to successful fieldwork, including: M. E. Abang, U. P. Achui, F. Addai, E. J. Agbachon, J. Agnaka, A. J. Akaza, G. Alaman, G. Alaman, A. E. Alexander, K. Allen, M. Amalphi, D. Amandus, J. Andju L. A. Limbanga, S. Asamoah, T. M. Ashu, M. Ashu, J. Asse, B. Augustine, H. Badjoko, M. Balimu, J. Baviogui-Baviogui, S. Benteh, A. Bertrand, A. Bettus, A. Bias, A. Bikoula, A. Bimba, 
P. Bissiemou, M. Boateng, E. Bonyenga, M. B. Ekaya, G. Bouka, J. Boussengui, D. B. Ngomo, C. Chalange, S. Chenikan, J. Dabo, E. Dadize, T. Degraft, J. Dibakou, J.-T. Dikangadissi, P. Dimbonda, E. Dimoto, C. Ditougou, D. Dorbor, M. Dorbor, V. Droissart, K. Duah, E. Ebe, O. J. Eji, E. B. Ekamam, J.-R. Ekomindong, E. J. Enow, H. Entombo, E. M. Ernest, C. Esola, J. Essouma, A. Gabriel, N. Genesis, B. Gideon, A. Godwin, E. Grear, D. J. Grear, M. Ismael, M. Iwango, M. Iyafo, N. Kamdem, B. Kibinda, A. Kidimbu, E. Kimumbu, J. Kintsieri, C. K. Opepa, A. Kitegile, T. Komo, P. Koué, A. Kouanga, J. J. Koumikaka, I. Liengola, E. Litonga, L. Louvouando, O. Luis, N. M. Mady, F. Mahoula, A. Mahundu, C. A. Mandebet, P. Maurice, K. Y. Mayossa, R. M. Nkogue, I. D. Mbe, C. Mbina, H. Mbona, A. Mboni, A. Mbouni, P. Menzo, M. Menge, A. Michael, A. Mindoumou, J. Minpsa, J. P. Mondjo, E. Mounoumoulossi, S. Mpouam, T. Msigala, J. Msirikale, S. Mtoka, R. Mwakisoma, D. Ndong-Nguema, G. Ndoyame, G. Ngongbo, F. Ngowa, D. Nguema, L. Nguye, R. Niangadouma, Y. Nkrumah, S. Nshimba, M. N. Mboumba, F. N. Obiang, L. Obi, R. Obi, E. L. Odjong, F. Okon, F. Olivieira, A. L. Owemicho, L. Oyeni-Amoni, A. Platini, P. Ploton, S. Quausah E. Ramazani, B. S. Jean, L. Sagang, R. Salter, A. Seki, D. Shirima, M. Simo, I. Singono, A. E. Tabi, T. G. Tako, N. G. Tambe, T. Tcho, A. Teah, V. Tehtoe, B. J. Telephas, M. L. Tonda, A. Tresor, H. Umenendo, R. Votere, C. K. Weah, S. Weah, B. Wursten, E. Yalley, D. Zebaze, L. Cerbonney, E. Dubiez, H. Moinecourt, F. Lanckriet, S. Samai, M. Swaray, P. Lamboi, M. Sullay, D. Bannah, I. Kanneh, M. Kannah, A. Kemokai, J. Kenneh and M. Lukulay. For logistical and administrative support, we are indebted to international, national and local institutions: the Forestry Department of the Government of Sierra Leone, the Conservation Society of Sierra Leone, the Royal Society for the Protection of Birds (RSPB, UK), The Gola Rainforest National Park (Sierra Leone), the Forestry Development Authority of the Government of Liberia (FDA), the University of Liberia, the Forestry Commission of Ghana (FC), the Forestry Research Institute of Ghana (FORIG), University of Ibadan (Nigeria), the University of Abeokuta (Nigeria), the Ministère des Eaux, Forêts, Chasse et Pêche (MEFCP, Central African Republic), the Institut Centrafricain de Recherche Agronomique (ICRA, Central African Republic), The Service de Coopération et d'Actions Culturelles (SCAC/MAE, Central African Republic), The University of Bangui (Centra African Republic), the Société Centrafricaine de Déroulage (SCAD, Central African Republic), the University of Yaounde I (Cameroon), the National Herbarium of Yaounde (Cameroon), the University of Buea (Cameroon), Bioversity International (Cameroon), the Ministry of Forests, Seas, Environment and Climate (Gabon), the Agence Nationale des Parcs Nationaux de Gabon (ANPN), Institut de Recherche en Écologie Tropicale du Gabon, Rougier-Gabon, the Marien Ngouabi University of Brazzaville (Republic of Congo), the Ministère des Eaux et Forêts (Republic of Congo), the Ministère de la Rercherche Scientifique et de l'Innovation Technologique (Republic of Congo), the Nouabalé-Ndoki Foundation (Republic of Congo), WCS-Congo, Salonga National Park (Democratic Republic of Congo), The Centre de Formation et de Recherche en Conservation Forestière (CEFRECOF, Epulu, Democratic Republic of Congo), the Institut National pour l'Étude et la Recherche Agronomiques (INERA, Democratic Republic of Congo), the École Régionale Postuniversitaire d'Aménagement et de Gestion intégrés des Forêts et Territoires tropicaux (ERAIFT Kinshasa, Democratic Republic of Congo), WWF-Democratic Republic of Congo, WCS-Democratic Republic of Congo, the Universite de Kisangani (Democratic Republic of Congo), Université Officielle de Bukavu (Democratic Republic of Congo), Université de Mbujimayi (Democratic Republic of Congo), le Ministère de l'Environnement et Développement Durable (Democratic Republic of Congo), the FORETS project in Yangambi (CIFOR, CGIAR and the European Union; Democratic Republic of Congo), the Lukuru Wildlife Research Foundation (Democratic Republic of Congo), Mbarara University of Science and Technology (MUST, Uganda), WCS-Uganda, the Uganda Forest Department, the Commission of Central African Forests (COMIFAC), the Udzungwa Ecological Monitoring Centre (Tanzania) and the Sokoine University of Agriculture (Tanzania). We thank C. Chatelain (Geneva Botanic Gardens) for access to the African Plants Database. Grants that have funded the AfriTRON network including data in this paper are: a European Research Council Advanced Grant to O.L.P. and S.L.L. (T-FORCES; 291585; Tropical Forests in the Changing Earth System), a NERC grant to O.L.P., Y.M., and S.L.L. (NER/A/S/2000/01002), a Royal Society University Research Fellowship to S.L.L., a NERC New Investigators Grant to S.L.L., a Philip Leverhulme Award to S.L.L., a European Union FP7 grant to E.G. and S.L.L. (GEOCARBON; 283080), Valuing the Arc Leverhulme Program Grant to Andrew Balmford and S.L.L., a Natural Environment Research Council (NERC) Consortium Grant to Jon Lloyd and S.L.L. (TROBIT; NE/DO05590/), the Gordon and Betty Moore Foundation to L.J.T.W and S.L.L., the David and Lucile Packard Foundation to L.J.T.W. and S.L.L., the Centre for International Forestry Research to T.S. and
S.L.L. (CIFOR), and Gabon's National Parks Agency (ANPN) to S.L.L. W.H. was funded by T-FORCES and the Brain programme of the Belgian Federal Government (BR/132/A1/AFRIFORD grant to Olivier Hardy and the BR/143/A3/HERBAXYLAREDD grant to H.B.). O.L.P., S.L.L., M.J.P.S, A.E.-M., A.L., G.L.-G., G.P. and L.Q. were supported by T-FORCES. Eight plots (codes ANK, IVI, LPG, MNG) included in AfriTRON are also part of the Global Ecosystem Monitoring network (GEM). Additional African data were included from the consortium MEFCP-ICRA-CIRAD (Centre de Coopération Internationale en Recherche Agronomique pour le Développement), the Tropical Ecology Assessment and Monitoring Network (TEAM), and the Forest Global Earth Observatory Network (ForestGEO; formerly the Center for Tropical Forest Science, CTFS). The TEAM network is a collaboration between Conservation International, the Missouri Botanical Garden, the Smithsonian Institution and the Wildlife Conservation Society, and funded by the Gordon and Betty Moore Foundation and other donors. The ForestGEO Network is a collaboration between the Smithsonian Institution, other federal agencies of the United States, the Wildlife Conservation Society (WCS) and the World Wide Fund for Nature (WWF), and funded by the US National Science Foundation and other donors. The paper was made possible by the RAINFOR network in Amazonia, with multiple funding agencies and hundreds of investigators working in Amazonia, acknowledged in ref. ${ }^{6}$, providing comprehensive published data and code and assisting in the onward analysis of their data; see ref. ${ }^{6}$. Data from AfriTRON and RAINFOR are stored and curated by ForestPlots.net, a long-term cyberinfrastructure initiative hosted at the University of Leeds that unites permanent plot records and their contributing scientists from the world's tropical forests. The development of ForestPlots.net and curation of most data analysed here was funded by many sources, including grants to O.L.P. (principally from ERC AdG 291585 'T-FORCES', NERC NE/B503384/1 and the Gordon and Betty Moore Foundation 1656 'RAINFOR'), T.R.B. (the University of Leeds contribution to 'AMAZALERT', NERC (NE/IO28122/1) with T. Pennington, the Gordon and Betty Moore Foundation ('MonANPeru') and a NERC Impact Accelerator grant for the initial development of the BiomasaFP R package), E.G. ('GEOCARBON' and NE/FO05806/1 'AMAZONICA') and S.L.L. (Royal Society University Research Fellowship, NERC New Investigators Award, NERC NE/PO08755/1). We acknowledge the contributions of the ForestPlots.net developers (M. Burkitt, G. Lopez-Gonzalez) and the steering committee (T.R.B., A.L., S.L.L., O.L.P., L.Q., E. N. H. Coronado and B. S. Marimon) for advice on database development and management.

Author Contributions S.L.L. conceived and managed the AfriTRON forest plot recensus programme, O.L.P., T.C.H.S. L.J.T.W. and Y.M. contributed to its development. W.H., S.L.L. O.L.P., B.S. and M.J.P.S. developed the study. W.H., S.L.L., O.L.P., K.A.-B., H.B., A.C.-S., C.E.N.E., S.F., D.S., B.S., T.C.H.S., S.C.T., K.A.A., S.A.-B., C.A.A., T.R.B., L.F.B., F. Baya, S.K.B., F. Benedet, R.B., Y.E.B., P. Boeckx, P. Boundja, T.B., E.C., G.B.C., C.J.C., M.C., J.A.C., D.C., A.K.D., G.C.D., T.d.H., M.D.K., J.-L.D., T.R.F., A.F., E.G.F., M.G., C.G., S.G.-F., J.S.H., A.C.H., D.J.H., T.B.H., M.B.N.H., A.H., S.A.I., K.J.J., T.J., E.K.Y., E.K., D.K., M.E.L., J.A.L., J.L., J.C.L., J.-R.M., Y.M., A.R.M., J.M., E.H.M., F.M.M., V.P.M., V.M., E.T.A.M., S.M., J.M.M., P.K.T.M., N.N.B., L.O., F.E., K.S.-H.P., A.D.P., J.R.P., L.Q., J.R., F.R., M.D.S., H.T., J. Talbot, J. Taplin, D.M.T., D.W.T., B.T., J.T.M., D.T., P.M.U., G.v.d.H., H.V., J.V., L.J.T.W., S.W., H.W., J.T.W. and L.Z. contributed data (with larger field contributions by S.L.L., W.H., A.C.-S., B.S., H.T., A.K.D., C.E.N.E., J.M.M., K.A.-B. and S.F.). O.L.P., T.R.B., S.L.L. and G.L.-G. conceived and managed forestplots.net; O.L.P., T.R.B., S.L.L., E.G., G.L.-G., G.C.P., A.L., R.J.W.B., T.R.F. and M.J.P.S. developed it. W.H., M.J.P.S., S.L.L., O.L.P., R.J.W.B., A.L., G.L.-G., A.E.-M., A.K., E.G., T.R.B., A.C.B. and G.C.P. contributed analysis tools. W.H. and S.L.L. analysed the data (with important contributions from M.J.P.S.). S.L.L. and W.H. wrote the paper. All co-authors read and approved the manuscript (with important insights provided by O.L.P., S.F., R.J.W.B., E.G., H.B., D.S., M.J.P.S., S.G.-F., P.B., H.V. and S.C.T).

Competing interests The authors declare no competing interests.

\section{Additional information}

Supplementary information is available for this paper at https://doi.org/10.1038/s41586-0202035-0.

Correspondence and requests for materials should be addressed to W.H.

Reprints and permissions information is available at http://www.nature.com/reprints. 


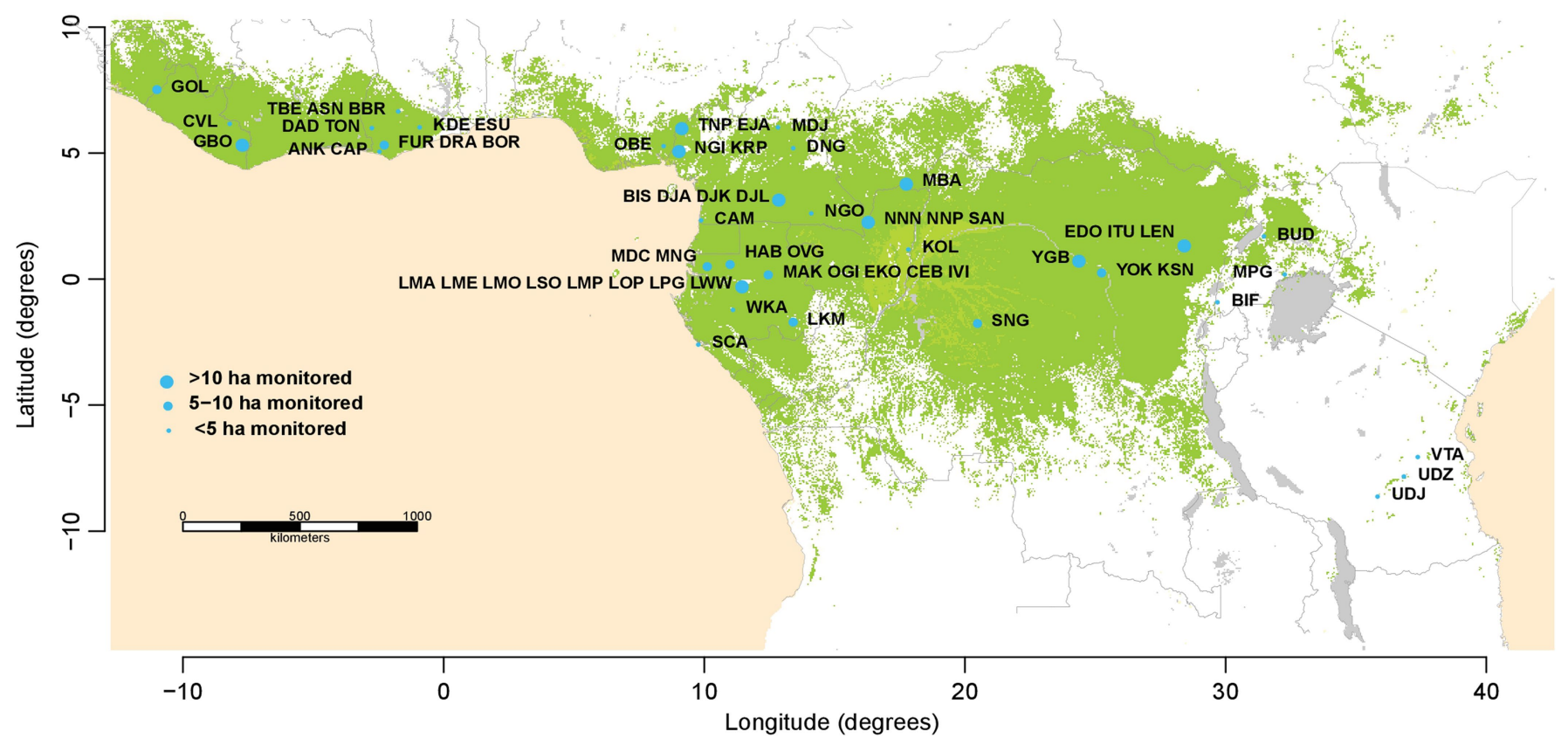

Extended Data Fig. 1 Map showing the locations of the 244 plots included in this study. Dark green represents all lowland closed-canopy forests, submontane forests and forest-agriculture mosaics; light green shows swamp forests and mangroves, blue circles represent plot clusters, referred to by three-letter codes (see Supplementary Table 1 for the full list of plots). Clusters
$<50 \mathrm{~km}$ apart are shown as one point for display only, with the circle size corresponding to sampling effort in terms of hectares monitored. Land cover data are from The Land Cover Mapfor Africa in the Year 2000 (GLC2000 database $)^{101,102}$. This map was created using the R statistical platform, version 3.2.1 (ref. ${ }^{62}$ ), which is under the GNU Public License. 


\section{Article}

a
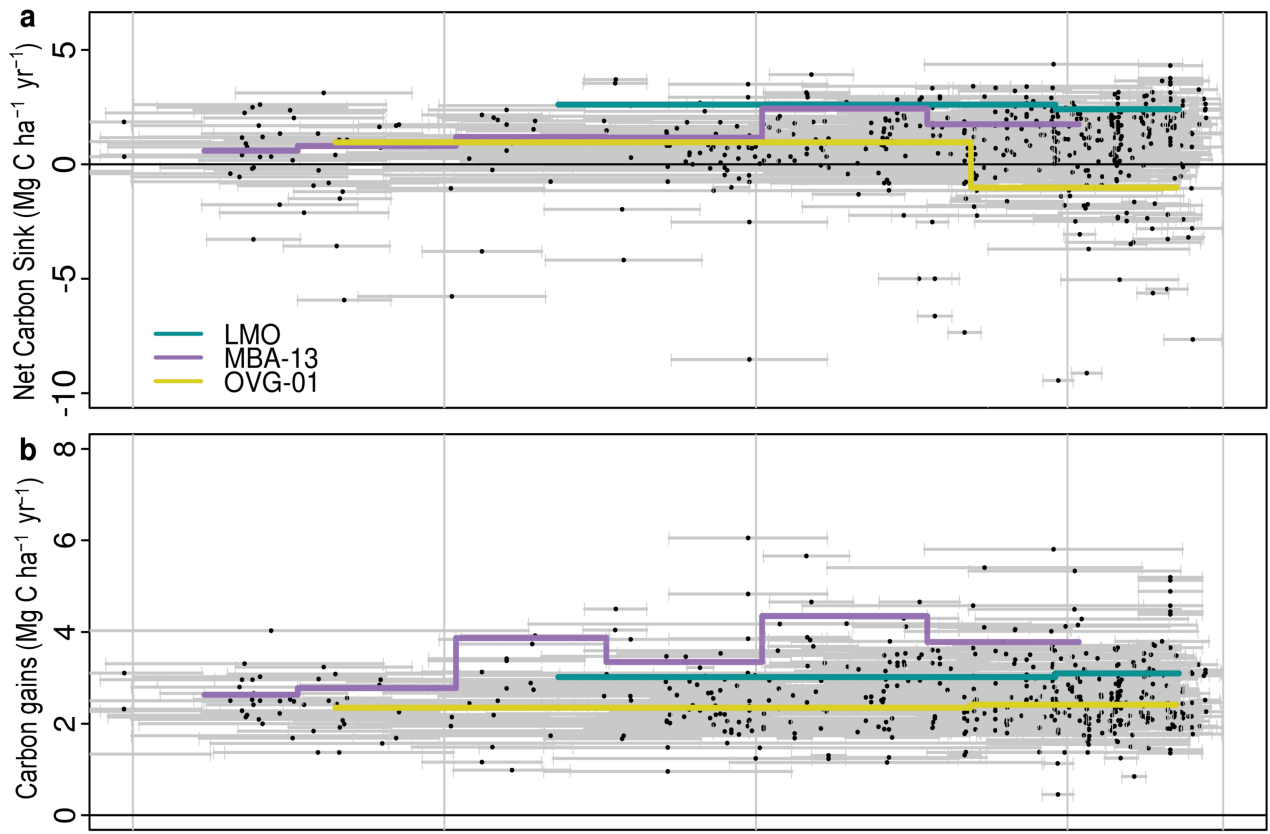

c

C
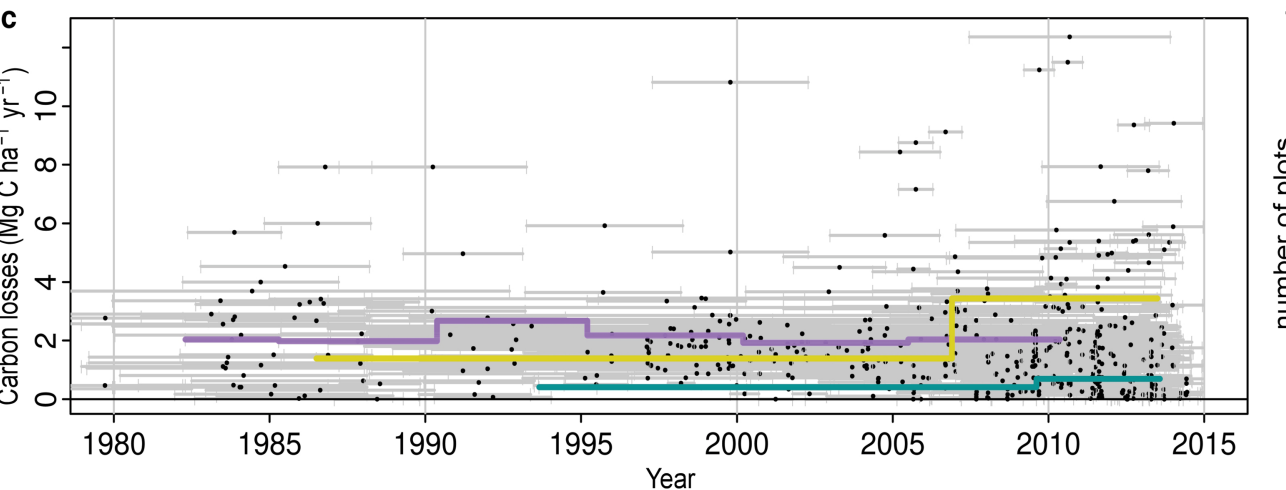

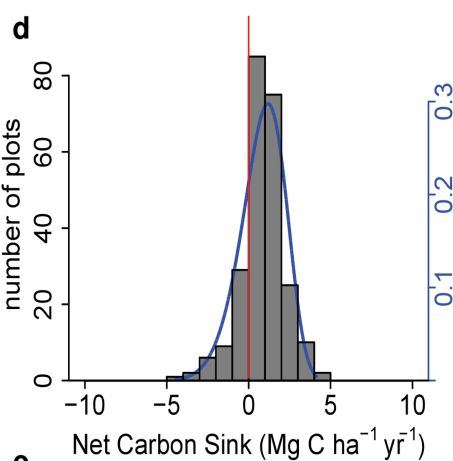

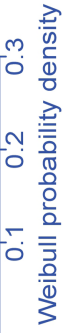

e
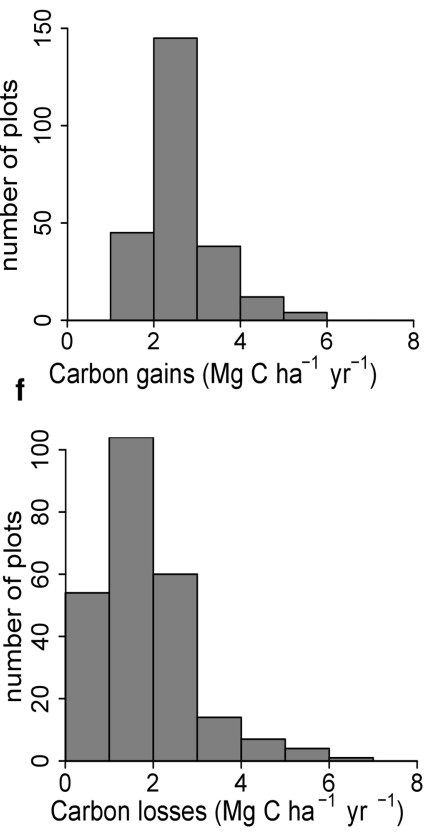

Extended Data Fig. 2 | Long-term aboveground carbon dynamics of 244 African structurally intact old-growth tropical forest inventory plots.

(from tree mortality) (c). Examples of time series for three individual plots are shown in purple, yellow and green. Associated histograms show the

Points in the scatterplots indicate the mid-census interval date, with horizontal bars connecting the start and end date for each census interval for net distribution of the plot-level net aboveground biomass carbon (with a threeparameter Weibull probability density distribution fitted in blue, showing that aboveground biomass carbon change (a), carbon gains (from woody the carbon sink is significantly larger than zero; one-tailed $t$-test: $P<0.001)(\mathbf{d})$, production from tree growth and newly recruited stems) (b), and carbon losses 

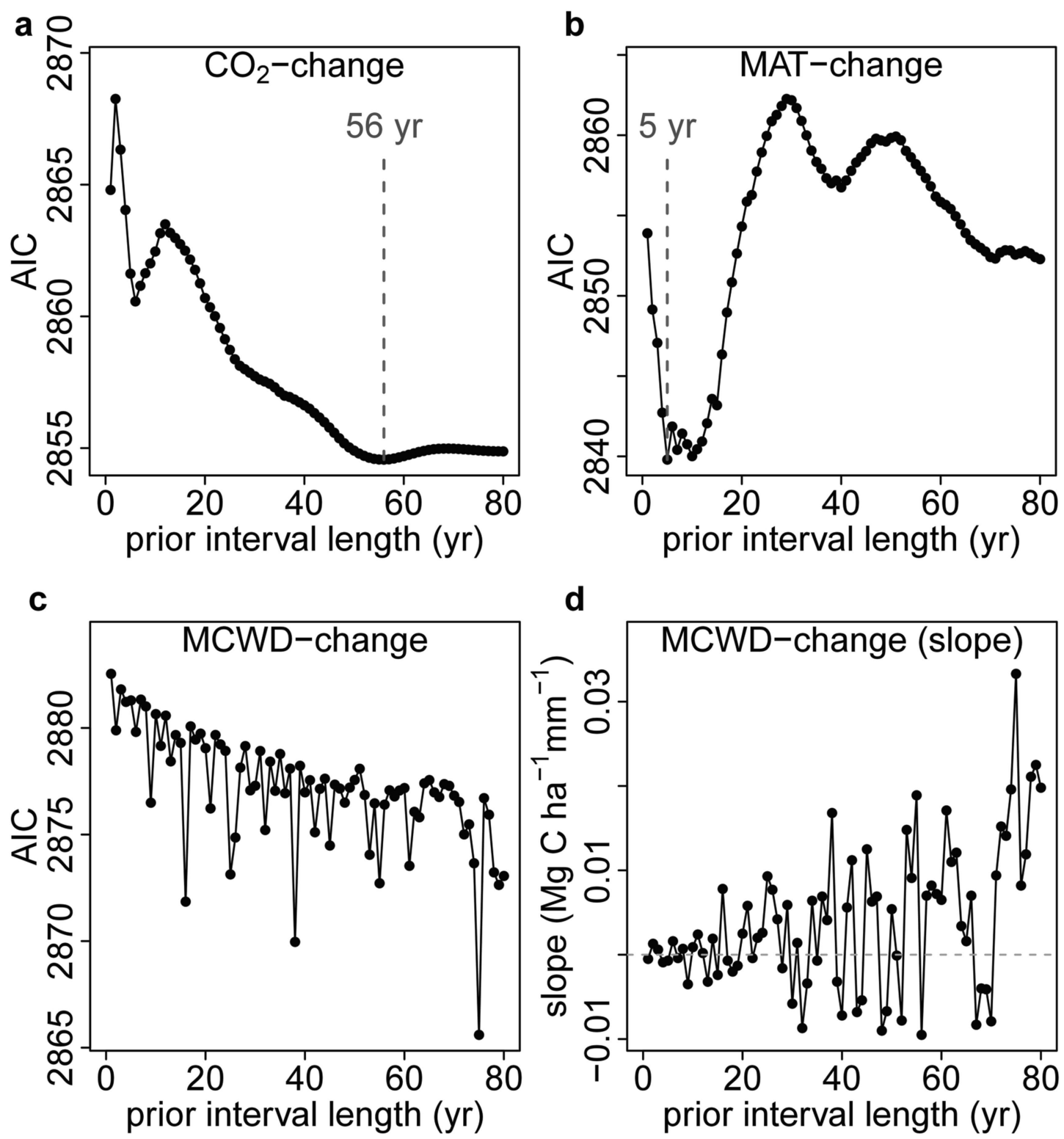

Extended Data Fig. 3 | AIC from correlations between the carbon gain in tropical forest inventory plots and changes in atmospheric $\mathrm{CO}_{2}$, temperature (MAT) or drought (MCWD), each calculated over everlonger prior intervals. Panels show the AIC from linear mixed effects models of carbon gains from 565 African and Amazonian plots and corresponding changes in atmospheric $\mathrm{CO}_{2}\left(\mathrm{CO}_{2}\right.$-change) (a), MAT (MATchange) (b), and drought (MCWD-change) (c). For $\mathrm{CO}_{2}$ the AIC minimum was observed when predicting the carbon gain from the change in $\mathrm{CO}_{2}$ calculated over a 56-year-long prior interval length. We use this length of time to calculate our $\mathrm{CO}_{2}$-change parameter. Such a value is expected because forest stands will respond most strongly to $\mathrm{CO}_{2}$ when most individuals have grown under the new rapidly changing condition, which should be at its maximum at a time approximately equivalent to the CRT of a forest $\operatorname{stand}^{30,90}$ (mean of 62 years in

this pooled African and Amazonian dataset). For MAT the AIC minimum was 5 years, which we use as the prior interval to calculate our MAT-change parameter. This length is consistent with experiments showing temperature acclimation of leaf- and plant-level photosynthetic and respiration processes over approximately half-decadal timescales ${ }^{31,91}$. For MCWD the AIC minimum is not obvious, while the slope of the correlation, shown in d, shows no overall trend and oscillates between positive or negative values, meaning there is no relationship between carbon gains and the change in MCWD over intervals longer than 1 year; therefore MCWD-change is not included in our models. This result suggests that once a drought ends, its impact on tree growth fades rapidly, as seen in other studies ${ }^{14,92}$. Furthermore, in the moist tropics wetseason rainfall is expected to recharge soil water, and hence lagged impacts of droughts are not expected. 

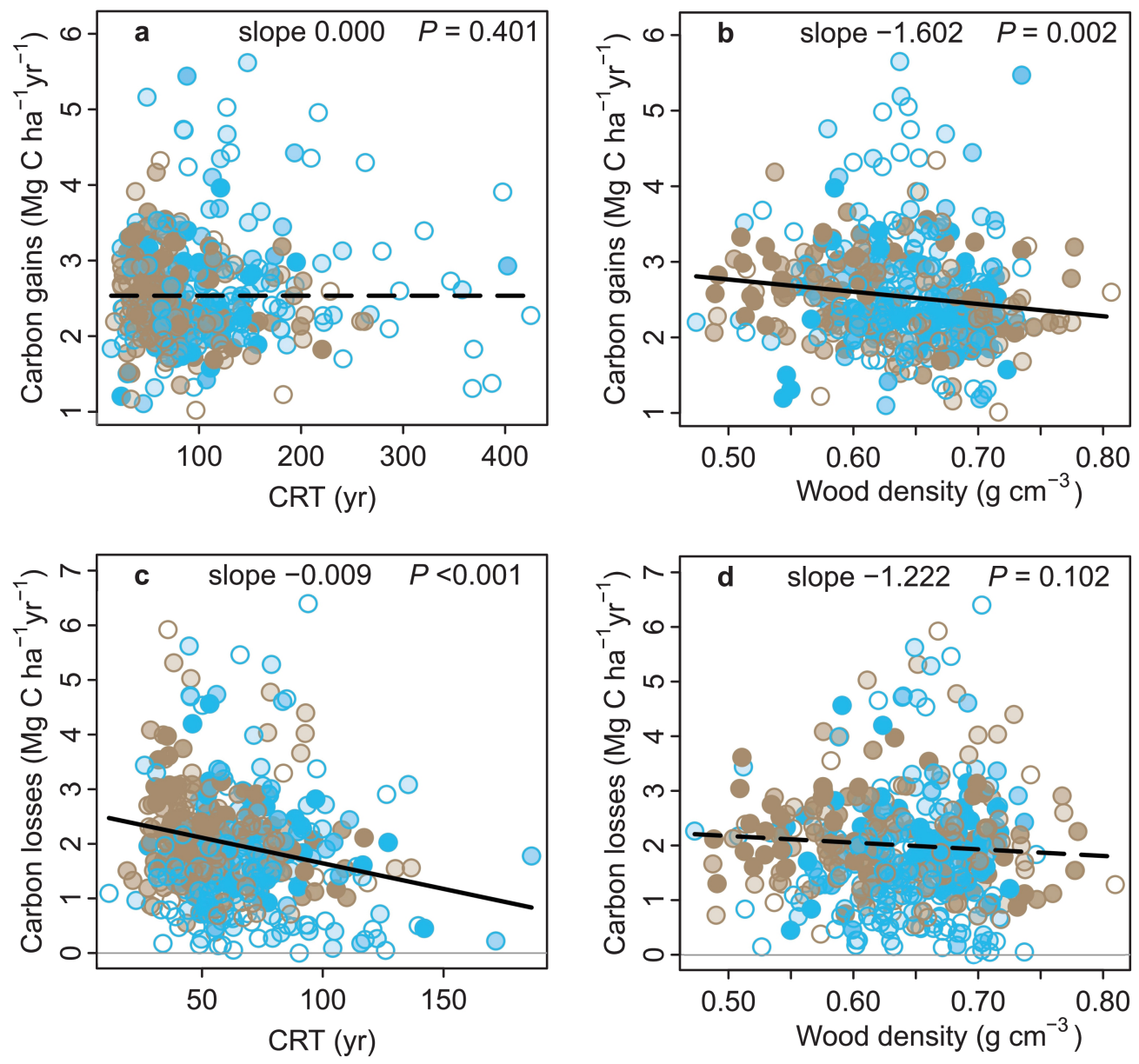

Extended Data Fig. 4 | Potential forest dynamics-related drivers of carbon gains and losses in structurally intact old-growth African and Amazonian tropical forest inventory plots. The aboveground carbon gains, from woody production (a, b), and aboveground carbon losses, from tree mortality $(\mathbf{c}, \mathbf{d})$, are plotted against the CRT, and wood density for African (blue) and Amazonian (brown) inventory plots. Linear mixed effects models were performed with census intervals $(n=1,566)$ nested within plots $(n=565)$ to avoid pseudo-replication, using an empirically derived weighting based on interval length and plot area (see Methods). Significant regression lines from

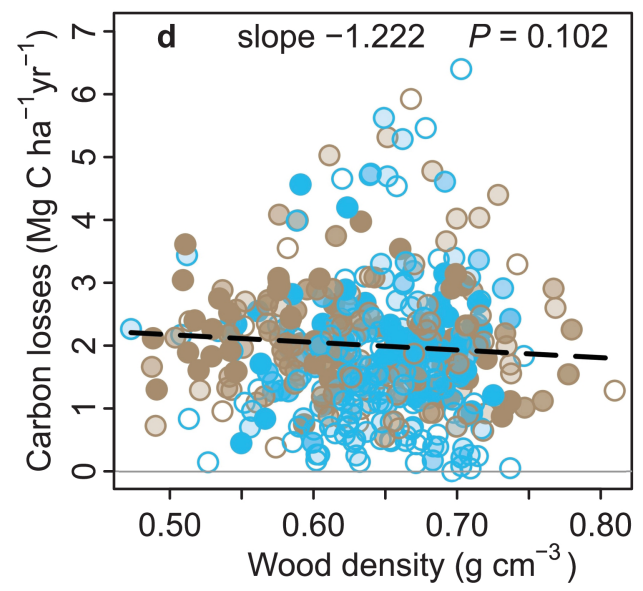

the linear mixed effects models for the complete dataset are shown as a solid line; non-significant regressions are shown as a dashed line. Each dot represents a time-weighted mean plot-level value; the shading of the dot represents total monitoring length, with empty circles corresponding to plots monitored for $\leq 5$ years and solid circles for plots monitored for $>20$ years. Carbon loss data are presented untransformed for comparison with carbon gains; linear mixed effects models on transformed data to fit normality assumptions do not change the significance of the results. Note that CRT is calculated differently for the carbon gains and losses models (see Methods). 

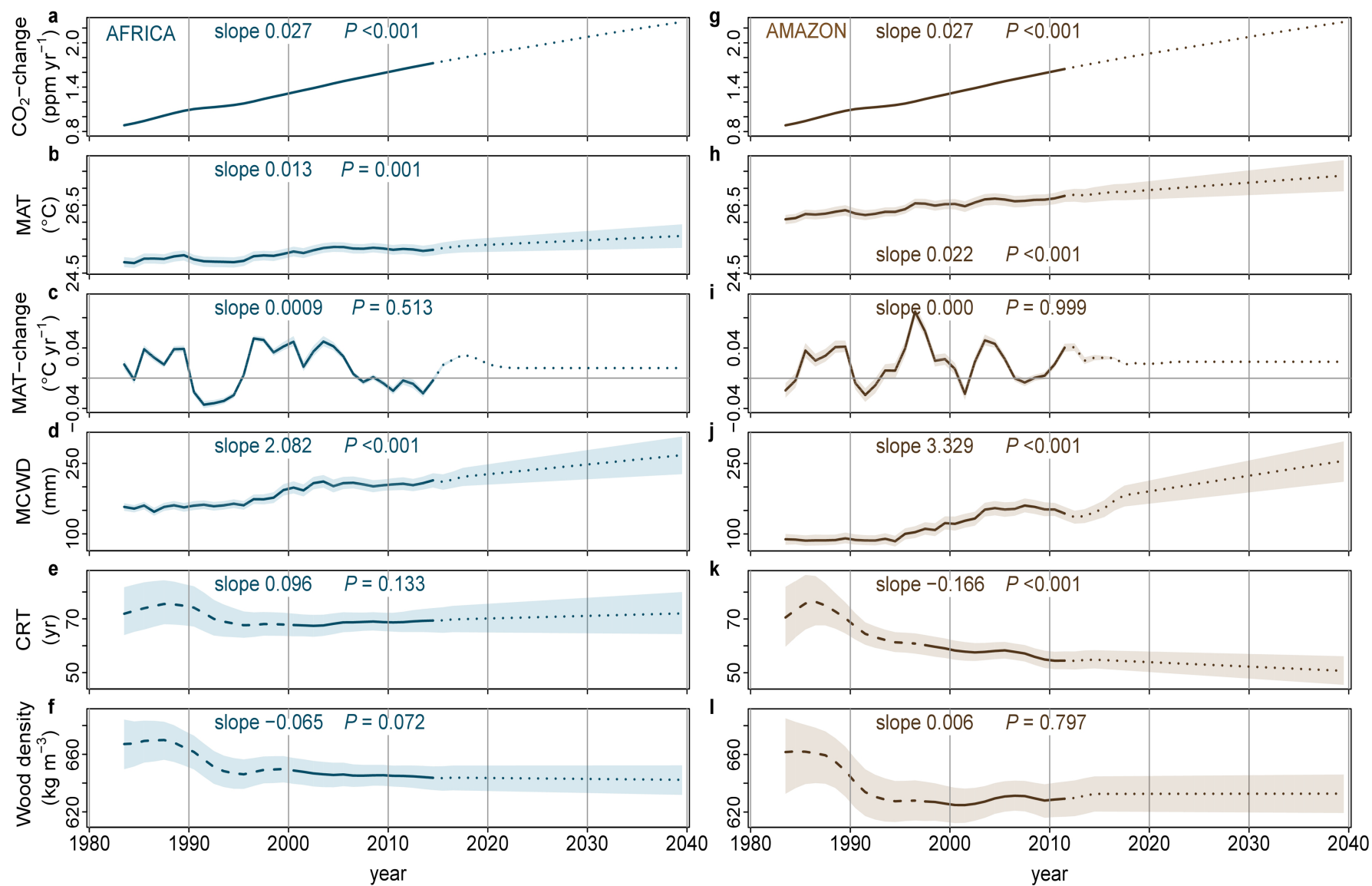

Extended Data Fig. 5 | Trends in predictor variables used to estimate longterm trends in aboveground carbon gains, carbon losses and the resulting net carbon sink in African and Amazonian structurally intact old-

growth tropical forest inventory plot networks. Mean annual $\mathrm{CO}_{2}$-change (a), MAT (b), MAT-change (c), MCWD (d), CRT (e) and wood density (f) for African plot locations in blue, and corresponding variables for Amazon plot locations in brown (g-1). Solid lines represent observational data where $>75 \%$ of the plots were monitored; long-dashed lines are plot means where $<75 \%$ of plots were monitored. Dotted lines are future values estimated from linear trends from

the 1January 1983 to 31 December 2014 (Africa) or 1January 1983 to mid-2011 (Amazon) data (slope and $P$ value reported in each panel), see Methods for details. Upper and lower confidence intervals (shaded area) for the past are calculated by respectively adding and subtracting $2 \sigma$ to the mean of each annual value. Upper and lower confidence intervals for the future (Africa: 1 January 2015 to 31 December 2039; Amazonia: mid-2011 to 31 December 2039) were estimated by adding and subtracting $2 \sigma$ from the slope of the regression model. 


\section{Article}

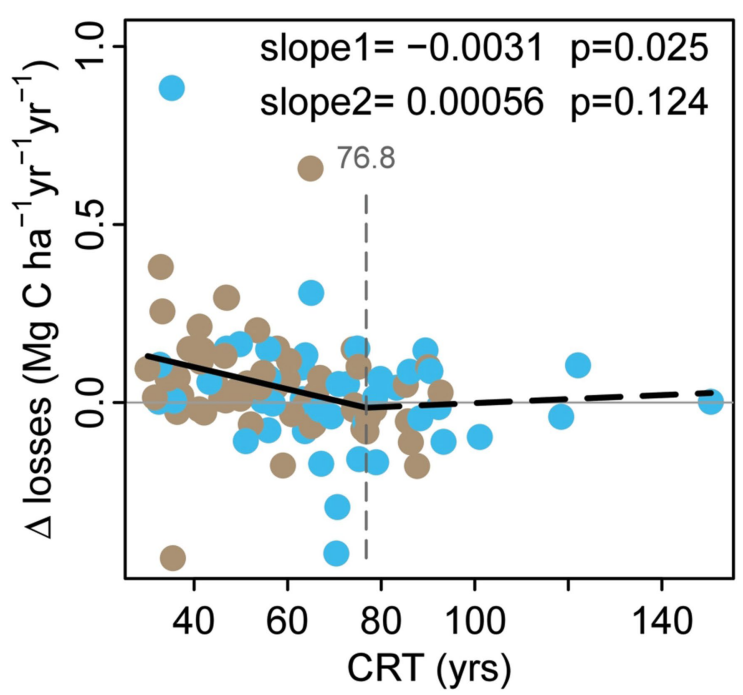

Extended Data Fig. 6 | The change in carbon losses versus CRT of long-term structurally intact old-growth forest inventory plots in Africa and

Amazonia. For plots with two census intervals, we calculated the change in carbon losses (' $\Delta$ losses') as the carbon losses (in $\mathrm{MgC} \mathrm{Cha}^{-1} \mathrm{yr}^{-1}$ ) of the second interval minus the carbon losses of the first interval, divided by the difference in mid-interval dates. For plots with more than two intervals, we calculated the change in carbon losses for each pair of subsequent intervals, then calculated the plot-level mean over all pairs, weighted by the time length between midinterval dates. This analysis includes only plots with at least two census intervals that were monitored for a total of $\geq 20$ years (that is, roughly one-third of the mean CRT of the pooled African and Amazon dataset; $n=116$ ). Breakpoint regression was used to assess the CRT length below which forest carbon losses begin to increase. Plots with CRT $<77$ years show a recent long-term increase in carbon losses; longer CRT plots do not. Blue points are African plots, brown points are Amazonian plots. 

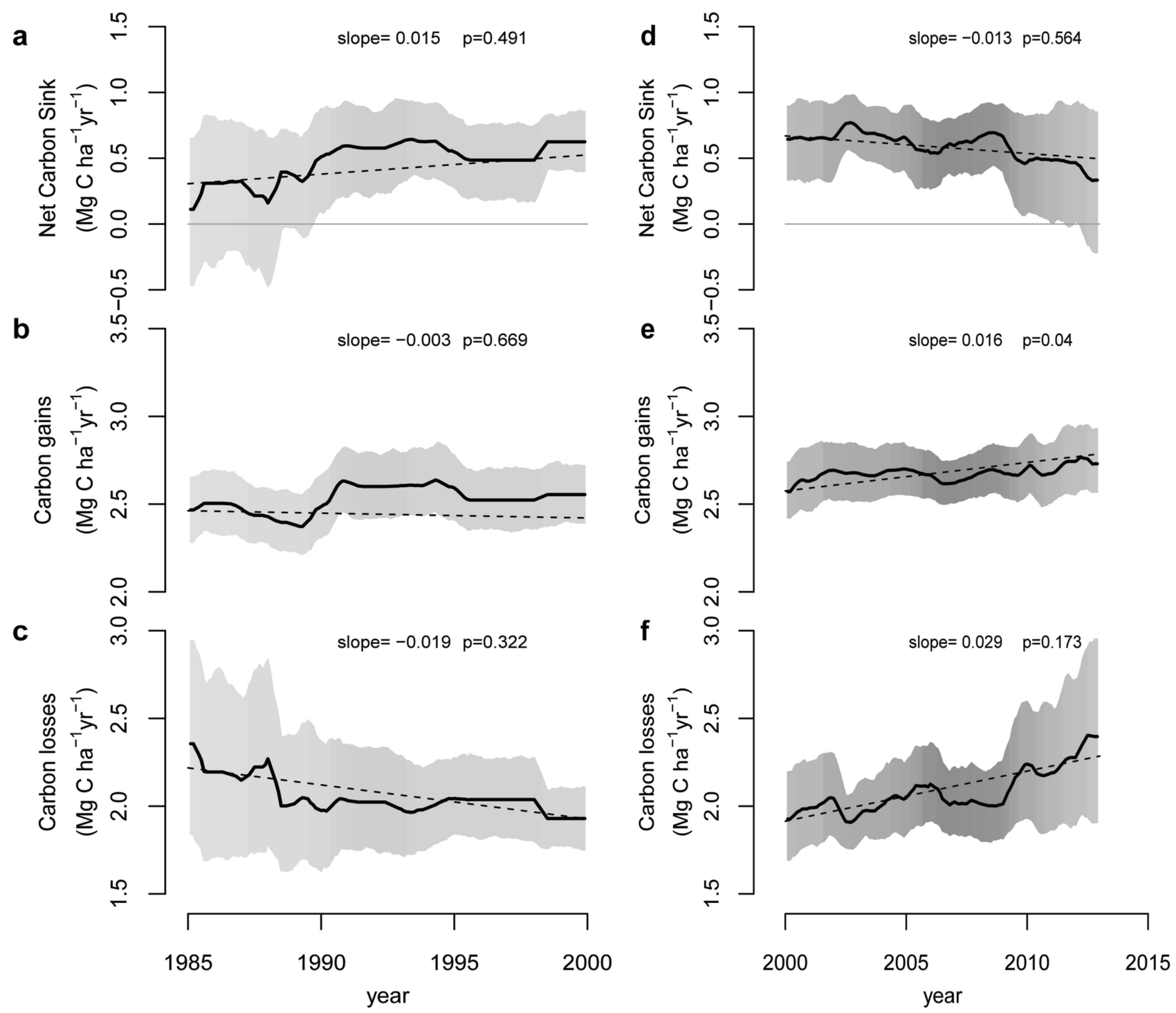

Extended Data Fig. 7 | Trends in net aboveground live biomass carbon, carbon gains and carbon losses from intensively monitored structurally intact old-growth tropical forest inventory plots in Africa. Trends are

Solid lines show mean values, and shading corresponds to the $95 \% \mathrm{Cl}$, as calculated in Fig. 1. Dashed lines, slopes and $P$ values are from linear mixed effects models, as in Fig. 1. The data shows a difference compared to Fig.1, notably the sink decline after about 2010 driven by rising carbon losses. This is because in Fig. 1 we include all available plots over the 1January 1983 to years of the twenty-first century (d-f). Plots were selected from the full dataset if their census intervals cover at least $50 \%$ of the respective time windows, that is, they are intensely monitored ( $n=56$ plots for 1 January 1985 to 31 December 1999 , and $n=134$ plots for 1 January 2000 to 31 December 2014, respectively). 31 December 2014 window, which includes clusters of plots monitored only in the 2010s, often monitored for a single census interval, that had low carbon loss and high carbon sink values. 
Long CRT

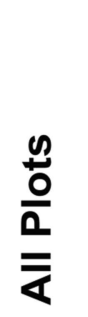

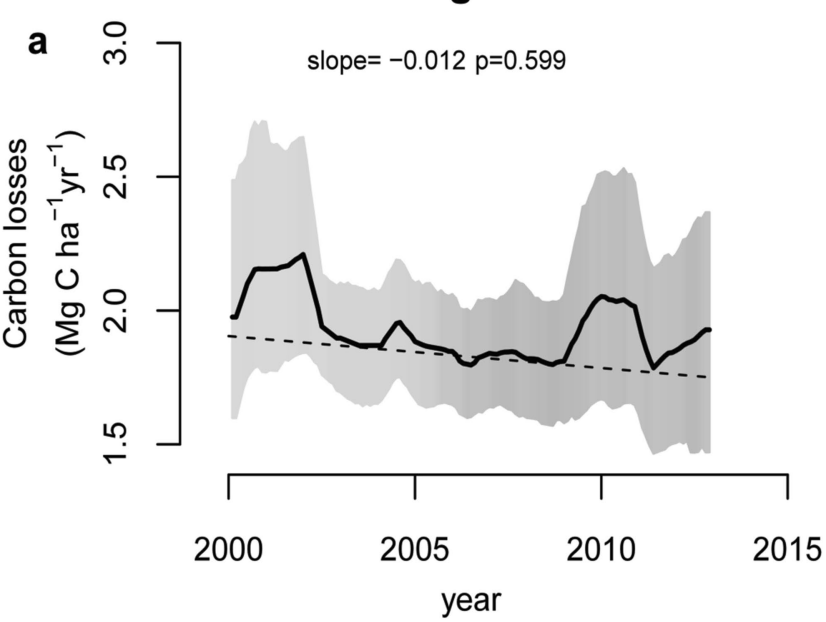

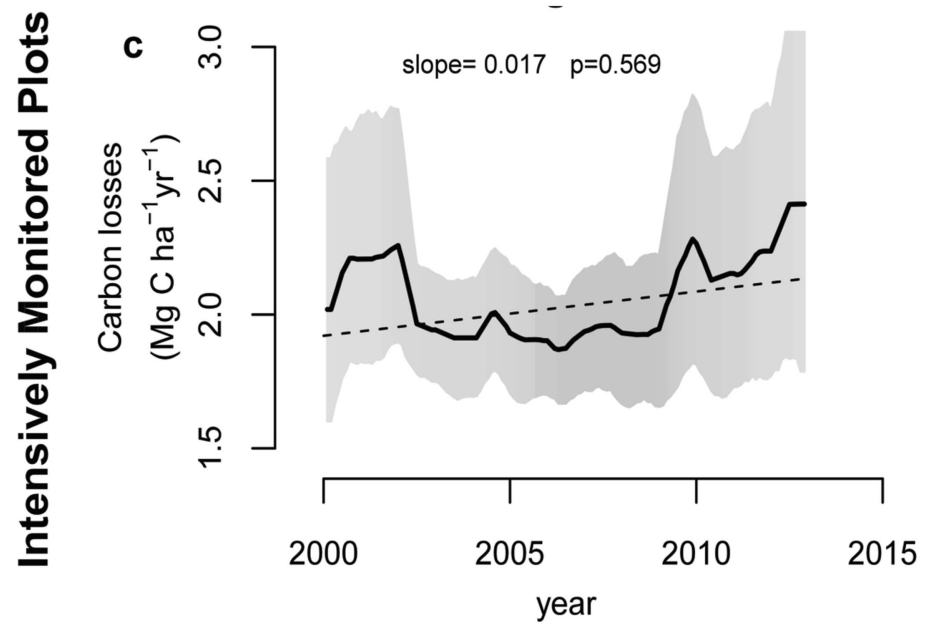

Extended Data Fig. 8 | Twenty-first-century trends in aboveground biomass carbon losses from structurally intact old-growth African tropical forest inventory plots with either long or short CRT. a, b, All plots, that is, as in Fig. 1, but split into a long-CRT group (a) and a short-CRT group (b), each containing half of the 244 plots. c, d, Plots are restricted to those spanning $>50 \%$ of the time window, that is, intensely monitored plots, as in Extended Data Fig. 7, but

\section{Short CRT}
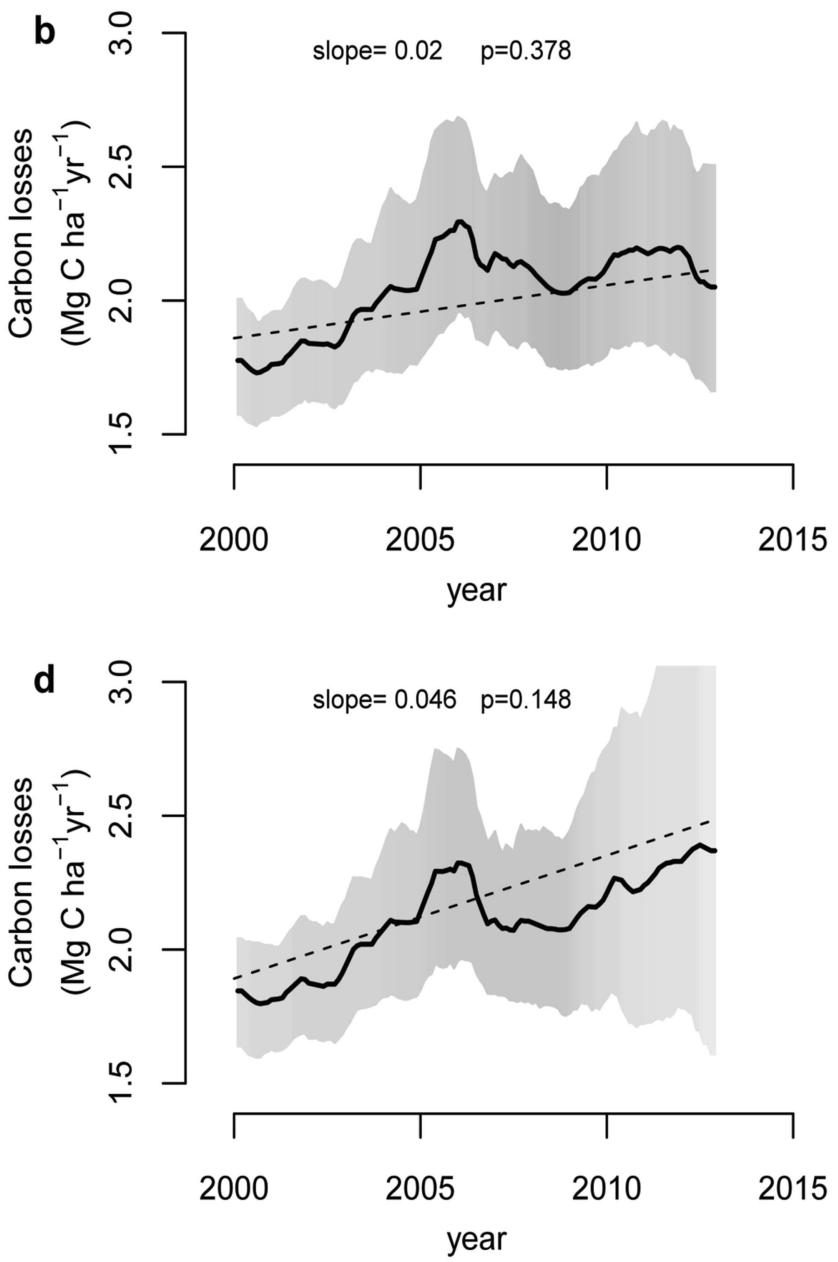

split into a long-CRT group (c) and a short-CRT group (d), each containing half of the 134 plots. Solid lines indicate mean values, shading the $95 \% \mathrm{Cl}$, as for

Fig. 1. Dashed lines, slopes and $P$ values are from linear mixed effects models, as for Fig. 1. Carbon losses increase at a higher rate in the short-CRT than the longCRT group of plots, in both datasets, although this increase is not statistically significant. 
Extended Data Table 1 | Models to predict carbon gains and losses in structurally intact old-growth African and Amazonian tropical forests

\begin{tabular}{|c|c|c|c|c|}
\hline \multicolumn{5}{|c|}{ Carbon gains $\left(\mathrm{Mg} \mathrm{C} \mathrm{ha}^{-1} \mathrm{yr}^{-1}\right)$} \\
\hline Predictor variable & Parameter value & Standard error & $t$ value & $P$ value \\
\hline Intercept & 4.694 & 0.739 & 6.354 & $<0.001$ \\
\hline $\mathrm{CO}_{2}(\mathrm{ppm})$ & 0.005 & 0.001 & 3.196 & 0.001 \\
\hline $\operatorname{MAT}\left({ }^{\circ} \mathrm{C}\right)$ & -0.143 & 0.021 & -6.844 & $<0.001$ \\
\hline MCWD (mm x1,000) & -1.232 & 0.210 & -5.878 & $<0.001$ \\
\hline \multicolumn{5}{|c|}{ Carbon losses $\left(\mathrm{Mg} \mathrm{C} \mathrm{ha}^{-1} \mathrm{yr}^{-1}\right)$} \\
\hline Predictor variable & Parameter value & Standard error & $t$ value & $P$ value \\
\hline Intercept & 0.926 & 1.854 & 0.499 & 0.617 \\
\hline $\mathrm{CO}_{2}(\mathrm{ppm})$ & 0.004 & 0.004 & 0.947 & 0.344 \\
\hline $\operatorname{MAT}\left({ }^{\circ} \mathrm{C}\right)$ & -0.011 & 0.044 & -0.249 & 0.804 \\
\hline MCWD (mm x1,000) & -0.498 & 0.505 & -0.985 & 0.325 \\
\hline
\end{tabular}

Models to predict carbon gains and losses in structurally intact old-growth African and Amazonian tropical forests, including only environmental variables that show long-term trends that affect theory-driven models of photosynthesis and respiration. Carbon loss values were normalized via power-law transformation, $\lambda=0.361$. 


\section{Article}

Extended Data Table 2 | Forest area estimates used to calculate total continental forest sink

Period

1980

1985

1990

1995

2000

2005

2010

2015

2020

2025

2030

2035

2040 intact forest area (Mha)

Amazon

Southeast Asia

Pan-tropics

958.3

233.6

207.4

1863.4

921.1

190.6

1762.8

885.2

163.5

1676.0

851.1

136.9

1580.5

817.2

129.2

1485.9

784.5

756.3

118.4

1418.5

726.7

101.5

1352.5

450.5

698.5

90.1

1278.7

425.5

671.5

80.0

1214.2

402.0

645.4

71.0

1153.4

379.7

620.4

63.0

1096.1

358.6

596.4

56.0

1042.1

338.8

Intact forest area for 1990, 2000, 2005 and 2010 is published in re

exponential models for each continent using the published data'. 


\section{natureresearch}

Corresponding author(s): Wannes Hubau

Last updated by author(s): 26/09/19

\section{Reporting Summary}

Nature Research wishes to improve the reproducibility of the work that we publish. This form provides structure for consistency and transparency in reporting. For further information on Nature Research policies, see Authors \& Referees and the Editorial Policy Checklist.

\section{Statistics}

For all statistical analyses, confirm that the following items are present in the figure legend, table legend, main text, or Methods section.

n/a Confirmed

\The exact sample size $(n)$ for each experimental group/condition, given as a discrete number and unit of measurement

$\bigotimes$ A statement on whether measurements were taken from distinct samples or whether the same sample was measured repeatedly

The statistical test(s) used AND whether they are one- or two-sided

Only common tests should be described solely by name; describe more complex techniques in the Methods section.

$\bigotimes$ A description of all covariates tested

$\bigotimes$ A description of any assumptions or corrections, such as tests of normality and adjustment for multiple comparisons

A full description of the statistical parameters including central tendency (e.g. means) or other basic estimates (e.g. regression coefficient)

$\triangle$ AND variation (e.g. standard deviation) or associated estimates of uncertainty (e.g. confidence intervals)

$X$ For null hypothesis testing, the test statistic (e.g. $F, t, r$ ) with confidence intervals, effect sizes, degrees of freedom and $P$ value noted

$\triangle$ Give $P$ values as exact values whenever suitable.

Х $\square$ For Bayesian analysis, information on the choice of priors and Markov chain Monte Carlo settings

Х $\square$ For hierarchical and complex designs, identification of the appropriate level for tests and full reporting of outcomes

Х $\square$ Estimates of effect sizes (e.g. Cohen's $d$, Pearson's $r$ ), indicating how they were calculated

Our web collection on statistics for biologists contains articles on many of the points above.

\section{Software and code}

\section{Policy information about availability of computer code}

Data collection

No software was used for data collection.

Data analysis

All calculations were performed using the R statistical platform, version 3.2.1 (R Development Core Team, 2015) using the BiomasaFP R package v0.2.1 (Lopez-Gonzalez, Sullivan, \& Baker, 2017). Source data and R-code to generate figures and tables are available from: https://figshare.com/s/60f48673202283421f43.

References:

Lopez-Gonzalez, G., Sullivan, M., \& Baker, T. 2017. BiomasaFP package. Tools for analysing data downloaded from ForestPlots.net. R package version 0.2.1. Available at http://www.forestplots.net/en/resources/analysis.

R Development Core Team. 2015. R: A Language and Environment for Statistical Computing. Available at http://www.R-project.org/.

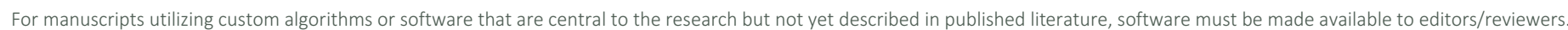
We strongly encourage code deposition in a community repository (e.g. GitHub). See the Nature Research guidelines for submitting code \& software for further information.

\section{Data}

Policy information about availability of data

All manuscripts must include a data availability statement. This statement should provide the following information, where applicable:

- Accession codes, unique identifiers, or web links for publicly available datasets

- A list of figures that have associated raw data

- A description of any restrictions on data availability

Source data and R-code to generate figures and tables are available from: https://figshare.com/s/60f48673202283421f43. This data and code package allows 


\section{Field-specific reporting}

Please select the one below that is the best fit for your research. If you are not sure, read the appropriate sections before making your selection.

\section{Ecological, evolutionary \& environmental sciences study design}

All studies must disclose on these points even when the disclosure is negative.

Study description
We reconstruct the evolution of the per unit area African tropical forest carbon sink (in Mg C ha-1 yr-1) over three decades to 2015 (Figure 1). To do so, we collected, compiled and analysed data from 244 repeatedly measured permanent forest inventory plots in 11 African countries. Selected plots are situated in structurally intact old-growth forests and are part of the African Tropical Rainforest Observation Network (AfriTRON; www.afritron.org; 217 plots) and other sources (27 plots). Plot monitoring periods span 2 to 40 years, between 1968 to 2015 (Extended Data Figure 1). In each plot (mean size, 1.1 ha), all trees $\geq 100 \mathrm{~mm}$ in stem diameter were identified, mapped and measured on at least two occasions using standardized methods (135,625 trees monitored) and live biomass carbon stocks were estimated for each census date, with carbon gains and losses calculated for each interval (Extended Data Figure 2). We compared trends in the per unit area African tropical forest carbon sink with published long-term trends in the Amazonian carbon sink (Brienen, et al. 2015). We pooled the new African and existing Amazonian plot inventory data together to investigate the putative environmental drivers of changes in the tropical forest carbon sink, and project its likely future evolution.

Aboveground Carbon ( $\mathrm{AGC}$, in $\mathrm{Mg} \mathrm{C}$ ha-1) in living biomass for each plot at each census date was estimated as the sum of the AGC of each living stem, then divided by plot area (in hectares).

Carbon Gain is the sum of the aboveground live biomass carbon additions from the growth of surviving stems and the addition of newly recruited stems, using standard methods (Brienen, et al. 2015). For each stem that survived a census interval, carbon additions from its growth ( $\mathrm{Mg} \mathrm{C}$ ha-1 yr-1) were calculated as the difference between its AGC at the end census of the interval and its AGC at the beginning census of the interval. For each stem that recruited during the census interval (i.e. reaching $D B H \geq 100 \mathrm{~mm}$ ), carbon additions were calculated in the same way, assuming $\mathrm{DBH}=0 \mathrm{~mm}$ at the start of the interval (Talbot, et al. 2014). The carbon additions in an interval, from surviving and newly recruited stems, were summed, then divided by the census interval length (in years), and scaled by plot area (in hectares) (Talbot, et al. 2014). As carbon gains are affected by a census interval bias, with the underestimate increasing with census length, we corrected this bias by accounting for (i) the carbon additions from trees that recruited and then died within the same interval (unobserved recruitment), and (ii) the carbon additions from trees that grew before they died within an interval (unobserved growth) (Talbot, et al. 2014). These typically add $<3 \%$ to plot-level carbon gains.

Carbon Loss (in Mg C ha-1 yr-1) is estimated, using standard methods (Brienen, et al. 2015), as the sum of aboveground biomass carbon from all stems that died during a census interval, divided by the census length (in years) and scaled by plot area (in hectares). Carbon loss is also affected by the same census interval bias, hence we corrected this bias by accounting for (i) the additional carbon losses from the trees that were recruited and then died within the same interval, and (ii) the additional carbon losses resulting from the growth of the trees that died in the interval (Kohyama, et al. 2018; Talbot, et al. 2014). Calculation details of both components are explained in Supplementary Methods.

Net Carbon Sink (in Mg C ha-1 yr-1) is estimated as carbon gains minus carbon losses.

The estimated mean carbon gains, carbon losses and the net carbon sink of the African plots from 1983-2014, the solid lines in Figure 1, were calculated following (Brienen, et al. 2015) to allow direct comparison with published Amazonian results. First, each census interval value was interpolated for each 0.1-yr period within the census interval. Then, for each 0.1-yr period between 1983 and 2014, we calculate a weighted mean of all plots monitored at that time, using the square root of plot area as a weighting factor. Finally, confidence intervals for each 0.1 -yr period are bootstrapped.

\section{References:}

Brienen, R. J. W., et al. 2015 Long-term decline of the Amazon carbon sink. Nature 519(7543):344-348. Kohyama, Takashi S., et al.

2018 Definition and estimation of vital rates from repeated censuses: Choices, comparisons and bias corrections focusing on trees. Methods in Ecology and Evolution 9(4):809-821.

Talbot, Joey, et al.

2014 Methods to estimate aboveground wood productivity from long-term forest inventory plots. Forest Ecology and Management 320:30-38.

Research sample
We use data from 244 plots in 11 African countries to present the first assessment of the temporal evolution of the tropical forest carbon sink in Africa. It represents 10 years of new field campaigns in Africa, extending sampling into extremely remote and previously unsampled regions. This is the first new manuscript using long-term inventory plots to estimate the intact forest carbon sink in Africa since (Lewis, et al. 2009) was published in Nature.

Plot selection: 244 permanent inventory plots were selected from 11 countries. These plots are situated in closed canopy (i.e. not 
woody savanna) old-growth mixed-age forests and were selected using commonly used criteria (Brienen, et al. 2015; Lewis, et al. 2009; Lewis, et al. 2013): free of fire and industrial logging; all trees with diameter at reference height $\geq 100 \mathrm{~mm}$ measured at least twice; $\geq 0.2$ ha area; $<1500$ m.a.s.l. altitude; MAT $\geq 20.0^{\circ} \mathrm{C}$ (Hijmans, et al. 2005); annual precipitation $\geq 1000 \mathrm{~mm}$; located $\geq 50 \mathrm{~m}$ from anthropogenic forest edges.

References:

Brienen, R. J. W., et al.

2015 Long-term decline of the Amazon carbon sink. Nature 519(7543):344-348.

Hijmans, Robert J., et al.

2005 Very high resolution interpolated climate surfaces for global land areas. International Journal of Climatology 25(15):1965-1978.

Lewis, S. L., et al.

2009 Increasing carbon storage in intact African tropical forests. Nature 457(7232):1003-1006.

Lewis, Simon L., et al.

2013 Above-ground biomass and structure of 260 African tropical forests. Philosophical Transactions of the Royal Society B: Biological Sciences 368(1625):20120295-20120295.

Sampling strategy

Data collection
No sample size calculation was performed. We selected all available plots meeting the criteria described above. All African tropical forest regions (West Africa, Lower Guinea, Congo Basin, East Africa) are adequately represented. This is the largest dataset of repeatedly measured plots ever used to calculate long-term trends in African forest carbon dynamics.

Plot inventory data was collected by teams led by at least one of the 104 researchers co-authoring this paper. All permanent inventory plots are part of one or several networks. Of the 244 plots included in the study, 217 contribute to the African Tropical Rainforest Observatory Network (AfriTRON; www.afritron.org), with data curated at www.ForestPlots.net. These include plots from Sierra Leone, Liberia, Ghana, Nigeria, Cameroon, Gabon, Republic of Congo, Democratic Republic of Congo (DRC), Uganda and Tanzania (Lopez-Gonzalez, et al. 2011; Lopez-Gonzalez, et al. 2009) (Extended Data Figure 1). Fifteen plots are part of the TEAM network, from Cameroon, Republic of Congo, Tanzania, and Uganda (Hockemba 2010; Kenfack 2011; Rovero, et al. 2009; Sheil and Bitariho 2009). Nine plots contribute to the ForestGEO network, from Cameroon and DRC (Anderson-Teixeira, et al. 2015) (9 plots from DRC, codes SNG, contribute to both AfriTRON and ForestGEO networks, included above in the AfriTRON total). Finally, three plots from Central African Republic are part of the CIRAD network (Claeys, et al. 2019; Gourlet-Fleury, et al. 2013).

Tree-level aboveground biomass carbon is estimated using an allometric equation (Chave, et al. 2014) with parameters for tree diameter, tree height and wood mass density. The estimated aboveground biomass of a plot is the sum of the estimated biomass of all live trees at that census date.

Tree Diameter: In all plots, all woody stems with $\geq 100 \mathrm{~mm}$ diameter at $1.3 \mathrm{~m}$ from the base of the stem ('diameter at breast height', $\mathrm{DBH}$ ), or $0.5 \mathrm{~m}$ above deformities or buttresses, were measured, mapped and identified using standard forest inventory methods (Phillips, et al. 2016). The height of the point of measurement (POM) was marked on the trees and recorded, so that the same POM is used at the subsequent forest census. For stems developing deformities or buttresses over time that could potentially disturb the initial POM, the POM was raised approximately $500 \mathrm{~mm}$ above the deformity. Estimates of the diameter growth of trees with changed POM used the ratio of new and old POMs, to create a single trajectory of growth from the series of diameters at two POM heights (Brienen, et al. 2015; Lewis, et al. 2009; Talbot, et al. 2014). We used standardized protocols to assess typographical errors and potentially erroneous diameter values (e.g. trees shrinking by $>5 \mathrm{~mm}$ ), missing values, failures to find the original POM, and other issues. Where necessary we estimated the likely value via interpolation or extrapolation from other measurements of that tree, or when this was not possible we used the median growth rate of trees in the same plot, census and size-class, defined as DBH = 100-199 mm, or 200-399 mm, or $>400 \mathrm{~mm}$ (Talbot, et al. 2014). We interpolate measurements for $1.3 \%$ of diameters, extrapolate $0.9 \%$, and use median growth rates for $1.5 \%$.

Tree height: Height of individuals from ground to the top leaf, hereafter $\mathrm{Ht}$, was measured in 204 plots, using a laser hypsometer (Nikon forestry Pro) from directly below the crown (most plots), a laser or ultrasonic distance device with an electronic tilt sensor, a manual clinometer, or by direct measurement, i.e. tree climbing. Only trees where the top was visible were selected (Sullivan, et al. 2018). In most plots, tree selection was similar: the 10 largest trees were measured, together with 10 randomly selected trees per diameter from five classes: 100-199 mm, 200-299 mm, 300-399 mm, 400-499 mm, and 500+ mm trees, following standard protocols (Sullivan, et al. 2018). We use these data and the local.heights function in R package BiomasaFP (Lopez-Gonzalez, et al. 2017) to fit 3parameter Weibull relationships (see Supplementary Methods for a full explanation of this procedure):

$H_{-} \mathrm{t}=\mathrm{a} \times\left(1-\mathrm{e}^{\wedge}\left(\left(-\mathrm{b} \times(\mathrm{DBH} / 10)^{\wedge} \mathrm{c}\right)\right)\right)$ (equation 1$)$.

We chose the Weibull model as it is known to be robust when a large number of measurements are available (Feldpausch, et al. 2012; Sullivan, et al. 2018). We parameterize this Ht-DBH relationship for four different combinations of edaphic forest type and biogeographical region (parameters in parentheses): (i) terra firme forest in West Africa ( $a=56.0 ; b=0.0401 ; c=0.744$ ); (ii) terra firme forest in Lower Guinea and Western Congo Basin ( $a=47.6 ; b=0.0536 ; c=0.755$ ); (iii) terra firme forest in Eastern Congo Basin and East Africa ( $a=50.8 ; b=0.0499 ; c=0.706$ ); and finally (iv) seasonally flooded forest from Lower Guinea and Western Congo Basin ( $a=38.2$; $b=0.0605 ; c=0.760$ ). The parameters were used to estimate $\mathrm{Ht}$ from $\mathrm{DBH}$ for all tree $\mathrm{DBH}$ measurements for input into the allometric equation.

Wood Density: Dry wood density $(\rho)$ measurements were compiled for 730 African species from published sources and stored in www. ForestPlots.net; most were sourced from the Global Wood Density Database on the Dryad digital repository (www.datadryad.org)(Chave, et al. 2009; Zanne, et al. 2009). Each individual in the tree inventory database was matched to a species-specific mean wood density value. Species in both the tree inventory and wood density databases were standardized for orthography and synonymy using the African Flowering Plants Database (www.ville-ge.ch/cjb/bd/africa/) to maximize matches (Lewis, et al. 2009). For incompletely identified individuals or for individuals belonging to species not in the $\rho$ database, we used the mean $\rho$ value for the next higher known taxonomic category (genus or family, as appropriate). For unidentified individuals, we used the mean wood density value of all individual trees in the plot (Lewis, et al. 2009; Lopez-Gonzalez, et al. 2011).

Allometric equation: For each tree we use a published allometric equation (Chave, et al. 2014) to estimate aboveground biomass. We 
then convert this to carbon, assuming that aboveground carbon (AGC) is $45.6 \%$ of aboveground biomass (Martin, et al. 2018). Thus: $\mathrm{AGC}=0.456 \times\left(\left(\left(0.0673 \times\left(\rho \times(\mathrm{DBH} / 10)^{\wedge} 2 \times \mathrm{H} \_\mathrm{t}\right)^{\wedge} 0.976\right)\right) /(1000)\right)$ (equation 2), with $\mathrm{DBH}$ in $\mathrm{mm}$, dry wood density, $\rho$, in $\mathrm{g} \mathrm{cm}-3$, and total tree height, $\mathrm{Ht}$, in $\mathrm{m}$ (Chave, et al. 2014).

References:

Anderson-Teixeira, Kristina J., et al.

2015 CTFS-ForestGEO: a worldwide network monitoring forests in an era of global change. Global Change Biology 21(2):528-549. Brienen, R. J. W., et al.

2015 Long-term decline of the Amazon carbon sink. Nature 519(7543):344-348.

Chave, Jerome, et al.

2009 Towards a worldwide wood economics spectrum. Ecology Letters 12(4):351-366.

Chave, Jérôme, et al.

2014 Improved allometric models to estimate the aboveground biomass of tropical trees. Global Change Biology 20(10):3177-3190. Claeys, Florian, et al.

2019 Climate change would lead to a sharp acceleration of Central African forests dynamics by the end of the century.

Environmental Research Letters 14(4):044002.

Feldpausch, T. R., et al.

2012 Tree height integrated into pantropical forest biomass estimates. Biogeosciences 9(8):3381-3403.

Gourlet-Fleury, Sylvie, et al.

2013 Tropical forest recovery from logging: a 24 year silvicultural experiment from Central Africa. Philosophical Transactions of the Royal Society B-Biological Sciences 368(1625):20120302.

Hockemba, M. B. N.

2010 Nouabalé Ndoki TEAM Site. Data Set Identifier: TEAM-DataPackage-20151201235855_1254

Kenfack, D.

2011 Korup National Park TEAM Site. Data Set Identifier: TEAM-DataPackage-20151201235855_1254.

Lewis, S. L., et al.

2009 Increasing carbon storage in intact African tropical forests. Nature 457(7232):1003-1006.

Lopez-Gonzalez, G., et al.

2011 ForestPlots.net: a web application and research tool to manage and analyse tropical forest plot data. Journal of Vegetation Science 22:610-613.

Lopez-Gonzalez, G., et al.

2009 ForestPlots.net Database. www.forestplots.net. Date of extraction [10/11/2017].

Lopez-Gonzalez, Gabriela, Martin Sullivan, and Tim Baker

2017 BiomasaFP package. Tools for analysing data downloaded from ForestPlots.net. R package version 0.2.1. Available at http:// www.forestplots.net/en/resources/analysis.

Martin, Adam R., Mahendra Doraisami, and Sean C. Thomas

2018 Global patterns in wood carbon concentration across the world's trees and forests. Nature Geoscience 11(12):915-920.

Phillips, O., et al.

2016 RAINFOR field manual for plot establishment and remeasurement. Available at http://www.rainfor.org/upload/

ManualsEnglish/RAINFOR_field_manual_version_2016.pdf.

Rovero, F., A. Marshall, and E. Martin

2009 Udzungwa TEAM Site. Data Set Identifier: TEAM-DataPackage-20151130235007_5069.

Sheil, D., and R. Bitariho

2009 Bwindi Impenetrable Forest TEAM Site. Data Set Identifier: TEAM-DataPackage-20151201235855_1254.

Sullivan, M. J. P., et al.

2018 Field methods for sampling tree height for tropical forest biomass estimation. Methods in Ecology and Evolution

9(5):1179-1189.

Talbot, Joey, et al.

2014 Methods to estimate aboveground wood productivity from long-term forest inventory plots. Forest Ecology and Management 320:30-38.

Zanne, A.E., et al.

2009. Data from: Towards a worldwide wood economics spectrum: Dryad Digital Repository.

Timing and spatial scale

The large majority of plots are sited in terra firme forests and have mixed species composition, although four are in seasonally flooded forest and 14 plots are in Gilbertiodendron dewevrei monodominant forest, a locally common forest type in Africa (Supplementary Table 1). The 244 plots have a mean size of 1.1 ha (median, 1 ha), with a total plot area of 277.9 ha. The dataset comprises 391,968 diameter measurements on 135,625 stems, of which $89.9 \%$ were identified to species, $97.5 \%$ to genus and $97.8 \%$ to family.

Plots were measured at least twice and maximum 10 times, between 1968 and 2015. Plot monitoring periods span 2 to 40 years; mean total monitoring period is 11.8 years, mean census length 5.7 years, with a total of 3,214 ha years of monitoring. The 321 Amazon plots are published and were selected using the same criteria (ref.6), (Brienen, et al. 2015)except in the African selection criteria we specified a minimum anthropogenic edge distance and added a minimum temperature threshold.

Brienen, R. J. W., et al.

2015 Long-term decline of the Amazon carbon sink. Nature 519(7543):344-348.

Plots were selected using the criteria described above (section Research sample). Plots that did not meet one or several of these criteria were not used for analysis.

Our analysis does not include experimental findings.

Trends in carbon gains, losses and the net carbon sink over time were assessed using linear mixed effects models (Imer function in R, 

census interval against the value of the response variable for that census interval. Plot identity was included as a random effect, i.e. assuming that the intercept can vary randomly among plots. Observations were weighted by plot size and census interval length. Weightings were derived empirically, by assuming a priori that there is no significant relation between the net carbon sink and census interval length or plot size (Lewis, et al. 2009).

References:

Bates, D., et al.

2013 Ime4: Linear mixed-effects models using Eigen andS4.Rpackage version, 1.0-4. Available at http://www.inside-r.org/packages/ Ime4/versions/1-0-4.

Lewis, S. L., et al.

2009 Increasing carbon storage in intact African tropical forests. Nature 457(7232):1003-1006.

Blinding

Blinding was not relevant to our study.

Did the study involve field work? \Yes $\square$ No

\section{Field work, collection and transport}

Field conditions

Location

Access and import/export
All plots are located in African tropical forests receiving at least $1000 \mathrm{~mm}$ rainfall annually and with a mean annual temperature of at least $20^{\circ} \mathrm{C}$.

Plots are located at low elevations ( $<1500$ m.a.s.l. altitude). A map showing locations of all plots is presented in Extended Data Figure 1.

This paper is a product of the African Tropical Rainforest Observatory Network (AfriTRON), the TEAM network, the ForestGEO network, and the CIRAD network. These permanent inventory plot networks only exists thanks to the support of governments, local administrations and villages across Africa who have given us permission for, and helped us complete, our fieldwork. A full list of partner institutions (excluding those in the co-author affiliations) can be found in (on-line only) acknowledgements. Furthermore, plot inventory data are the product of many field-teams which mainly consisted of local assistants. A full list of people involved in data collection can be found in (on-line only) acknowledgements, along with a full list of villages and communities that hosted the field-teams and provided logistical and infrastructural support.

This paper includes 264 plot-censuses (out of 746) that are published for the first time here, including censuses from plots located in extremely remote areas such as the Salonga National Park in the heart of the Congo Basin. Each plot-census represents several months of preparation, transport, data collection, digitalisation and data quality assessment.

No significant disturbance was caused by our measurements. Trees were tagged using a single aluminum nail (no iron), avoiding damage to trees due to corrosion.

Disturbance

\section{Reporting for specific materials, systems and methods}

We require information from authors about some types of materials, experimental systems and methods used in many studies. Here, indicate whether each material, system or method listed is relevant to your study. If you are not sure if a list item applies to your research, read the appropriate section before selecting a response.

Materials \& experimental systems

\begin{tabular}{l|l}
\hline n/a & Involved in the study \\
$\searrow$ & $\square$ Antibodies \\
$\searrow$ & $\square$ Eukaryotic cell lines \\
$\square$ & $\square$ Palaeontology \\
$\searrow$ & $\square$ Animals and other organisms \\
$\searrow$ & $\square$ Human research participants \\
$\searrow$ & $\square$ Clinical data
\end{tabular}

Methods

$\mathrm{n} / \mathrm{a}$ Involved in the study

X $\square$ ChIP-seq

Х $\square$ Flow cytometry

Х $\square$ MRI-based neuroimaging 